\title{
Every steps counts
}

Citation for published version (APA):

den Ouden, M. (2018). Every steps counts: daily activities of nursing home residents and the role of nursing staff. [Doctoral Thesis, Maastricht University]. Datawyse / Universitaire Pers Maastricht. https://doi.org/10.26481/dis.20181004mo

Document status and date:

Published: 01/01/2018

DOI:

10.26481/dis.20181004mo

Document Version:

Publisher's PDF, also known as Version of record

\section{Please check the document version of this publication:}

- A submitted manuscript is the version of the article upon submission and before peer-review. There can be important differences between the submitted version and the official published version of record.

People interested in the research are advised to contact the author for the final version of the publication, or visit the DOI to the publisher's website.

- The final author version and the galley proof are versions of the publication after peer review.

- The final published version features the final layout of the paper including the volume, issue and page numbers.

Link to publication

\footnotetext{
General rights rights.

- You may freely distribute the URL identifying the publication in the public portal. please follow below link for the End User Agreement:

www.umlib.nl/taverne-license

Take down policy

If you believe that this document breaches copyright please contact us at:

repository@maastrichtuniversity.nl

providing details and we will investigate your claim.
}

Copyright and moral rights for the publications made accessible in the public portal are retained by the authors and/or other copyright owners and it is a condition of accessing publications that users recognise and abide by the legal requirements associated with these

- Users may download and print one copy of any publication from the public portal for the purpose of private study or research.

- You may not further distribute the material or use it for any profit-making activity or commercial gain

If the publication is distributed under the terms of Article $25 \mathrm{fa}$ of the Dutch Copyright Act, indicated by the "Taverne" license above, 


\section{Every steps counts}

\section{Citation for published version (APA):}

den Ouden, M. (2018). Every steps counts: daily activities of nursing home residents and the role of nursing staff . Maastricht: Datawyse / Universitaire Pers Maastricht. https://doi.org/10.26481/dis.20181004mo

Document status and date:

Published: 01/01/2018

DOI:

10.26481/dis.20181004mo

Document Version:

Publisher's PDF, also known as Version of record

\section{Please check the document version of this publication:}

- A submitted manuscript is the version of the article upon submission and before peer-review. There can be important differences between the submitted version and the official published version of record.

People interested in the research are advised to contact the author for the final version of the publication, or visit the DOI to the publisher's website.

- The final author version and the galley proof are versions of the publication after peer review.

- The final published version features the final layout of the paper including the volume, issue and page numbers.

Link to publication

\footnotetext{
General rights rights.

- You may freely distribute the URL identifying the publication in the public portal. please follow below link for the End User Agreement:

www.umlib.nl/taverne-license

Take down policy

If you believe that this document breaches copyright please contact us at:

repository@maastrichtuniversity.nl

providing details and we will investigate your claim.
}

Copyright and moral rights for the publications made accessible in the public portal are retained by the authors and/or other copyright owners and it is a condition of accessing publications that users recognise and abide by the legal requirements associated with these

- Users may download and print one copy of any publication from the public portal for the purpose of private study or research.

- You may not further distribute the material or use it for any profit-making activity or commercial gain

If the publication is distributed under the terms of Article 25fa of the Dutch Copyright Act, indicated by the "Taverne" license above, 


\section{EVERY STEP COUNTS}

Daily activities of nursing home residents and the role of nursing staff

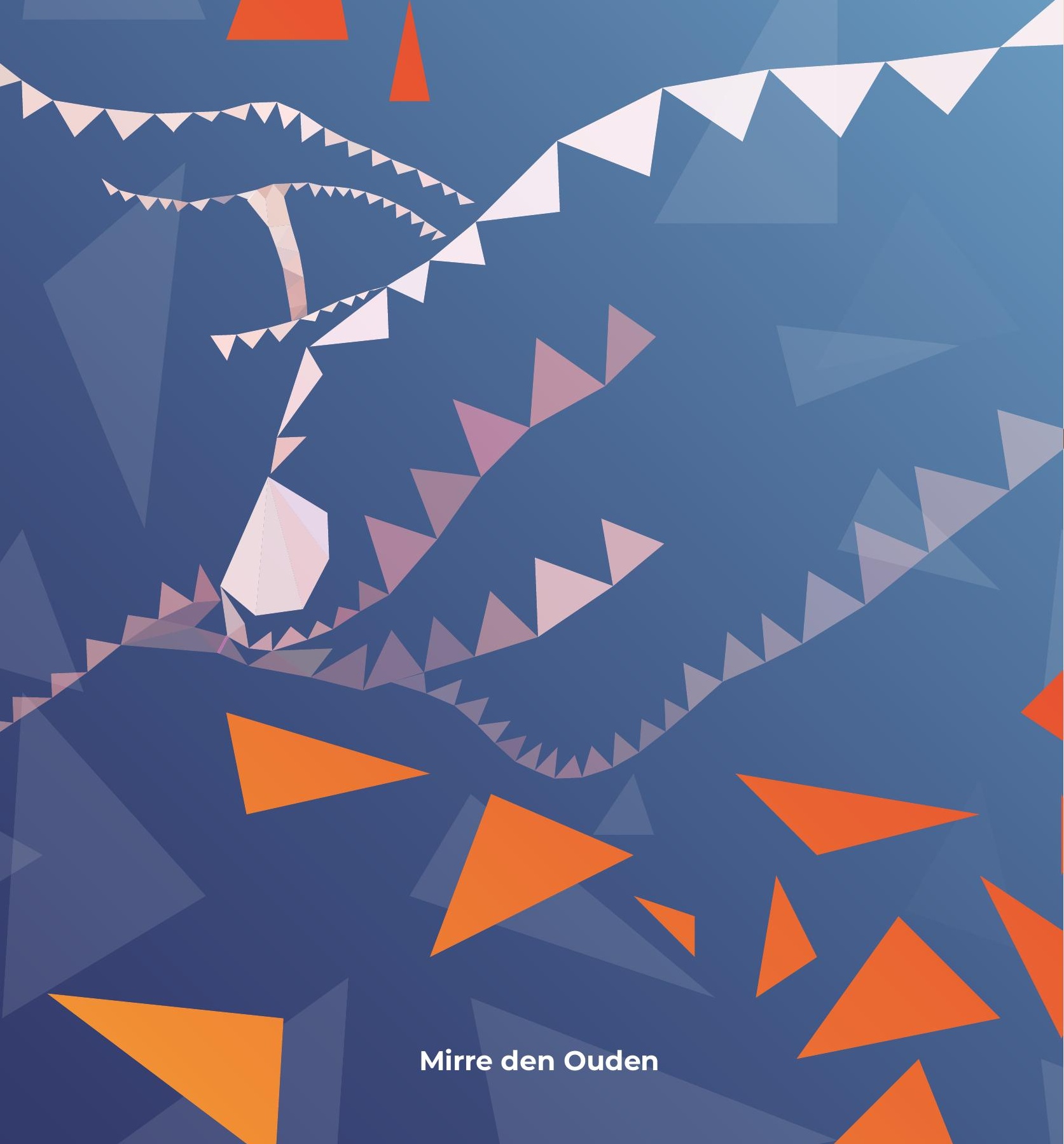


The research presented in this dissertation was part of the research line 'Nurses on the Move: towards high quality care in nursing homes,' which was funded by ZonMw, the Netherlands Organization for Health Research and Development (grant 520001003).

(C) Copyright Mirre den Ouden, Maastricht 2018

Cover: Kevin Vierwind

Printing: Datawyse | Universitaire Pers Maastricht

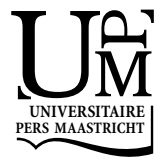

ISBN 9789493019539 


\title{
EVERY STEP COUNTS
}

\section{Daily activities of nursing home residents and the role of nursing staff}

\author{
PROEFSCHRIFT \\ ter verkrijging van de graad van doctor aan de Universiteit Maastricht, \\ op gezag van de Rector Magnificus, Prof. dr. Rianne M. Letschert, \\ volgens het besluit van het College van Decanen, \\ in het openbaar te verdedigen \\ op donderdag 4 oktober 2018 om 12.00 uur
}

door

Mirre den Ouden 


\section{PROMOTORES}

Prof. dr. J.P.H. Hamers

Prof. dr. S.M.G. Zwakhalen

\section{COPROMOTOR}

Dr. J.M.M. Meijers

\section{BEOORDELINGSCOMMISSIE}

Prof. dr. M.E. de Vught (voorzitter)

Prof. dr. B.M. Buurman (Universiteit van Amsterdam)

Prof. dr. L.J.C. van Loon

Prof. dr. E.J.A. Scherder (Vrije Universiteit Amsterdam)

Prof. dr. J.M.G.A. Schols 


\section{CONTENTS}

CHAPTER 1 General introduction 7

CHAPTER 2 Daily (in)activities of nursing home residents in their wards: an 17 observation study Journal of the American Medical Directors Association, 2015

CHAPTER 3 The role of nursing staff in the activities of daily living of nursing 33 home residents

Geriatric Nursing, 2016

CHAPTER 4 Do nursing staff encourage functional activity among nursing home residents? A cross-sectional study of nursing staff perceived behaviors and associated factors

BMC Geriatrics, 2017

CHAPTER 5 Feasibility of DAlly NURSE: a nursing intervention to change 69 nursing staff behavior towards encouraging residents' daily activities and independence in the nursing home

Submitted for publication

CHAPTER 6 Encourging the daily activities and independence of nursing home residents, the impact of nursing intervention DAlly NURSE: a quasi-experimental study.

submitted for publication

CHAPTER 7 General discussion

Summary

Samenvatting

Valorization

Dankwoord

About the author

List of publications

Living lab in aging and long-term care 

CHAPTER 1

General introduction

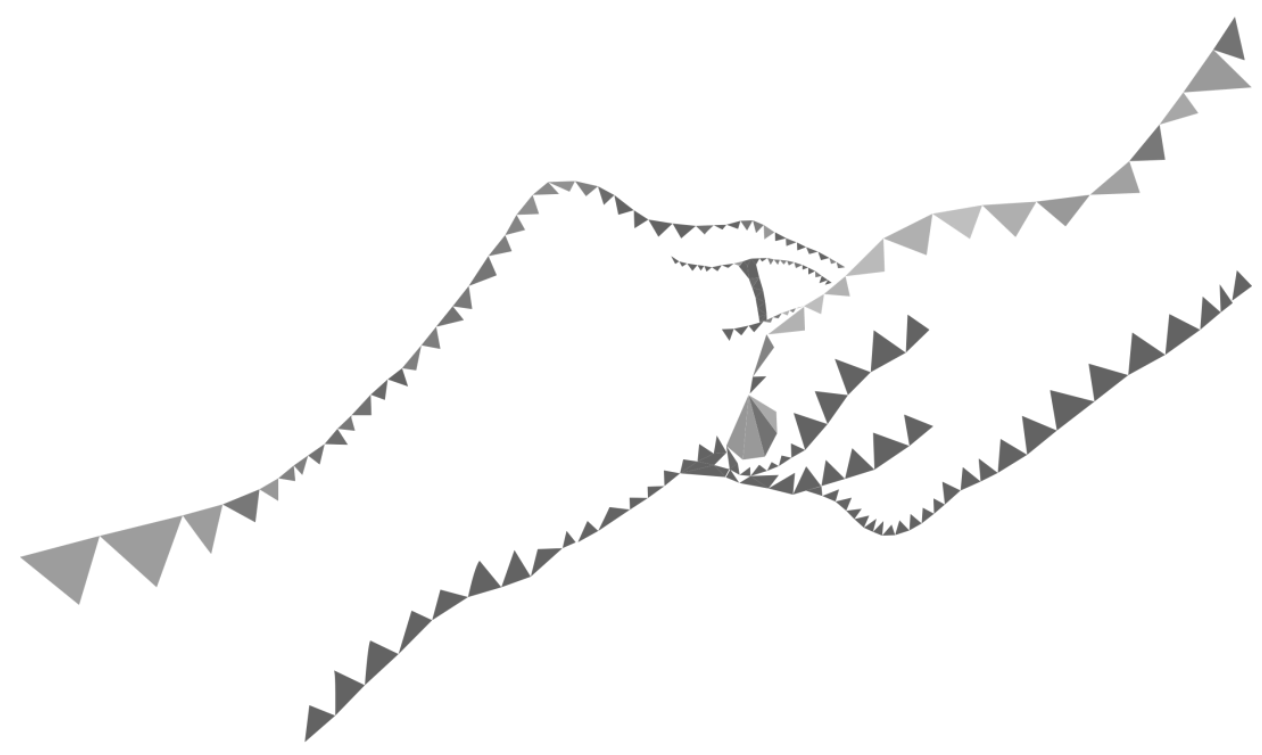





\section{Physical activity}

'Physical activity is good, more activity is even better,' state the physical activity guidelines updated by the Health Council of the Netherlands in August 2017. ${ }^{1}$ Physical activity is defined as 'any bodily movement produced by skeletal muscles that requires energy expenditure'. ${ }^{2}$ The physical activity guidelines for adults and older people advise at least 150 minutes of physical activity at moderate intensity per week, spread over different days. In addition, exercises to strengthen muscles and bones at least twice a week are recommended, in combination with balance exercises for older people. Finally, it is essential to avoid sedentary behavior (sitting still for longer periods of time) as much as possible. ${ }^{1}$ These guidelines of the Dutch Health Council are comparable with the recommendations provided by the World Health Organization (WHO). ${ }^{3}$ It is expected that only $44 \%$ of the adults and older adults do reach the recommended activity levels of 150 minutes of physical activity at moderate intensity, combined with exercises to strengthen muscles and bones. ${ }^{1}$ Physical activity improves muscle strength, walking speed, and physical fitness in older adults, and that reduces the risk of disabilities, fractures, cognitive decline, and dementia. ${ }^{1}$ Furthermore, it reduces the risk of cardiovascular diseases, such as coronary heart disease and stroke, diabetes, cancers (including breast and colon cancer), depression, and even mortality. ${ }^{1}$ Therefore, physical activity is essential for health. Sedentary behavior on the other hand is associated with an increased risk of mortality. ${ }^{1}$ To increase activity levels, it is recommended to integrate physical activity into daily life as much as possible.

\section{Physical activity in nursing homes}

Physical activity is not only beneficial for healthy (older) adults; it also has positive effects on more frail populations, such as nursing home residents. Many nursing home residents suffer from multi-morbidities and are severely care dependent; ${ }^{4}$ they require assistance with their daily activities and show a decreased initiation of these activities. ${ }^{5}$ Long-term nursing home care in the Netherlands is provided in psychogeriatric or somatic wards. ${ }^{6}$ Psychogeriatric wards house nursing home residents with dementia, whereas somatic wards are mainly focused on residents suffering from cerebrovascular accidents, neurological disorders, mobility problems, and/or malignancies. ${ }^{6}$ The wards can differ in size from small-scale (up to 8 residents) wards up to more traditional largescale wards of up to 30 residents. ${ }^{7}$ In nursing home wards, a home-like environment is provided that focuses on residents' wellbeing; nursing home residents take their meals in the dining room and many wards have kitchen facilities to prepare meals. Nursing homes in the Netherlands are, in general, part of non-profit care organizations. ${ }^{8}$ The care provided in the nursing homes is complex and requires a multidisciplinary approach. ${ }^{6}$ A multidisciplinary team of nursing home staff is employed in Dutch nursing 
homes, consisting of nursing staff and allied health professionals such as physiotherapists, occupational therapists, dieticians, psychologists, and nursing home physicians. ${ }^{6}$ Furthermore, residents' families and volunteers are involved in nursing home care.

Research indicates that the physical activity levels of nursing home residents are extremely low. ${ }^{9-12}$ Only $4 \%$ of the Dutch nursing home residents living in somatic wards were physically active for 30 minutes, five times a week. ${ }^{13}$ Furthermore, a study with activity trackers showed that nursing home residents were sedentary (sitting or lying) for $74 \%$ of the time between 10 a.m. and 4 p.m. ${ }^{10}$ These results are comparable with a study of ambulatory nursing home residents with dementia, who were sedentary for $72 \%$ of the day. ${ }^{14}$ A previous observation study conducted in the USA (2002) showed that nursing home residents were doing nothing, or as little as watching TV, in $66 \%$ of the observations conducted during the day. ${ }^{12}$

The WHO activity guidelines recommend that older adults who are not able to perform the recommended amounts of physical activity, due to health conditions, should be as physically active as their abilities and conditions allow. ${ }^{3}$ The Dutch activity guidelines do not specify their recommendations for specific populations, such as nursing home residents. Recently, however, a task force report of de Souto Baretto ${ }^{15}$ provided recommendations for activity levels among nursing home residents; they recommended exercise training, e.g. strength and aerobic exercises, for those residents who are still capable. $^{15}$ Exercise has positive effects on muscle strength, flexibility, endurance, balance, physical functioning, and quality of life ${ }^{16}$ however, the positive effects of exercising a few times a week for a limited amount of time might be small when the residents are still inactive and sedentary during the rest of their day. ${ }^{10}$ In addition, taking into account the vulnerability of nursing home residents and their care dependency, it cannot be expected that all residents perform intensive exercises. ${ }^{17}$ Therefore, rather than performing exercises, it is recommended that sedentary behavior of all nursing home residents be reduced by enhancing activity levels to maintain these residents' functioning, which can be done by increasing light activities during the day. ${ }^{15,17}$ Residents could perform activities of daily living (ADL), such as washing, dressing, mobility, and eating, and instrumental activities of daily living (IADL), such as setting a table, preparing food, and watering plants. Physical activity does not need to be vigorous, because participation in daily activities already contributes to maintenance of physical functioning and higher quality of life. ${ }^{10,18-22}$ In addition, different studies have shown the associations between performing these ADL and IADL and positive mood, ${ }^{23}$ higher levels of wellbeing, ${ }^{24}$ and higher self-esteem. ${ }^{25}$ 


\section{The role of nursing staff in residents' physical activity levels}

Nursing staff providing twenty-four hour care in the nursing homes play a key role in the residents' daily lives, and have the opportunity to encourage residents in their daily activities and their independence. In Dutch nursing homes, different levels of nursing staff provide direct care. In general, most of the direct care is provided by certified nursing assistants (in Dutch: verzorgenden), who have two to three years of secondaryvocational training. ${ }^{26}$ Other levels of nursing staff are: nurse aides (in Dutch: zorghulpen), nursing assistants (in Dutch: helpenden) with two years of secondaryvocational training; registered nurses (in Dutch: $M B O$ verpleegkundigen) with four years of secondary-vocational training; and bachelor-educated registered nurses (in Dutch: HBO verpleegkundigen).

The essential role of nursing staff was already emphasized by Henderson's definition of nursing (1960): 'The unique function of the nurse is to assist the individual, sick or well, in the performance of those activities contributing to health or its recovery that he/she would perform unaided if he had the necessary strength, will or knowledge. And to do this in such a way as to help him gain independence as rapidly as possible. ${ }^{27}$ Encouraging nursing home residents in their daily activities is an important part of their job, and is mentioned as part of basic care by various nursing scientists. ${ }^{28}$ Nursing staff can assist a resident by providing adequate support in eating and drinking (for example, providing all the necessary items to prepare a sandwich, or pouring a drink without sugar and milk). Additionally, nursing staff can promote residents' independence by encouraging them to continue as much as possible with activities that they performed before they entered the nursing home (for example, walking to the reception with a resident every day to pick up the newspaper). Nursing staff can encourage nursing home residents' independence especially during daily care activities. Moreover, nursing staff could provide meaningful activities adjusted to the preferences of the resident, such as preparing a meal, walking, or watering plants, ${ }^{29}$ which should create a personalized home-like environment, and should sustain residents' sense of self and normality. ${ }^{30}$ With the right support, nursing home residents are still able to perform a lot of daily activities. ${ }^{31}$

The focus on encouraging residents' activities and independence fits into the shift in the nursing home care culture during the last years. A shift is ongoing from the traditional medical care model ('hospital-like', 'institutional', and impersonal) towards a more social model of care that focuses on residents' well-being, capabilities, autonomy, and quality of life. ${ }^{30,32}$ The Dutch Quality Improvement Framework for Nursing Home Care, published in 2017, stated that nursing home care aims to contribute to residents' quality of life, and it is specified that nursing homes should involve residents in meaningful activities during their day. ${ }^{33}$ Nevertheless, nursing staff are likely to do things for the residents and tend to take over residents' activities, even when the 
residents could perform these activities themselves. ${ }^{34}$ Nursing staff are often used to task-oriented working, focusing on the task they need to fulfill in time, rather than person-centered working, focusing on the residents' needs and preferences. ${ }^{35}$ Several barriers could influence nursing staff, such as the high workload they experience ${ }^{36}-$ nursing staff might perceive that they have no time to talk about or listen to the residents' needs and preferences ${ }^{37}$-as well as lack of support from colleagues, ${ }^{38}$ and lack of knowledge and awareness. Nursing staff indicate that encouragement of residents is liable to be pushed aside due to the other tasks that they need to fulfill. ${ }^{31}$ Despite these various barriers, nursing staff are still the key to creating an environment in which residents are encouraged. Nursing staff might need support at the organizational and social levels to change to their behavior to encourage residents' daily activities and independence. An essential first step within this behavioral change, is to create awareness of own practices among nursing staff. ${ }^{39}$

\section{Objectives and outline}

To conclude, it is known that nursing home residents are inactive. However, it is unknown which activities nursing home residents are involved in during the day. Furthermore, the role of nursing staff in these activities is unknown, despite the fact that they can make a difference in residents' activity levels and independence. Therefore, this dissertation focuses on both nursing home residents' daily activities and the role of nursing staff in these activities. First, it describes the situation in the nursing homes with respect to the activities of the resident, the role of nursing staff and their perceived behavior aimed at encouraging residents. In addition, to encourage residents' daily activities and independence, a nursing intervention is developed and tested in terms of its feasibility and its effects on both the residents and the nursing staff. 


\section{Objectives}

The overall objective of this dissertation is to develop a nursing intervention aiming to 1 change nursing behavior towards encouraging the daily activities and independence of nursing home residents, and to evaluate the impact of this nursing intervention on both nursing staff and residents. In the view of this objective, this dissertation aims:

1. to provide insight into the daily activities of nursing home residents;

2. to provide insight into the role of nursing staff in the daily activities of nursing home residents;

3. to provide insight into the extent to which nursing staff in the Netherlands perceive to encourage the activities of residents;

4. to develop and test a feasible nursing intervention to change nursing staff behavior towards encouraging nursing home residents in their daily activities and independence;

5. to evaluate the impact of this nursing intervention on both nursing staff behavior and the daily activities and independence of nursing home residents.

\section{Outline}

The different aims of the dissertation are addressed in the subsequent chapters. Chapter 2 obtains insight into the daily activities of nursing home residents, based on an observation study. The role of nursing staff in the daily activities of nursing home residents is explored in Chapter 3. The results of a cross-sectional study on the extent to which nursing staff perceive to encourage nursing home residents in functional activity are presented in Chapter 4; in addition, this chapter describes the association between nursing staff behavior and their professional characteristics, contextual-factors, and their information-seeking behavior. Chapters 2-4 provide essential input for the development of the nursing intervention. Chapter 5 addresses the feasibility of this intervention; furthermore, the step-by-step development of the nursing intervention is represented in a box in this chapter. Chapter 6 describes a quasi-experimental study that shows the impact of the nursing intervention on both nursing staff behavior and residents' functioning and independence. In Chapter 7 , the main findings of the studies in this dissertation are summarized and discussed, including methodological and theoretical considerations and implications for both research and practice. 


\section{Research line: 'Nurses on the Move: towards high-quality care in nursing homes'}

The studies in this dissertation were conducted as part of the research line 'Nurses on the Move: towards high quality care in nursing homes,' which was funded by ZonMw, The Netherlands Organization for Health Research and Development (grant 520001003). This research line aims to contribute to the improvement of quality of care in general, and, more specifically, to the improvement of functional status and the reduction of disability among nursing home residents. The research line consists of three interrelated PhD-projects:

1) Encouraging daily activities and independence among residents (this dissertation)

2) Supporting nursing staff in implementing innovations

3) Directing nursing care staff and quality of care in nursing homes

\section{Living Lab in Ageing and Long-Term Care}

This research was embedded in the Living Lab in Ageing and Long-Term Care, a formal collaboration between Maastricht University, Zuyd University of Applied Sciences, and seven long-term care organizations, all located in the southern part of the Netherlands. ${ }^{40}$ The goal of this multidisciplinary collaboration is to improve quality of life, quality of long-term care, and quality of work. 


\section{References}

1. Gezondheidsraad. Beweegrichtlijnen 2017. Den Haag: Gezondheidsraad. Publicatienr, 2017/08.

2. Caspersen CJ, Powell KE, Christenson GM. Physical activity, exercise, and physical fitness: definitions and distinctions for health-related research. Public Health Rep 1985;100:126-131.

3. World Health Organization. Global Recommendations on Physical Activity for Health. Geneva: WHO Press, 2010.

4. Schüssler S, Dassen T, Lohrmann C. Care dependency and nursing care problems in nursing home residents with and without dementia: a cross-sectional study. Aging Clin Exp Res. 2016; 28:973-982.

5. Cook C, Fay S, Rockwood K. Decreased initiation of usual activities in people with mild-to-moderate Alzheimer's disease: a descriptive analysis from the VISTA clinical trial. Int Psychogeriatr. 2008;20:952-963.

6. Schols JM, Crebolder HF, van Weel C. Nursing home and nursing home physician: the Dutch experience. J Am Med Dir Assoc. 2004;5:207-212.

7. Verbeek H, Rossum E, Zwakhalen SM, et al. Small, homelike care environments for older people with dementia: a literature review. Int Psychogeriatr. 2009;21:252-64.

8. Bos A, Boselie P, Trappenburg M. Financial performance, employee well-being, and client well-being in forprofit and not-for-profit nursing homes: a systematic review. Health Care Manage Rev. 2017;42:352-368.

9. Binnekade TT, Eggermont LHP, Scherder EJA. Onbewogen om bewegen: lichamelijke (in)activiteit in zorginstellingen. Amsterdam: Vrije Universiteit; afd. Klinische Neuropsychologie, 2012.

10. Ikezoe T, Asakawa $\mathrm{Y}$, Shima $\mathrm{H}$, et al. Daytime physical activity patterns and physical fitness in institutionalized elderly women: an exploratory study. Arch Gerontol Geriatr. 2013;57:221-225.

11. MacRae PG, Schnelle JF, Simmons SF, et al. Physical activity levels of ambulatory nursing home residents. J Aging Phys Activ. 1996;4:264-278.

12. Ice HG. Daily life in a nursing home: Has it changed in 25 years? J Aging Stud 2002;16:345-359.

13. Tiessen-Raaphort A, Verbeek D, de Haan J et al. Sport: een leven lang. Rapportage sport 2010. Den Haag: Sociaal en Cultureel Planbureau, 2010.

14. van Alphen HJ, Volkers KM, Blankevoort CG, et al. Older adults with dementia are sedentary for most of the day. PloS One. 2016;11:e0152457.

15. de Souto Barreto P, Morley JE, Chodzko-Zajko W, et al. Recommendations on physical activity and exercise for older adults living in long-term care facilities: a taskforce report. J Am Med Dir Assoc. 2016:17(5):381-392.

16. Weening-Dijksterhuis $\mathrm{E}$, de Greef $\mathrm{MH}$, Scherder EJ, et al. Frail institutionalized older persons: a comprehensive review on physical exercise, physical fitness, activities of daily living, and quality-of-life. Am J Phys Med Rehabil. 2011;90:156-168.

17. Sparling PB, Howard BJ, Dunstan DW, et al. Recommendations for physical activity in older adults. BMJ. 2015;350:h100.

18. Edvardsson D, Petersson L, Sjogren K, et al. Everyday activities for people with dementia in residential aged care: associations with person-centredness and quality of life. Int J Older People Nurs. 2014;9:269-276.

19. Gronstedt H, Frandin K, Bergland A, et al. Effects of individually tailored physical and daily activities in nursing home residents on activities of daily living, physical performance and physical activity level: a randomized controlled trial. Gerontology. 2013;59:220-229.

20. Xue QL, Bandeen-Roche K, Mielenz TJ, et al. Patterns of 12-year change in physical activity levels in community-dwelling older women: can modest levels of physical activity help older women live longer? Am J Epidemiol. 2012;176:534-543.

21. Andersen CK, Wittrup-Jensen KU, Lolk A, et al. Ability to perform activities of daily living is the main factor affecting quality of life in patients with dementia. Health Qual Life Out. 2004;2:52.

22. Chan C, Slaughter S, Jones C, et al. Greater independence in activities of daily living is associated with higher health-related quality of life scores in nursing home residents with dementia. Healthcare. 2015;3:503-518. 


\section{CHAPTER 1}

23. Beerens HC, Zwakhalen SM, Verbeek H, et al. The relation between mood, activity, and interaction in long-term dementia care. Aging Ment Health. 2018;22:26-32.

24. Smit D, de Lange J, Willemse B, et al. Activity involvement and quality of life of people at different stages of dementia in long term care facilities. Aging Ment Health. 2016;20:100-109.

25. Blair CE. Effect of self-care ADLs on self-esteem of intact nursing home residents. Issues Ment Health Nurs. 1999;20:559-570.

26. Verkaik R, Francke AL, van Meijel B, et al. The introduction of a nursing guideline on depression at psychogeriatric nursing home wards: effects on Certified Nurse Assistants. Int J Nurs Stud. 2011;48:710-719.

27. Henderson V. Basic principles of nursing care. Geneva: International Council of Nurses. 1960.

28. Zwakhalen SMG, Hamers JPH, Metzelthin SF, et al. Basic nursing care: the most provided, the least evidence based. A discussion paper. J Clin Nurs. 2018. Accepted Author Manuscript. doi:10.1111/jocn.14296

29. Kleynen M, Braun SM, van Vijven K, et al. The development of the MIBBO: a measure of resident preferences for physical activity in long term care settings. Geriatr Nurs. 2015;36:261-266.

30. Edvardsson D, Fetherstonhaugh D, Nay R. Promoting a continuation of self and normality: person-centred care as described by people with dementia, their family members and aged care staff. J Clin Nurs. 2010;19:2611-2618.

31. Inspectie voor de Gezondheidszorg (Dutch Health Care Inspectorate). Staat van de gezondheidszorg 2012. Preventie in de curatieve en langdurige zorg: noodzaak voor kwetsbare groepen. https://www.rijksoverheid.nl/ documenten/rapporten/2012/11/29/staat-van-de-gezondheidszorg-2012 Accessed 25 Apr 2016.

32. Eliopoulos C. Guest Editorial: Cultural transformation in nursing homes. Int J Older People Nurs. 2010;5(1):1-2.

33. Zorginstituut Nederland. Kwaliteitskader Verpleeghuiszorg 2017. https://www.zorginstituutnederland.nl/ publicaties/publicatie/2017/01/13/kwaliteitskader-verpleeghuiszorg

34. Brown D, McWilliam C, Ward-Griffin C. Client-centred empowering partnering in nursing. J Adv Nurs. 2006;53:160-168.

35. Tuinman A, de Greef MH, Krijnen WP, et al. Examining time use of Dutch nursing staff in long-term institutional care: a time-motion study. J Am Med Dir Assoc. 2016;17:148-154.

36. Kieft RA, de Brouwer BB, Francke AL, et al. How nurses and their work environment affect patient experiences of the quality of care: a qualitative study. BMC Health Serv Rev. 2014;14:249.

37. Mallidou AA, Cummings GG, Schalm C, et al. Health care aides use of time in a residential long-term care unit: a time and motion study. Int J Nurs Stud. 2013;50:1229-1239.

38. Kuk NO, Zijlstra GAR, Bours GJJW, et al. Promoting functional activity among nursing home residents: a cross-sectional study on barriers experienced by nursing staff. J Aging Health. 2017:0898264316687407.

39. Elwyn G, Marrin K, Frosch D, et al. Sustainable change sequence: a framework for developing behavior change interventions for patients with long-term conditions. Eur J Pers Cent Healthc. 2014;2:212-216.

40. Verbeek H, Zwakhalen SMG, Schols JMGA, et al. Keys to successfully embedding scientific research in nursing homes: a win-win perspective. J Am Med Dir Assoc. 2013;14:855-857. 


\section{CHAPTER 2}

\section{Daily (in)activities of nursing home residents}

in their wards: an observation study

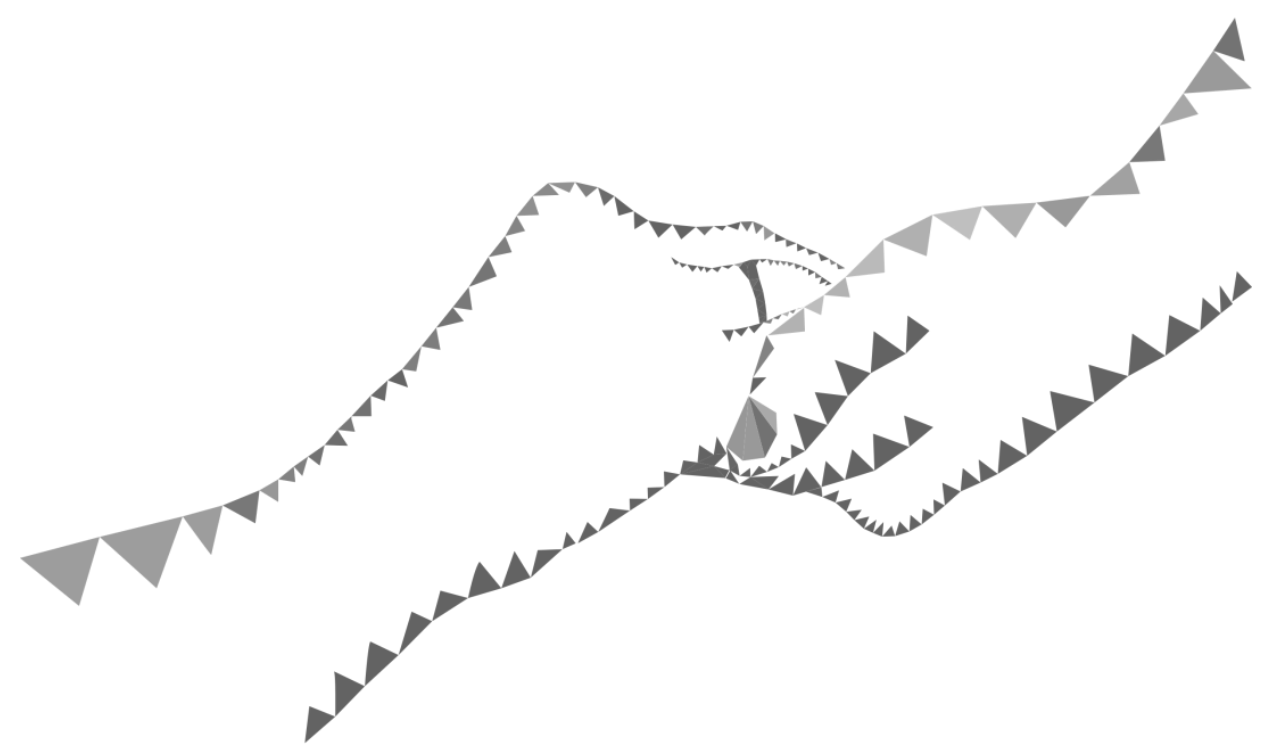

This chapter was published as:

den Ouden M, Bleijlevens MHC, Meijers JMM, Zwakhalen SMG, Braun SM, Tan FES, Hamers JPH. Daily (in)activities of nursing home residents in their wards: an observation study. Journal of American Medical Directors Association. 2015;16:963-968. 


\begin{abstract}
Objectives: Research shows that nursing home residents are largely inactive. This inactivity negatively influences physical fitness, and participation in daily activities is known to have a positive influence on physical function and quality of life. Existing research does not provide sufficient insight into the daily activities in which nursing home residents participate. This insight is needed to develop future interventions in order to encourage nursing home residents to participate in daily activities and, thereby, decrease inactivity. The purpose of this study was to obtain insight into daily (in)activities of psychogeriatric and somatic nursing home residents during the day and their body positions during these (in)activities.
\end{abstract}

Design: Cross-sectional observation study.

Setting: Nursing homes in the Netherlands (19 psychogeriatric and 11 somatic wards).

Participants: Seven hundred and twenty-three nursing home residents in seven nursing homes.

Measurements: Observations were conducted using a self-developed observation list. Residents were observed in their wards during five random observation times between 7:00 a.m. and 11:00 p.m., in which the daily activity and position of the resident during this activity were scored. Percentages of activities and positions were calculated for each observation time.

Results: In total, 3,282 observations (91\% of the intended 3,615 observations) were conducted. Nursing home residents of both psychogeriatric and somatic wards were mainly observed partaking in inactivities such as sleeping, doing nothing and watching TV (range: $45-77 \%$ of the five observation times). Furthermore, residents were engaged in Activities of Daily Living (ADL) (range: 15-38\%), which mainly comprised activities related to mobility (range: 10-19\%) and eating and drinking (range: 2-17\%). Engagement of residents in Instrumental ADL (IADL) was rarely observed (up to 3\%). Residents were largely observed in a lying or sitting position (range: 89-92\%).

Conclusion: The majority of the psychogeriatric and somatic nursing home residents spend their day inactive in a lying or sitting position in the ward. To encourage nursing home residents in daily activities in the wards, interventions are needed that a) focus on increasing $A D L$ and $I A D L$ and $b$ ) encourage standing and walking in nursing home residents. 


\section{Introduction}

There is increasing evidence that nursing home residents are largely inactive. ${ }^{1-5}$ The consequences of inactivity can be enormous for frail nursing home residents, since inactivity is negatively related to physical fitness. ${ }^{1}$ Subsequently, a decline in physical fitness, including muscle strength, balance and physical performance, can be a risk factor for sedentary behavior in nursing home residents. ${ }^{1}$ This decline in physical fitness has a negative effect on the care dependency of older people, which has an influence on the workload of nursing staff. ${ }^{6}$ Even in healthy older people, ten days of bed rest has disastrous effects on muscle function and aerobic capacity, and leads to an overall reduction of physical activity. ${ }^{7}$ Therefore, and because of the known benefits of physical activity on physical fitness, physical performance and quality of life, diverse exercise interventions, e.g. resistance, flexibility, balance and/or functional training, have been developed. ${ }^{8}$ However, physical activity does not need to be vigorous to have positive effects, since participation in daily activities already contributes to maintaining physical functioning $^{9-11}$ and is associated with a higher quality of life. ${ }^{5}$

Insight into the current level of daily activities of nursing home residents is necessary in order to tailor interventions to increase these daily activities. However, it is challenging to obtain valid and reliable information about daily activities among nursing home residents. Different measurement methods are available to measure physical activity such as questionnaires, activity monitors and observations. Not all of these methods are appropriate to obtain insight into daily activities. Questionnaires, as used in Edvardsson et al., ${ }^{5}$ could be biased by proxy ratings, ${ }^{5}$ have limited reliability and validity, ${ }^{12}$ show floor effects and suffer from recall bias in low levels of physical activity. ${ }^{13}$ Activity monitors, as used in Ikezoe et al. ${ }^{1}$ and Egerton and Brauer, ${ }^{4}$ could identify body positions, but cannot provide detailed information about the kind of daily activity in which residents were partaking. Even though they are time consuming, observations seem to be the best measurement method to obtain detailed information about daily activities.

Different observation studies collected data only during specific time slots, such as meal times and organized activities, which does not provide insight into the kind of activities that occur during the whole day. ${ }^{14,15}$ To our knowledge, in the last 20 years, only two observation studies provided insight into the activities and/or positions of nursing home residents over the whole day. MacRae et al. ${ }^{2}$ observed the positions of ambulant nursing home residents $(n=95)$ in five nursing homes from 7:00 a.m. to 7:00 p.m. ${ }^{2}$ Positions were defined as lying, sitting, standing, walking or wheelchair propelling. This study found that nursing home residents were observed lying or sitting in 83.5-93.8\% of the observations. Harper $1 \mathrm{ce}^{3}$ provided information about activities and positions during the activities of nursing home residents $(n=27)$ at one nursing home. The observations took place from 8:00 a.m. to bedtime. Activity categories were personal care, social and 
expressive activities, doing little or nothing, and movement; positions were classified as reclining, sitting or upright. The results showed that residents were mainly lying (29\%) or sitting (69\%) during the day. Furthermore, it showed that residents spent $66 \%$ of their day doing little or nothing, doing social activities (12\%), handling personal care $(18 \%)$, or $3 \%$ moving (walking and moving in a wheelchair).

The aforementioned studies ${ }^{2,3}$ provide important information about the level of physical activity in nursing home residents and recommend residents partake in activities throughout the day to prevent further decline. However, these studies included only small sample sizes and were both conducted in the US, and demographic changes have most likely occurred the past two decades. These demographic changes could influence the possibilities for residents' activities and positions. This study purposes to include a larger sample of nursing homes and nursing home residents outside the US. Furthermore, previous studies did not distinguish between psychogeriatric and somatic residents. The main admission reason of psychogeriatric residents is dementia, and somatic residents are mostly admitted to the nursing home because of cerebrovascular accidents, neurological disorders, mobility problems and malignancies. ${ }^{16}$ Based on the admission reasons for these wards, differences in care dependency and mobility and, therefore, activities and positions could be expected. Thus, the aim of this study is to gain insight into the daily (in)activities of psychogeriatric and somatic nursing home residents during the day and their positions during these (in)activities.

\section{Methods}

\section{Study design and sample}

An explorative, cross-sectional, observation study was conducted in June and July of 2014. The sample consisted of nursing home residents living in psychogeriatric $(n=19)$ and somatic ( $n=11$ ) wards (long stay) in seven nursing homes in the southern part of the Netherlands. These wards housed 723 (383 psychogeriatric and 340 somatic) residents. Rehabilitation (short stay) wards were excluded.

\section{Measures}

Residents' gender, age, mobility, functioning in Activities of Daily Life (ADL) and cognitive functioning were assessed. The residents' mobility was scored as mobile or immobile (wheelchair dependent or bedridden). ADL functioning was scored with the Barthel Index, which ranges from 0-20: a lower score indicates a higher dependency in ADL functioning. ${ }^{17}$ Cognitive functioning was assessed using the Cognitive Performance 
Scale (CPS) ranging from 0 (no cognitive impairment) to 6 (very severe cognitive impairment). ${ }^{18}$

The focus of this study was to report on the daily activities residents were engaged in during the times of observation. Furthermore, the positions of the residents during the performance of these activities were scored. No standard observation list was found to score daily activities and positions; therefore, a self-developed observation list was used.

The development of the observation list consisted of the following steps. First, a pilot observation study was conducted without a predefined list of activities and positions. During this pilot study, nine nursing home residents (four psychogeriatric and five somatic residents) were observed for one minute every 15 minutes (16 hours in total). The observation list was composed based on the observed daily activities during this pilot study. Based on the observation study of de Bruin et al., ${ }^{19}$ games, crafts and domestic activities were added. In the next step, face and content validity of the observation list were checked by five observers (three nurses, one research assistant and one researcher). They checked whether the list was complete (any activities missing that could be observed in the nursing home ward) and appropriate for the nursing home setting. After this check, minor adjustments to the observation list were made, i.e. three daily activities were added: physiotherapy, nonverbal communication, and putting on a hearing aid). Eventually, the observation list consisted of 33 different daily activities plus the options 'resident not present in the ward' and 'comments' (comments could be made; for example, if the activity did not fit into one of the predefined activities, the observer could describe the observed activity).

The observations were conducted by five individual observers who received training before the start of the observations. The aim of this 3.5-hour training was to explain the observation manual and to practice observations using 20 video fragments of older people performing daily activities. The observers scored the daily activity and position during this activity for each fragment independently. After this exercise, differences in scores were discussed together until an agreement was reached with all observers.

To test the reliability of the observation list, the extent of agreement between observers during observations in the nursing home was calculated with the intraclass correlation coefficient (ICC). The ICC was 0.859 for the activities and 0.873 for the positions.

In this study, daily activities were defined as all activities residents were engaged in during a day. Being engaged in an activity did not necessarily mean that the resident was physically active (e.g., dressing or walking around), since daily activities also include passive activities (e.g., getting dressed by a nurse).

The daily activities were clustered into four categories: 'inactivity', 'ADL', 'Instrumental $A D L$ ' (IADL) and 'communication and hobbies'. The category 'inactivity' was scored 
when the resident was observed sleeping, doing nothing, watching TV or smoking based on the category of passive activities found in Harper Ice. ${ }^{3}$ The categories 'ADL' and 'IADL' were based on the Barthel Index ${ }^{17}$ and the Groningen Activity Restriction Scale (GARS). ${ }^{20}$ These instruments are reliable and valid for measuring physical functioning. ${ }^{17,20}$ 'ADL' consisted of personal care, going to the bathroom, eating and drinking, mobility, dressing and bathing. Domestic activities (e.g., setting the table) and preparing food were categorized as 'IADL'. ${ }^{20}$ The last category was 'communication and hobbies', which consisted of activities such as verbal communication and reading. The categories do not indicate whether the resident was actively or passively engaged in the activity. Detailed information on categories and corresponding activities on the observation list is provided in Table 2.1.

Positions were defined as lying, sitting, standing, walking or transferring. Transferring was defined as a change in position during the observation. The different positions were based on the observation study of MacRae et al., ${ }^{2}$ in which the observations were coded as lying, sitting, standing, walking or wheelchair propelling. However, in the current study, wheelchair propelling was defined as an activity in which the position of the residents was sitting.

Table 2.1: (Sub)Categories of activities and the 33 corresponding activities of the observation list in which residents could be engaged

\begin{tabular}{|l|l|l|}
\hline Categories & Subcategories & 33 activities of the observation list \\
\hline Inactivity & $\begin{array}{l}\text { no activity } \\
\text { watching TV } \\
\text { sleeping }\end{array}$ & $\begin{array}{l}\text { doing nothing, smoking } \\
\text { watching TV } \\
\text { sleeping }\end{array}$ \\
\hline ADL & personal care \\
& $\begin{array}{l}\text { going to the bathroom } \\
\text { eating and drinking } \\
\text { mobility }\end{array}$ & $\begin{array}{l}\text { personal hygiene, putting on glasses or hearing aid, } \\
\text { taking medication, wiping off hands } \\
\text { going to the bathroom } \\
\text { drinking, eating with hands, eating with cutlery } \\
\text { walking, moving forward in a wheelchair with arms, } \\
\text { moving forward in a wheelchair with legs, moving } \\
\text { forward in an electric wheelchair, moving with arms, } \\
\text { changing positions, transferring, physiotherapy } \\
\text { dressing } \\
\text { washing, showering }\end{array}$ \\
& $\begin{array}{l}\text { dressing } \\
\text { bathing }\end{array}$ & $\begin{array}{l}\text { setting table, cleaning } \\
\text { preparing food, pouring a drink } \\
\text { preparing food/drinks }\end{array}$ \\
\hline IADL & $\begin{array}{l}\text { communication } \\
\text { hobbies }\end{array}$ & $\begin{array}{l}\text { verbal communication, nonverbal communication, } \\
\text { visits } \\
\text { reading, crafts, games }\end{array}$ \\
\hline
\end{tabular}

ADL = Activities of Daily Living; $\mid A D L=$ Instrumental Activities of Daily Living 


\section{Procedure}

The management of the nursing home or the contact person within the nursing home provided information about the nursing home and the wards, and they informed the nursing staff about the observations. Nursing staff members in the wards assessed the background characteristics of each resident using an inventory consisting of different questionnaires. The information needed for the questionnaires was gathered using the residents' records and nurses' knowledge about the resident. This inventory was sent to the contact person of the nursing home, and this person spread the inventory to the nursing staff in the wards and collected the completed inventories.

Observations were scored on a hand-held tablet (Samsung Galaxy Tab 3, Suwon, Korea) using the e-Droid-cell Pro app to open and adjust the observation list. The observation list was integrated into an Excel file and included the random sequence and observation times in each ward (see Figure 2.1).

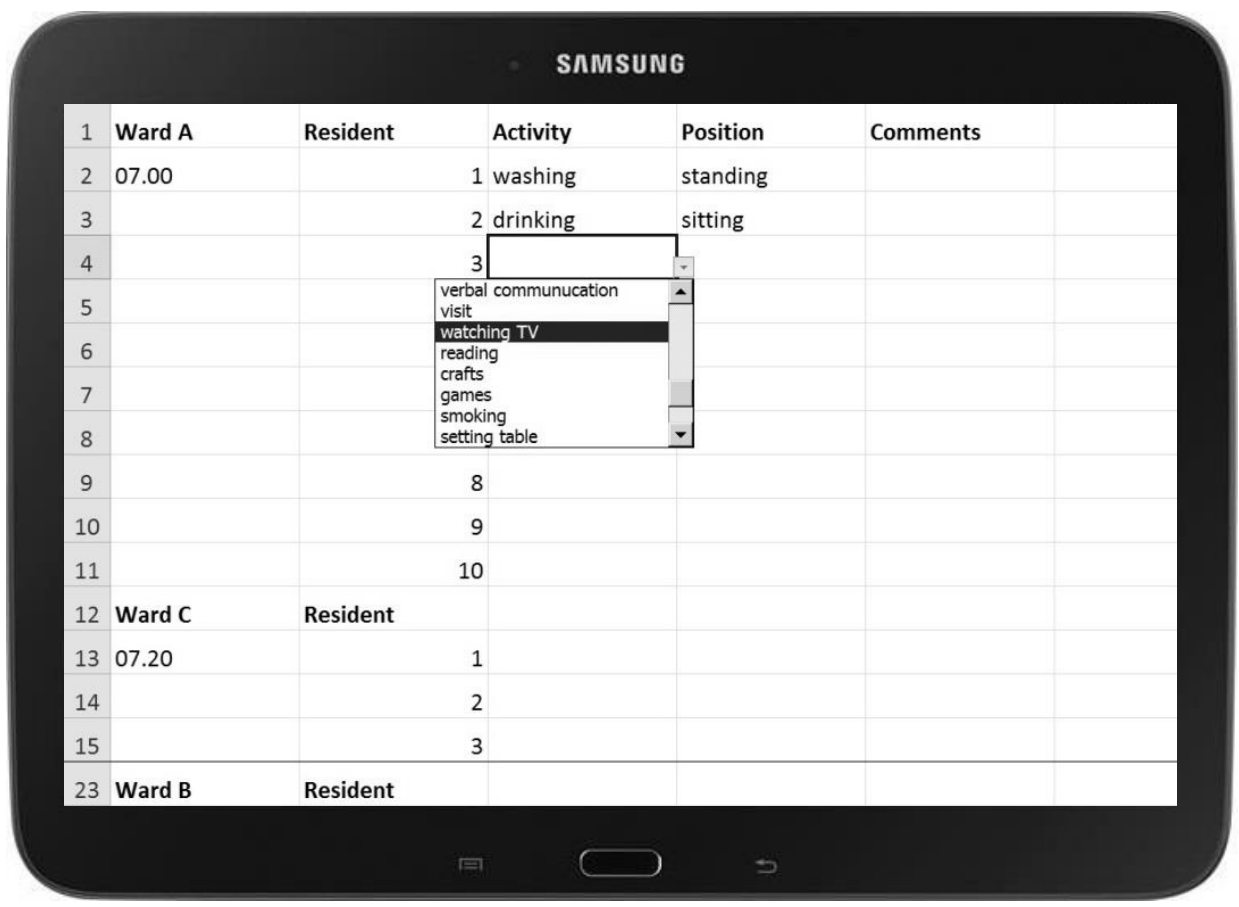

Figure 2.1: Self-developed observation list on a tablet

In order to observe residents for one complete day, observations were conducted over a 16-hour period. Since observations in a ward were completed by one observer, observations were conducted over two days. To obtain an overview of the whole day, the observations were divided into five time blocks. Each ward was randomly observed once during each of the five time blocks: 7:00 to 10:00 a.m. (observation time 1), 10:00 
a.m. to 1:00 p.m. (observation time 2), 1:00 to 4:00 p.m. (observation time 3), 4:00 to 7:00 p.m. (observation time 4) and 7:00 to 11:00 p.m. (observation time 5). All wards were visited in a random sequence during each observation time. Randomization was conducted using the website http://www.randomizer.org/. The observer walked around the ward, observed each resident for one minute and registered the daily activity and position of the resident. If residents were observed performing more than one activity, the main daily activity was reported. The main activity was defined as the most relevant or meaningful activity for the resident. Comments were processed and, if needed, the described activity was redefined in one of the 33 activities. Only nursing home residents who were present in the ward were observed.

\section{Ethical considerations}

The medical research ethics committee of Atrium-Orbis-Zuyd approved the study protocol (14-N-84). The management of each nursing home signed research declaration to obtain the observations anonymously and to gather background characteristics of the residents. The privacy of the residents was considered during all observations; for example, when the resident was in the bathroom with the door closed, the door was not opened by the observer.

\section{Data analyses}

The data from the Excel files were transferred to SPSS version 22, which was used to conduct the analyses (SPSS Inc., Chicago, IL). Descriptive statistics were performed for all wards together and separately for the psychogeriatric and somatic wards. Due to the anonymous observations, it was not possible to follow a single resident over time. Therefore, percentages of activities and positions were calculated for each observation time separately based on all individual observations. To compare the different types of wards, an independent t-test was used for the continuous variables and a chi-square test was used for the categorical variables. Additional analyses were conducted to compare the activities and positions of residents in psychogeriatric and somatic wards. Percentages of activity categories and positions were estimated and analyzed based on the expected percentage of each ward. A linear, mixed-effects, regression model was used to calculate the differences in activity categories and positions between psychogeriatric and somatic wards for each observation time. 


\section{Results}

\section{Study population}

All 30 wards (19 psychogeriatric and 11 somatic) at seven nursing homes were observed. The nursing home wards housed 723 residents in total. The nursing homes varied in size from 2-10 wards. Per ward, the number of residents ranged from 10-47 residents. Demographic characteristics of the nursing home residents are presented in Table 2.2. The mean age of all nursing home residents was 83.0 (SD 8.9) years, and 68\% of the residents were female. Compared to somatic residents, on average, the psychogeriatric residents were older, were more often mobile, were less severely dependent in ADL and had more severe cognitive impairments. Ninety-one percent $(n=3,282)$ of the intended $(n=3,615)$ observations were completed, which equates to an average of 4.5 observations per resident.

Table 2.2: Demographic characteristics of participants

\begin{tabular}{lllllll}
\hline & $\mathrm{N}$ & $\begin{array}{l}\text { Mean age } \\
(\mathrm{SD}) *\end{array}$ & \% female & \% mobile residents* & $\begin{array}{l}\text { Mean Barthel score } \\
(\mathrm{SD})^{*}\end{array}$ & $\begin{array}{l}\text { Mean CPS score } \\
(\mathrm{SD})^{*}\end{array}$ \\
\hline Total & 723 & $83.0(8.9)$ & 68 & 45 & $7.6(5.8)$ & $2.6(1.9)$ \\
Psychogeriatric & 383 & $85.2(6.4)$ & 70 & 61 & $8.0(6.1)$ & $3.5(1.7)$ \\
Somatic & 340 & $80.5(10.6)$ & 66 & 27 & $7.1(5.3)$ & $1.7(1.7)$ \\
\hline
\end{tabular}

*significant at $p<0.05$; Range Barthel: 0-20 (a lower score indicates an increased disability). ${ }^{17}$ Range Cognitive Performance Scale (CPS): 0-6 (a higher score indicates a more severe cognitive impairment). ${ }^{18}$

\section{Daily activities in the wards}

Table 2.3 presents the percentages of the observed daily activities residents were engaged in during the five observation times based on all individual observations. Most nursing home residents were observed to be inactive, i.e. watching TV, sleeping or doing nothing (range: $45-77 \%$ for the five observation times). When engaged in ADL (range: 15-38\%), nursing home residents were most often engaged in activities related to mobility (range: 10-19\%) and eating and drinking (range: $2-17 \%$ ), such as walking or eating, respectively. $A D L$, like dressing, bathing and personal care, were mostly observed in the morning between 7:00-10:00 a.m. Mobility activities were observed during all observation times, but the greatest number of mobility activities was observed during the early afternoon between 1:00-4:00 p.m. IADL, like setting the table, was rarely observed (up to $3 \%$ ). Residents were observed in communication activities, like chatting with others, during $4-10 \%$ of the observations. Engagement in hobbies, e.g. painting, reading or knitting, was particularly observed between 10 a.m. 
and 4 p.m. Based on the additional regression analysis at the ward level, no significant differences between psychogeriatric and somatic wards were found with regard to the activity categories.

Table 2.3: Observed activities in the nursing home wards (\%) based on each observed resident

\begin{tabular}{|c|c|c|c|c|c|c|c|c|c|c|c|c|c|c|c|}
\hline \multirow{3}{*}{$\begin{array}{l}\text { Observation time } \\
\text { N observations }\end{array}$} & \multicolumn{5}{|c|}{ Total } & \multicolumn{5}{|c|}{$\begin{array}{l}\text { Psychogeriatric wards } \\
(n=19)\end{array}$} & \multicolumn{5}{|c|}{$\begin{array}{l}\text { Somatic wards } \\
(n=11)\end{array}$} \\
\hline & $\mathrm{T} 1$ & $\mathrm{~T} 2$ & T3 & $\mathrm{T} 4$ & T5 & T1 & $\mathrm{T} 2$ & T3 & $\mathrm{T} 4$ & T5 & $\mathrm{T} 1$ & $\mathrm{~T} 2$ & T3 & $\mathrm{T} 4$ & T5 \\
\hline & 705 & 657 & 588 & 637 & 695 & 376 & 362 & $315^{*}$ & 342 & 374 & 329 & 295 & 273 & 295 & 321 \\
\hline Inactivity & 57 & 45 & 53 & 51 & 77 & 65 & 48 & 51 & 51 & 78 & 49 & 41 & 55 & 51 & 77 \\
\hline No activity & 17 & 22 & 23 & 18 & 8 & 15 & 24 & 25 & 21 & 4 & 20 & 19 & 20 & 16 & 13 \\
\hline Sleeping & 37 & 18 & 22 & 18 & 54 & 49 & 19 & 18 & 21 & 64 & 24 & 16 & 26 & 14 & 41 \\
\hline Watching TV & 3 & 5 & 8 & 15 & 16 & 1 & 4 & 7 & 10 & 10 & 4 & 6 & 10 & 21 & 23 \\
\hline$A D L$ & 32 & 38 & 28 & 32 & 15 & 28 & 37 & 28 & 35 & 15 & 37 & 40 & 29 & 30 & 16 \\
\hline Personal care & 4 & 3 & 2 & 3 & 1 & 2 & 3 & 3 & 2 & 1 & 6 & 4 & 2 & 3 & 1 \\
\hline Going to the bathroom & 2 & 2 & 2 & 1 & 1 & 2 & 2 & 0 & 1 & 1 & 2 & 2 & 4 & 2 & 1 \\
\hline Eating and drinking & 8 & 17 & 5 & 10 & 2 & 6 & 17 & 6 & 10 & 2 & 11 & 17 & 4 & 10 & 2 \\
\hline Mobility & 13 & 14 & 19 & 18 & 10 & 11 & 14 & 20 & 21 & 10 & 14 & 15 & 18 & 14 & 9 \\
\hline Dressing & 2 & 1 & $<1$ & 1 & 2 & 2 & 1 & 0 & 1 & 1 & 1 & 1 & $<1$ & $<1$ & 2 \\
\hline Bathing & 4 & 1 & 0 & $<1$ & $<1$ & 5 & 1 & 0 & 0 & 0 & 3 & 1 & 0 & $<1$ & 1 \\
\hline IADL & 2 & 1 & 1 & 3 & 0 & 1 & 1 & 2 & 4 & 0 & 3 & 1 & 1 & 3 & 0 \\
\hline Domestic activities & 1 & 1 & 1 & 2 & 0 & 1 & 1 & 1 & 2 & 0 & 1 & $<1$ & 1 & 2 & 0 \\
\hline Preparing food & 1 & 1 & $<1$ & 2 & 0 & 1 & 0 & $<1$ & 2 & 0 & 2 & 1 & 0 & 1 & 0 \\
\hline $\begin{array}{l}\text { Communication \& } \\
\text { hobbies }\end{array}$ & 8 & 16 & 16 & 13 & 6 & 6 & 14 & 18 & 11 & 5 & 10 & 18 & 14 & 16 & 7 \\
\hline Communication & 6 & 9 & 10 & 9 & 4 & 5 & 8 & 14 & 8 & 5 & 7 & 10 & 6 & 11 & 4 \\
\hline Hobbies & 2 & 7 & 6 & 4 & 2 & 1 & 6 & 4 & 3 & 1 & 3 & 8 & 9 & 6 & 3 \\
\hline Missing & 1 & 1 & 1 & 1 & 1 & 1 & $<1$ & 1 & $<1$ & 2 & 1 & 1 & 1 & 1 & 1 \\
\hline
\end{tabular}

$<1$ = percentages below 0.5\%, variation in sum of percentages (around 100\%) exist due to rounding;

Observation time blocks: T1: 7:00-10:00 a.m., T2: 10:00 a.m.-1:00 p.m., T3: 1:00-4:00 p.m., T4: 4:00-7:00 p.m., T5: 7:00-11:00 p.m.;

*During T3, one psychogeriatric ward (residents $n=23$ ) was not observed.

\section{Positions during the activities}

Table 2.4 presents the positions of the nursing home residents during the observation times. During all observation times, residents were observed primarily sitting or lying (range: 89-92\%). Lying was especially observed in the early morning and late evening when residents slept in their beds. However, during the daytime (10 a.m.-7 p.m.), between $16-24 \%$ of the residents were observed in a lying position. Transfers, in which the resident changed position, were rarely observed (up to 1\%). Both psychogeriatric 
and somatic residents were mainly sedentary (lying or sitting) during the day (psychogeriatric range: 85-91\% versus somatic range: 91-93\%). No significant differences were found in positions between the different types of wards based on the additional regression analysis at the ward level.

Table 2.4: Positions of the nursing home residents (\%)

\begin{tabular}{llllll|llllll|lllll}
\hline & \multicolumn{5}{c|}{ Total } & & \multicolumn{3}{|c}{ Psychogeriatric wards $(\mathrm{n}=19)$} & \multicolumn{5}{c}{ Somatic wards $(\mathrm{n}=11)$} \\
Observation time & T1 & T2 & T3 & T4 & T5 & T1 & T2 & T3 & T4 & T5 & T1 & T2 & T3 & T4 & T5 \\
N observations & 705 & 657 & 588 & 637 & 695 & 376 & 362 & 315 & 342 & 374 & 329 & 295 & 273 & 295 & 321 \\
\hline Lying & 48 & 16 & 20 & 24 & 67 & 54 & 11 & 13 & 18 & 69 & 42 & 23 & 29 & 31 & 65 \\
Sitting & 40 & 74 & 69 & 65 & 24 & 33 & 78 & 74 & 67 & 22 & 49 & 70 & 63 & 62 & 27 \\
Standing & 2 & 2 & 2 & 2 & 1 & 4 & 2 & 2 & 3 & 0 & 1 & 1 & 1 & 1 & 2 \\
Walking & 6 & 5 & 7 & 9 & 5 & 7 & 6 & 10 & 12 & 7 & 6 & 5 & 4 & 5 & 3 \\
Transferring & 1 & 1 & 1 & $<1$ & 1 & 1 & 1 & 1 & 1 & 1 & 1 & 1 & 1 & 0 & 1 \\
Missing & 2 & 2 & 1 & 1 & 2 & 2 & 2 & 1 & $<1$ & 2 & 2 & 1 & 2 & 1 & 2 \\
\hline
\end{tabular}

$<1$ = percentages below 0.5\%, variation in sum of percentages (around 100\%) exist due to rounding.

Observation time blocks: T1: 7:00-10:00 a.m., T2: 10:00 a.m.-1:00 p.m., T3: 1:00-4:00 p.m., T4: 4:00-7:00 p.m., T5: 7:00-11:00 p.m.

\section{Discussion}

The results of this study show that the majority of nursing home residents spend their day inactive (sleeping, watching TV or doing nothing). If psychogeriatric and somatic residents were engaged in $A D L$, it mainly consisted of activities related to mobility, eating and drinking. Findings indicate that residents were rarely engaged in IADL related activities, like preparing food or setting the table. Most residents were observed in a lying or sitting position during daily activities. Ninety-one percent of the residents were present in the ward during all observations.

The large amount of inactivity observed in this study is in line with the previous studies of MacRae et al. $^{2}$ and Harper Ice. ${ }^{3}$ Despite a different country specific context, the comparable degree of inactivity from US nursing homes indicates that the large amount of inactivity observed in the current study is not unique to the Dutch nursing home setting. In addition, it indicates that, almost 20 years later, there is still a relatively unchanged nursing home situation with regard to inactivity.

The fact that residents were mainly inactive could be explained by patient related, organizational or environmental aspects. Different patient related aspects, such as care dependency, mobility problems, chronic diseases, fatigue, cognition and habitual inactivity of the resident, could have influenced the large amount of observed inactivity and sedentary positions. As indicated by the low score on the Barthel Index, both 
psychogeriatric and somatic residents are largely dependent in ADL functioning. This high level of dependency could have influenced the number of observed activities.

The observed inactivity could also possibly be influenced by organizational aspects, for example, a potential lack of relevant and meaningful activities offered in the nursing home. Meaningful activities are defined as enjoyable activities for nursing home residents. ${ }^{21}$ If they engage in meaningful activities, residents improve their emotional wellbeing, cognitive status and physical functioning while reducing problematic behaviors. ${ }^{21}$ Research shows that if activities are not relevant or meaningful to residents, residents prefer to do nothing or to watch TV. ${ }^{22}$ Residents could be encouraged in activities they prefer, and, especially mobile residents, could be encouraged to perform activities in which they stand or walk during the day. Other organizational aspects that could possibly influence residents' activities are staff related such as attitude towards activities, workload, amount of staff, work experience and education level. Environmental aspects are the facilities of the ward and the nursing home; for example, facilities that make it possible for nursing home residents to walk around the ward or nursing home, to set the table or to perform other household activities.

Increasing daily activities in nursing home residents will become of greater importance in the near future because there is a change occurring in the care system in the Netherlands. This change will result in a longer stay at home, with more severe cases admitted to the nursing home. Therefore, the nursing home residents will have more complex care problems, will be more severely disabled and more care dependent. It will become increasingly important to encourage residents in their daily activities and to maintain their physical capacity as much and as long as possible.

Research shows that older people who spend more time doing daily and household activities have a lesser decline in mobility. ${ }^{23}$ Participation in daily activities can positively influence physical functioning ${ }^{9-11}$ and quality of life. ${ }^{5}$ Sparling et al. ${ }^{24}$ argued that it is more important for older adults to increase light activities during the day and to decrease sedentary time rather than to exercise. Therefore, future interventions should focus on increasing the daily activities of nursing home residents (especially ADL and IADL) and tailoring these activities to each individual.

It is important to give residents the opportunity to be physically active in the ward during the day, in which nursing staff play an important role. Nursing staff can help residents by tailoring daily activities to the functional abilities, interests and prospects of each individual, and fitting these tailored activities to daily routines while taking into account the possible cognitive impairments. For example, a nurse could encourage a resident to walk to the dining room, or they could walk together instead of the nurse pushing the wheelchair. ${ }^{25}$ In order to understand how nursing staff members could encourage nursing home residents in daily activities, it would be necessary to gain 
insight into the role of nursing staff during daily activities of nursing home residents. Moreover, it is essential to know which activities the residents prefer. This preference of the residents could, for example, be identified by the MIBBO (Dutch acronym for 'Measure to Identify Meaningful Physical Activities in the Elderly'). ${ }^{26}$ The MIBBO is a photo-interview conducted to investigate the preferences of residents. A previous study utilizing the MIBBO found that residents' preferred activities were gymnastics, orchestra, preparing food, walking, watering plants and feeding pets. ${ }^{26}$ Aside from nursing staff, informal caregivers can be involved in encouraging residents to perform daily activities. Prospective studies should focus on feasible interventions to encourage daily activities among nursing home residents.

To our knowledge, this is the first study to distinguish between psychogeriatric and somatic wards. Based on different admission reasons ${ }^{16}$ and differences found in age, mobility, ADL and cognitive functioning, differences in activities and positions between psychogeriatric and somatic wards could be expected. For example, somatic residents were mainly observed in a lying or sitting position (range: 91-93\%), which could be partly explained by the fact that the majority of the somatic residents were immobile (73\%). Even though more psychogeriatric residents were mobile (61\%), they were mainly observed in a lying or sitting position as well (range: 85-91\%). Additional multilevel analyses did not find significant differences in activities or positions between the different types of wards. Future interventions in nursing home residents should take a different approach to focusing on the psychogeriatric and somatic residents' daily activities. For the psychogeriatric residents especially, their cognitive impairments should be taken into account as for the somatic resident their somatic impairment should be taken into account.

The strength of this study is the large number of observed nursing home residents. Although previous observation studies performed more observations per resident, these studies observed smaller groups. MacRae et al. ${ }^{2}$ completed 64 to 96 observations per individual ( $n=95)$, Harper Ice, ${ }^{3}$ on average, completed 146 observations per individual ( $n=27)$, and the current study completed a maximum of five observations per individual ( $n=723$ ). Observing a large group of residents anonymously provided insight into daily activities (in general) instead of individual activity patterns, and reduced the intensity of the observation method. Furthermore, the anonymous observations made it possible to observe all residents in the ward. During a pilot observation study in which individual informed consent was obtained, it was noticed that participating residents were not representative of the whole ward regarding their activity level. By observing all residents anonymously without individual consent for participation, no selection bias could arise based on willingness to participate.

There are also limitations to using anonymous observations. Observations could not be linked to previous observations or to individual characteristics of a resident. This made 
it impossible to calculate correlations between residents' characteristics and activities. Bias could arise in this study if all active residents were outside their ward and only inactive residents stayed in the ward. However, the findings showed that, on average, more than $90 \%$ of the residents were present in their ward during the day, which means that most residents spent their day in the ward, and the group of observed residents probably did not largely change between the observation times. Despite using only nursing home residents in the southern part of the Netherlands, the study population is expected to be representative of the nursing home population in the Netherlands as a whole. Residents of different organizations, different nursing homes and different types of wards were observed. The observer did not monitor the residents while they were in the bathroom and respected privacy at all times. Therefore, up to $2 \%$ of the activities and positions were missing. Nursing staff were informed of the observations. Since wards were visited in a random sequence and the residents in the wards were randomly observed, it is not presumable that this influenced the observations by, e.g. nurses providing extra encouragement for residents to perform activities.

\section{Conclusion}

This study shows that the majority of psychogeriatric and somatic nursing home residents spend their day inactively (doing nothing, watching TV or sleeping) in the ward. When nursing home residents were engaged in $A D L$, it mainly consisted of activities related to mobility, eating and drinking. Engagement in IADL was rarely observed. Both psychogeriatric and somatic residents were mainly observed sitting and lying during the day, while the majority of the psychogeriatric residents were mobile. Future interventions to prevent further decline should focus on encouraging residents in ADL and IADL in the nursing home ward and increasing the activities in which mobile residents are encouraged to stand and walk during the day. 


\section{References}

1. Ikezoe $\mathrm{T}$, Asakawa $\mathrm{Y}$, Shima $\mathrm{H}$, et al. Daytime physical activity patterns and physical fitness in institutionalized elderly women: an exploratory study. Arch Gerontol Geriat. 2013;57:221-225.

2. MacRae PG, Schnelle JF, Simmons SF, Ouslander JG. Physical activity levels of ambulatory nursing home residents. J Aging Phys Activ. 1996;4:264-278.

3. Harper Ice G. Daily life in a nursing home: Has it changed in 25 years? J Aging Stud. 2002;16:345-359.

4. Egerton T, Brauer SG. Temporal characteristics of habitual physical activity periods among older adults. $J$ Phys Act Health. 2009;6:644-650.

5. Edvardsson D, Petersson L, Sjogren K, et al. Everyday activities for people with dementia in residential aged care: associations with person-centredness and quality of life. Int J Older People Nurs. 2013;9:269-276.

6. Dijkstra A, Buist G, Dassen T. Operationalization of the concept of 'nursing care dependency' for use in long-term care facilities. Aust N Z J Ment Health Nurs. 1998;7:142-151.

7. Kortebein $\mathrm{P}$, Symons TB, Ferrando A, et al. Functional impact of 10 days of bed rest in healthy older adults. J Gerontol A-Biol. 2008;63:1076-1081.

8. Weening-Dijksterhuis $\mathrm{E}$, de Greef $\mathrm{MH}$, Scherder EJ, et al. Frail institutionalized older persons: a comprehensive review on physical exercise, physical fitness, activities of daily living, and quality-of-life. Am J Phys Med Rehab. 2011;90:156-168.

9. Bates-Jensen BM, Schnelle JF, Alessi CA, et al. The effects of staffing on in-bed times of nursing home residents. J Am Geriatr Soc. 2004;52:931-938.

10. Gronstedt H, Frandin K, Bergland A, et al. Effects of individually tailored physical and daily activities in nursing home residents on activities of daily living, physical performance and physical activity level: a randomized controlled trial. Gerontology. 2013;59:220-229.

11. Xue QL, Bandeen-Roche K, Mielenz TJ, et al. Patterns of 12-year change in physical activity levels in community-dwelling older women: Can modest levels of physical activity help older women live longer? Am J Epidemiol. 2012;176:534-543.

12. Shephard RJ. Limits to the measurement of habitual physical activity by questionnaires. Br J Sports Med. 2003;37:197-206.

13. Tudor-Locke CE, Myers AM. Challenges and opportunities for measuring physical activity in sedentary adults. Sports Med. 2001;31:91-100.

14. Casey AN, Low LF, Goodenough B, et al. Computer-assisted direct observation of behavioral agitation, engagement, and affect in long-term care residents. J Am Med Dir Assoc. 2014;15:514-520.

15. Smit D, Willemse B, de Lange J, Pot AM. Wellbeing-enhancing occupation and organizational and environmental contributors in long-term dementia care facilities: an explorative study. Int Psychogeriatr. 2014;26:69-80.

16. Schols JM, Crebolder HF, van Weel C. Nursing home and nursing home physician: the Dutch experience. J Am Med Dir Assoc. 2004;5:207-212.

17. de Haan R, Limburg M, Schuling J, et al. Clinimetric evaluation of the Barthel Index, a measure of limitations in daily activities [in Dutch]. Ned Tijdschr Geneeskd. 1993;137:917-921.

18. Morris JN, Fries BE, Mehr DR, et al. MDS Cognitive Performance Scale. J Gerontol. 1994;49:M174-M182.

19. de Bruin SR, Oosting SJ, Tobi H, et al. Day care at green care farms: a novel way to stimulate dietary intake of community-dwelling older people with dementia? J Nutr Health Aging. 2010;14:352-357.

20. Kempen GI, Miedema I, Ormel J, Molenaar W. The assessment of disability with the Groningen Activity Restriction Scale. Conceptual framework and psychometric properties. Soc Sci Med. 1996;43:1601-1610.

21. Morley JE, Philpot CD, Gill D, Berg-Weger M. Meaningful activities in the nursing home. J Am Med Dir Assoc. 2014;15:79-81.

22. Tak SH, Kedia S, Tongumpun TM, Hong SH. Activity engagement: perspectives from nursing home residents with dementia. Educ Gerontol. 2015;41:182-192.

23. Visser M, Pluijm SM, Stel VS, et al. Physical activity as a determinant of change in mobility performance: the Longitudinal Aging Study Amsterdam. J Am Geriatr Soc. 2002;50:1774-1781. 
24. Sparling PB, Howard BJ, Dunstan DW, Owen N. Recommendations for physical activity in older adults. BMJ. 2015;350:h100.

25. Resnick B, Rogers V, Galik E, Gruber-Baldini AL. Measuring restorative care provided by nursing assistants: reliability and validity of the Restorative Care Behavior Checklist. Nurs Res. 2007;56:387-398.

26. Kleynen M, Braun SM, van Vijven K, et al. The development of the MIBBO: a measure of resident preferences for physical activity in long term care settings. Geriatr Nurs. 2015;36:261-266. 


\section{CHAPTER 3}

\section{The role of nursing staff in the activities of daily living of nursing home residents}

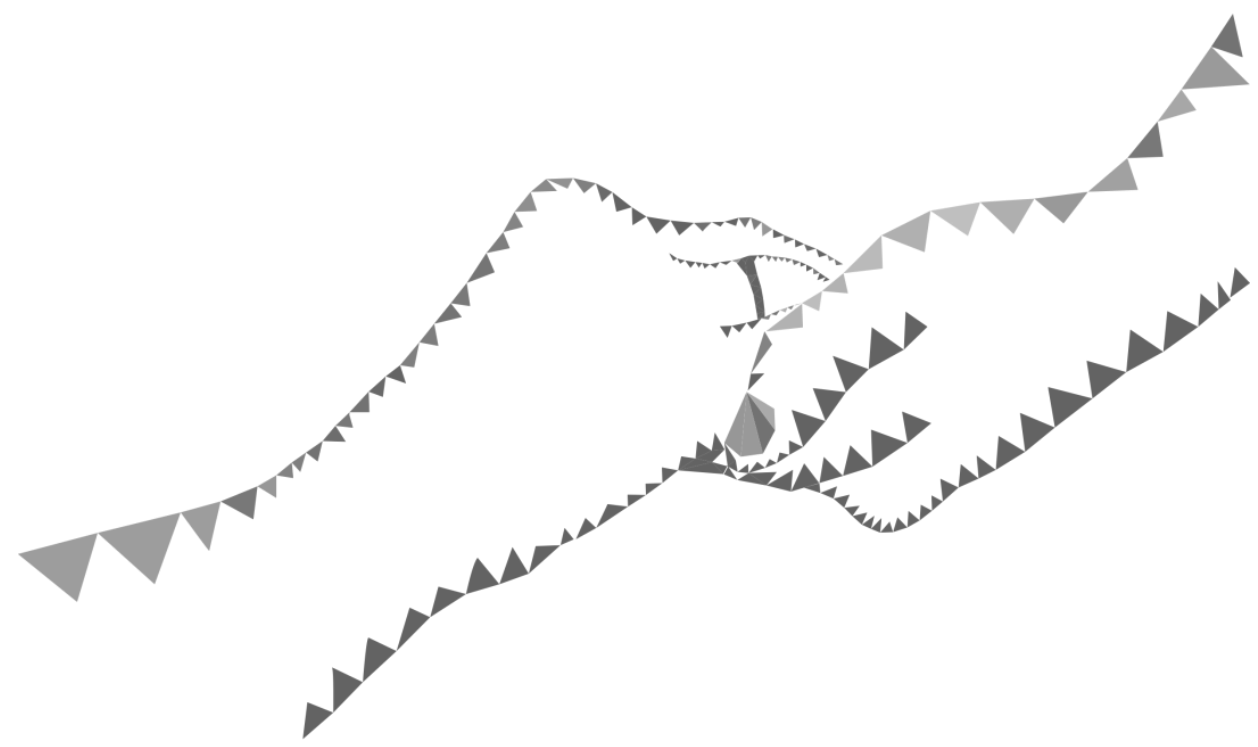

This chapter was published as:

den Ouden M, Kuk NO, Zwakhalen SMG, Bleijlevens MHC, Meijers JMM, Hamers JPH. The role of nursing staff in the activities of daily living of nursing home residents. Geriatric Nursing. 2016;38:225-230. 


\section{Abstract}

The aim of this cross-sectional study was to explore the role of nursing staff in residents' activities. Nursing home residents ( $n=723$ ) were observed in their wards, randomly five times for one minute between 7 a.m. and 11 p.m. Resident's (in)activity and the role of nursing staff or others in this activity were recorded. Roles were defined as 'taking over the activity,' 'giving support,' or 'supervision.' Nurse observers were interviewed to obtain insight into their observation-experiences. Residents were observed in activities of daily living in 31\% of all 3282 observations, and inactive in 57\%. Nursing staff provided support in $51 \%$ of the observations and took over activities in $45 \%$; supervision was rarely observed (4\%). Nurse observers who knew the residents reported that a large part of activities were taken over unnecessarily. Based on these results, nursing staff are recommended to provide more supervision and support to optimize residents' activities and independence. 


\section{Introduction}

Maintaining activities of daily living (ADL) and instrumental ADL (IADL) is of major importance in the frail nursing home population. It is well known that performing ADL and IADL, such as washing, dressing and preparing food, has a positive influence on physical functioning ${ }^{1}$ and is associated with a higher self-esteem ${ }^{2}$ and with a higher quality of life. ${ }^{3,4}$ Furthermore, residents' quality of life is positively influenced by their independence in these daily activities. ${ }^{5,6}$ Despite these positive effects, nursing home residents spend their day mainly inactive. ${ }^{7-9}$

Nursing homes are facilities that provide $24 \mathrm{~h}$ functional support and care for people who require assistance with daily activities, and have identified health needs. Nursing home care aims to provide a supportive, safe, and homelike environment in which residents are assisted to maintain their functional status as long as possible. ${ }^{10}$ In Dutch nursing homes, nursing staff are mainly certified nurse assistants (CNAs), ${ }^{11,12}$ with three years of secondary-vocational training. Besides, registered nurses (RNs), with four years of secondary-vocational training or bachelor-education, are part of the nursing staff. Henderson ${ }^{13}$ defined nursing in 1960 as: 'The unique function of the nurse is to assist the individual, sick or well, in the performance of those activities contributing to health or its recovery that he would perform unaided if he had the necessary strength, will or knowledge. And to do this in such a way as to help him gain independence as rapidly as possible.' This definition by Henderson ${ }^{13}$ implies that, also in the nursing home, it is the core business of nursing staff to encourage residents to perform daily activities and to encourage their independence.

Since nursing staff provide $24 / 7$ care, they play a key role in care provision and, ideally, demonstrate leadership behavior in encouraging nursing home residents in daily activities and maintaining independence. Nursing home residents' dependence is related to nursing staff behavior. ${ }^{14}$ Nursing staff can play different roles in the activities of the residents, for example, nursing staff could give instructions to complete the activity step-by-step. Moreover, nursing staff could take over residents' activities, which is not encouraging independence and physical activity. Previous intervention studies $^{2,15-24}$ have focused on changing the nursing behavior towards motivating and supportive behavior in the daily activities of nursing home residents. In these studies, nursing staff were taught motivational techniques to encourage residents. Most intervention studies reported on the effects on residents, for example, residents' functioning in ADL. Other studies ${ }^{22-24}$ evaluated change in behavior of nursing assistants using observations. Nursing staff were observed for 15-30 minutes in these studies, and their performance of function-focused care activities was evaluated using the Restorative Care Behavior Checklist $(\mathrm{RCBC}){ }^{25}$ Function-focused care activities performed by nursing staff could be encouraging the resident verbally to walk or walk together with the resident instead of pushing their wheelchair. Although these studies 
showed whether or not nursing assistants performed function focus care behaviors during care moments at an intervention setting, they do not provide insight into different roles of nursing staff in residents' activities during the day. Insight into the role of nursing staff in different activities of residents, especially ADL and IADL, could provide useful information for developing and evaluating nursing interventions to encourage residents in activities and their independence. Therefore, the aim of the current study was to explore the role of nursing staff in residents' $A D L$ and IADL.

\section{Methods}

A cross-sectional mixed-method design was used in this study, consisting primarily of quantitative observations in Dutch nursing homes and additional qualitative semistructured interviews. To explore the role of nursing staff in residents' ADL and IADL during daily nursing care, the observations were conducted anonymously. Due to the anonymous observations all residents and all nursing staff in the wards could be observed without participation bias. The observations were conducted in June and July of 2014. Dutch nursing homes provide long-term care in psychogeriatric and somatic wards. Psychogeriatric wards are provided for people with dementia, while somatic wards focus on people with physical problems. ${ }^{26}$ The qualitative component of this study consisted of semi-structured interviews with the nurse observers, these interviews were conducted after the quantitative data collection.

\section{Participants}

Seven nursing homes in the southern part of the Netherlands participated in this study. The participating nursing homes are embedded in the Living Lab in Ageing and LongTerm Care. ${ }^{27}$ The nursing homes consisted of 19 psychogeriatric and 11 somatic longterm care wards and housed 723 residents (383 and 340 residents from psychogeriatric and somatic wards, respectively). The sample included the nursing home residents present in the ward during the observations, and the people who were involved in residents' activities, distinguishing between nursing staff (both RNs and CNAs) and others (such as family and volunteers). No distinction was made between CNAs and RNs, they were put together as 'nursing staff.' Furthermore, three of the five observers were RNs between 25 and 39 years of age, with up to 20 years of work experience.

\section{Measures}

The following background characteristics of the residents were extracted from the residents files: gender, age, mobility (mobile, wheelchair dependent or bedridden), functioning in $A D L$ (measured by the Barthel index; $\mathrm{BI}$ ), ${ }^{28}$ and cognitive functioning 
(assessed by the Cognitive Performance Scale; CPS). ${ }^{29}$ The $\mathrm{BI}$ ranges from 0 to 20, with a lower score indicating increased disability, ${ }^{28}$ and the CPS ranges from 0 to 6 with a higher score indicating more severe cognitive impairment. ${ }^{29}$

A self-developed observation list was used to register the daily (in)activity the resident was engaged in, and the role of nursing staff and others in the resident's activity. The development of the observation list consisted of a pilot observation study, validity check, and adjustments to the list; more details about the development can be found elsewhere. ${ }^{7}$ The daily (in)activities residents could be engaged in were categorized into 1) inactivity, 2) $A D L$ and $I A D L$, and 3) communication and hobbies. When residents were engaged in daily activities, it did not mean that residents were physically active themselves, since their activities could be taken over.

ADL consisted of personal care (e.g., brushing teeth, combing one's hair), going to the bathroom, eating and drinking (e.g., eating with hands or cutlery), mobility (e.g., walking, pushing a wheelchair, changing position), dressing (e.g., taking off one's clothes), and bathing (e.g., having a shower, washing at the sink). IADL that can be relevant for nursing home residents in their wards included domestic activities (e.g., setting the table) and preparing food/ pouring a drink (e.g., preparing a sandwich).

The role of nursing staff in residents' ADL and IADL was categorized as 'taking over the activity,' 'giving support,' or 'supervision.' 'Taking over the activity' was registered when nursing staff performed the activity instead of the resident (e.g., a resident in a wheelchair was pushed by the nurse, or a resident was dressed by a nurse). 'Giving support' consisted of verbal support (e.g., giving instructions), and/or physical support (e.g., taking somebody by the arm). 'Supervision' meant that the nurse observed the resident's activity and interfered when necessary (e.g., the nurse walked beside the resident and could intervene if the resident stumbled). These categories were based on a pilot observation study, in which residents' activities and positions, and the kind of support residents received (no support, some support or a lot of support) were scored.

Semi-structured interviews were conducted with each of the three nurse observers who performed the observations. The nurse observers were asked about their experiences during the observations, their perceptions of the role of nursing staff, and their ideas for positively changing the role of nursing staff in residents' daily activities.

\section{Procedure}

Permission for the anonymous observations was provided by the management of each participating nursing home by signing a research declaration. The contact person within the nursing home provided information about the number of residents in each ward. Nursing staff in the wards were informed about the observations and completed the inventory of the background characteristics of each resident living in the ward. 
The observations were conducted by one out of five observers (three nurses, one research assistant, and one researcher). Two of the nurse observers conducted the observations within the nursing home they were employed in. In order to prevent observation bias and to reach a high interrater reliability, all observers received a three and a half hours' training program before starting, in which they received instructions for observations, practiced observations using video fragments, and discussed the definitions 'taking over', 'support,' and 'supervision' to reach consensus between the observers.

In each nursing home, the observations were performed during a $16 \mathrm{~h}$ period (between 7.00 a.m. and 11.00 p.m.), divided over two days. To provide an overview of the whole time period, the observations were divided into 5 time blocks. All wards within a nursing home were visited by an observer in a random sequence during each time block (randomization was carried out using http://www.randomizer.org). Theoretically, if all 723 residents were present in the wards during the five observation times, a total of 3615 observations could be conducted.

An observer walked around the ward and observed each resident present for one minute. The observer noted the main (in)activity the resident was engaged in during that minute. In addition, the role of nursing staff or others in the resident's activity was recorded, namely, who was involved (nursing staff or others) and, in the case of nursing staff, what their role was ('taking over the activity,' 'giving support,' or 'supervision'). If an observation did not fit within the predefined categories, the observer could describe the observation in the 'comment column.' The observer used a hand-held tablet, which was loaded with the observation list. The observation list was integrated into an Excel file and could be opened and adjusted during the observations using the e-Droid-cell Pro app. This file also provided information to the observer about the sequence of wards and observation times.

\section{Data analysis}

The data collected during the observations on the Excel files were transferred to SPSS (version 22, IBM, Armonk, NY). The residents' background characteristics were compared between the psychogeriatric and somatic wards using the chi-square test for the dichotomous variable (gender), and independent t-tests for the continuous variables (age, $\mathrm{BI}$, and CPS). Descriptive analyses of the anonymous observations were conducted for all wards and the five observation times together. To obtain insights into the role of nursing staff, percentages of the different types of roles were calculated. Additionally, a chi-square test was conducted to compare the role of nursing staff in residents' $A D L$ and IADL between the psychogeriatric and somatic wards. The interviews were recorded and transcribed afterward. The researcher summarized each interview and sent the summary to the nurse for a member check before analyzing the data. 
To test the interrater reliability of the observers regarding their score of the role of nursing staff, an intraclass correlation coefficient (ICC) was calculated. ${ }^{30}$ Reliability was tested by the extent of agreement of a small sample of 85 observations (in nine wards) between two observers during their observations in the nursing home. The role was scored as 1: taking over; 2: support; 3: supervision; and 4: no involvement. The ICC (two-way mixed absolute agreement) was 0.865 for the role of nursing staff, indicating good agreement between the raters. This ICC was high enough to decide to continue with the observations in the nursing home and not test the reliability any further.

\section{Ethical considerations}

The study protocol was approved by the Medical Research Ethics Committee. During all observations, the privacy of the residents was taken into account. For instance, the bathroom doors were not opened by the observer. All data, including background characteristics, were collected anonymously at ward level, which meant that residents could not be followed over time and that residents' characteristics could not be linked to the observations. Since the data were collected anonymously at ward level, the Medical Research Ethics Committee deemed exempt from individual consent of the nursing home residents. The three nurse observers signed an informed consent form for recording the interview.

\section{Results}

\section{Background characteristics of the residents}

Table 3.1 shows the background characteristics of the 723 nursing home residents living in the observed wards. In total, $68 \%$ of the residents were female. The nursing home residents living in psychogeriatric wards were, compared with the residents living in somatic wards, older, less severe dependent in ADL and more severe cognitive impaired. Furthermore, $61 \%$ of the residents in psychogeriatric ward were mobile, versus $27 \%$ of the residents in somatic wards. In total, $91 \%(n=3282)$ of the intended ( $n=3615$ ) observations were completed, the observation was not conducted if a resident was not present in the ward. In the psychogeriatric wards, $93 \%$ of the intended observations were completed and $89 \%$ in the somatic wards. The maximum number of observed residents in each ward during the different observation moments showed that at least 717 of the 723 individual residents were observed. 
Table 3.1 Background characteristics of nursing home residents living in psychogeriatric and somatic wards.

\begin{tabular}{|c|c|c|c|c|}
\hline & Total $[N=723]$ & Psychogeriatric [ $n=383]$ & Somatic $[n=340]$ & $p$ \\
\hline Age: mean \pm SD & $83.0 \pm 8.9$ & $85.2 \pm 6.4$ & $80.5 \pm 10.6$ & $<.001^{*}$ \\
\hline $\mathrm{BI}:$ mean $\pm \mathrm{SD}^{\mathrm{a}}$ & $7.6 \pm 5.8$ & $8.0 \pm 6.2$ & $7.1 \pm 5.3$ & $<.001^{*}$ \\
\hline $\mathrm{BI} \leq 9: n(\%)$ & $455(63)$ & $224(58)$ & $231(68)$ & $.007 *$ \\
\hline CPS: mean $\pm S D^{b}$ & $2.6 \pm 1.9$ & $3.5 \pm 1.7$ & $1.7 \pm 1.7$ & $<.001 *$ \\
\hline
\end{tabular}

*Significant difference $(p<0.05)$ between residents living in psychogeriatric and somatic wards.

${ }^{\mathrm{a}} \mathrm{BI}=$ Barthel index, range BI: 0-20 (a lower score indicates increased disability, where a score $\leq 9$ means severe need of help). ${ }^{28}$

${ }^{\mathrm{b}}$ CPS = cognitive performance scale, range CPS: 0-6 (a higher score indicates more severe cognitive impairment). ${ }^{29}$

\section{Overall involvement in daily activities}

Nursing home residents were engaged in ADL and IADL during 31\% ( $n=1005)$ of all observations, and residents were observed as inactive during $57 \%$ of all observations. The flowchart in Figure 3.1 provides an overview of the observed (in)activities with and without involvement of nursing staff and others. The flowchart also shows the involvement of nursing staff and others in the residents' $A D L$ and $I A D L$, and the role of nursing staff. A small number of involvement observations ( $n=31,1 \%$ ) was missing, they were not recorded on the tablet by the observer.

In $11 \%$ of all observations, the involvement of nursing staff or others in the residents' daily activities was noted. Activities in which involvement was noted were mainly ADL and IADL (78\%). When no involvement was recorded, residents were generally observed as inactive (65\%) (see Figure 3.1). Nursing staff ( $n=235$ observations) were four times more often involved in residents' $A D L$ and IADL than others, such as family and volunteers ( $n=52$ observations). Table 3.2 shows the observed involvement, which varied between the different ADL and IADL. Eating and drinking, and mobility, were most often observed without the involvement of nursing staff or others, respectively $76 \%(n=209)$ and $78 \%(n=374)$. Bathing, dressing, and going to the bathroom were most often observed with the involvement of nursing staff or others, respectively $88 \%$ $(n=35), 69 \%(n=20)$, and $51 \%(n=23)$. 

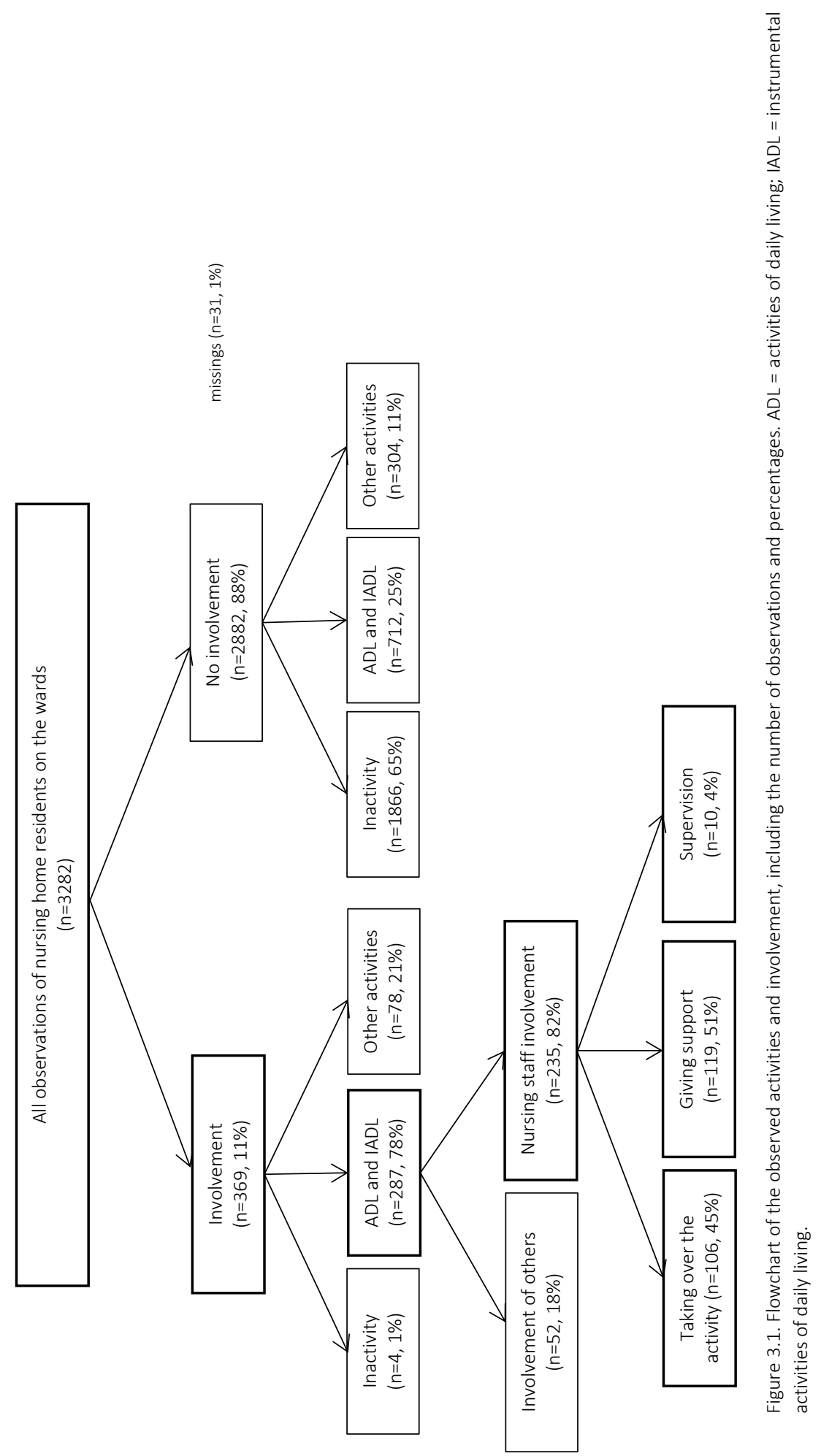
Table 3.2 Observed involvement and the different roles of nursing staff in residents' ADL and IADL.

\begin{tabular}{|c|c|c|c|c|c|c|}
\hline & \multirow{2}{*}{$\begin{array}{l}\text { No } \\
\text { involvement } \\
{[n=712]} \\
n\end{array}$} & \multirow{2}{*}{$\begin{array}{l}\text { Involvement } \\
\text { of others } \\
{[n=52]} \\
\end{array}$} & \multicolumn{4}{|c|}{$\begin{array}{l}\text { Involvement of nursing staff }- \text { and their roles } \\
{[n=235]}\end{array}$} \\
\hline & & & $n$ & $\begin{array}{l}\text { Taking over } \\
n(\%)\end{array}$ & $\begin{array}{l}\text { Support } \\
n(\%)\end{array}$ & $\begin{array}{l}\text { Supervision } \\
n(\%)\end{array}$ \\
\hline \multicolumn{7}{|l|}{$A D L$} \\
\hline Personal care & 51 & 4 & 28 & $17(61)$ & $11(39)$ & $0(0)$ \\
\hline Going to the bathroom & 22 & 0 & 23 & $5(22)$ & $17(74)$ & $1(4)$ \\
\hline Eating and drinking & 209 & 12 & 54 & $25(46)$ & $28(52)$ & $1(2)$ \\
\hline Mobility & 374 & 32 & 71 & $29(41)$ & $35(49)$ & $7(10)$ \\
\hline Dressing & 9 & 1 & 19 & $8(42)$ & $11(58)$ & $0(0)$ \\
\hline Bathing & 5 & 1 & 34 & $17(50)$ & $16(47)$ & $1(3)$ \\
\hline \multicolumn{7}{|l|}{$I A D L$} \\
\hline Domestic activities & 27 & 0 & 0 & - & - & - \\
\hline Preparing food & 15 & 2 & 6 & $5(83)$ & $1(17)$ & $0(0)$ \\
\hline
\end{tabular}

$A D L=$ activities of daily living; $I A D L=$ instrumental activities of daily living.

The role of nursing staff in residents' $A D L$ and IADL

When nursing staff were involved, they provided physical and/or verbal support in 51\% ( $n=119$ ) of the observations, took over residents' activities in $45 \%$ ( $n=106)$, and provided supervision in $4 \%(n=10)$. The nursing staff's role differed per activity (see Table 3.2); they commonly took over activities involving preparing food/pouring a drink $(83 \%, n=5)$, personal care $(61 \%, n=17)$, and bathing $(50 \%, n=17)$, and provided physical and/or verbal support mostly when residents were going to the bathroom $74 \%$ ( $n=17)$. Supervision of ADL and IADL was seldom observed. There were no statistically significant differences in the role of nursing staff in residents' ADL and IADL between the psychogeriatric $(n=105)$ and somatic wards $(n=130)$. 'Taking over' was scored in $51 \%$ of the observations in the somatic wards and in $40 \%$ of the observations in the psychogeriatric wards $(p=0.080)$. Nursing staff provided 'support' in $44 \%$ of the observations in the somatic wards, compared with $56 \%$ in the psychogeriatric wards $(p=0.060)$. 'Supervision' was observed in $5 \%$ of all observations in the somatic wards and in $4 \%$ of the observations in the psychogeriatric wards $(p=0.730)$.

\section{Experience of the nurse observers}

The nurse observers $(n=3)$, acknowledged the large amount of inactivity of nursing home residents. Further, the nurse observers who knew the residents mentioned that a large part of residents' activities were unnecessarily taken over by the nursing staff: 
residents could have performed the activities themselves (with support or supervision). Reasons for nursing staff to take over activities included time pressure, expectations, and lack of knowledge. The nurse observers found it most remarkable that the observations made them aware of the large amount of inactivity of among the nursing home residents and the amount of activities that were taken over by nursing staff. The nurses stated that, given the findings, a change is necessary, however, it will be hard and take time to change nursing staff behavior. Their ideas for improvement were obtaining insight into residents' capacity and preferences, making appointments, pronouncing expectations, and being aware of their own behavior.

\section{Discussion}

The aim of this study was to explore the role of nursing staff in residents' ADL and IADL. When nursing staff were involved in residents' $A D L$ or IADL, they provided verbal and/or physical support in $51 \%$ of the observations; in $45 \%$ they completely took over the residents' activities. Supervision was rarely observed (4\%). The observations created awareness among the nurse observers about the large amount of inactivity of nursing home residents and a large part of $A D L$ and IADL were unnecessarily taken over by nursing staff.

Involvement of nursing staff and others was mainly observed in residents' ADL and $I A D L$, which was to be expected, since nursing home residents show a dependency in their functioning. Eating and drinking, and mobility, were frequently performed without involvement of nursing staff or others, whereas bathing was most often observed with involvement. This is in line with the hierarchical order of ADL decline; first, older people lose their ability to bathe independently, thereafter, they lose their independence in mobility, and at the last, older people lose their ability to eat independently. ${ }^{31,32}$

Nursing staff have a major role in increasing the activity levels of nursing home residents; however, this might be challenging. Nursing home care is a high demanding nursing practice area and the availability of nursing staff is limited. A Dutch report about staffing and quality of care indicates that, in nursing home wards of 30 residents, on average four direct care members are available, and about 1.5 staff members to support the nursing staff. ${ }^{33}$ Geriatric nurses are trained to perform in a complex care environment so that nursing home residents remain as independent as possible in this institutionalized long-term care setting. Without any doubt this complexity requires nursing staff awareness of the possibilities and possible complications in the process of encouraging activities. Nursing staff have various tasks, such as direct and indirect care, practical nursing tasks, support, logistics, administration, and communication. ${ }^{34,35}$ They need to switch rapidly between these tasks; ${ }^{36}$ and multi-tasking is part of the job. ${ }^{34}$ Nursing staff may experience a high workload; ${ }^{21,37}$ consequently, they may feel that 
they do not have time to talk or listen to the residents. ${ }^{36}$ This perceived shortage of time and focus on their tasks could have led to more activities being taken over by nursing staff in the current study, instead of providing supervision or support. Nursing staff are mainly focused on the tasks they need to do (task-oriented) instead of focusing on the residents' needs and preferences (person-centered). ${ }^{38}$ Nurses should ensure that residents receive optimal care based on the person's abilities and nursing care needs. Therefore, nursing models that emphasize individualized person-centered care should be embraced. By applying such an individualized care approach; nursing staff create a stimulating living environment.

When reflecting upon the observations with the nurse observers, they pointed out that the observations made them aware of the large amount of inactivity, and that many activities that were taken over by nursing staff could have been performed by the residents themselves. This awareness seems to be essential in the process of behavioral change. $^{39}$ An observational approach to become aware of the magnitude of the problem and the explicit role of the nurses may be an important aspect to achieve a change in the nursing staff behavior that can be included in intervention and training programs.

Encouraging residents to engage in daily activities is challenging, but essential since residents may show decreased initiation of activities. ${ }^{40}$ If nursing staff do not encourage residents in daily activities but take over these activities instead, the residents will become more care dependent. ${ }^{41}$ For example, losing mobility is associated with different care problems, such as incontinence and pressure ulcers. ${ }^{42}$ In addition, encouraging residents' mobility is necessary since it gives residents a sense of freedom, choice and independence, and is therefore a key factor in their quality of life. ${ }^{43}$

Nursing staff provide care in the residents' direct environment and have the most contact with them; therefore, it is expected that they should encourage nursing home residents to carry out daily activities. Based on the results of this study, nursing staff are advised to change their behavior to encourage residents to become engaged in more activities, and to provide more supervision or support instead of taking over residents' activities, in order to increase activity levels and to maintain the residents' capacity and independence.

Despite the differences in cognitive and physical status between residents in psychogeriatric and somatic wards, the large amount of residents' inactivity and the role of nursing staff in these wards are comparable. Therefore, in both wards interventions should be aimed at encouraging residents' daily activities and independence. However, the differences in residents' cognitive and physical status implicates that nursing staff should use a different approach in encouraging residents. ${ }^{44}$ Residents in psychogeriatric wards commonly have cognitive problems, and therefore might need demonstration of a certain activity with step-by-step support. Residents 
living in somatic wards suffer from physical impairments, they often understand explanations, and therefore, might need more physical support, general instructions, and feedback during daily activities.

Nursing staff could decrease the large amount of inactivity by offering relevant activities during the day, tailored to residents' capacity and preferences. ${ }^{4}$ To encourage nursing home residents it is important to avoid highly demanding activities and build a trusting relationship. ${ }^{45}$ Nursing staff should discuss activity preferences with the resident (and family) and could collaborate with the nursing home physician and the multidisciplinary team, including physiotherapists, occupational therapists, and recreational therapists. This encouragement of activities and independence, based on residents' capacity and preference, fits into the cultural change that is ongoing from the medical model towards resident-directed care. ${ }^{46}$ Traditional nursing home wards shift to small scale wards with a homelike environment, for example in Green House homes. ${ }^{47}$ Nursing home residents living in these wards could be engaged in IADL activities, such as preparing food or setting the table.

To change nursing behavior, nursing staff need education on how to encourage residents in daily activities. ${ }^{2,15-24}$ Other important components of existing intervention studies that aim to change nursing behavior, such as function-focused care, ${ }^{19-24}$ are policy and coaching. Nursing staff should be supported by their management in the encouragement of activities and independence of nursing home residents. The management should underline the importance of activities and independence of resident and could facilitate training and coaching for nursing staff in the encouragement of residents.

\section{Limitations}

Some limitations of this study need to be addressed. Because of the anonymous observations, it is unknown which particular resident and nursing staff were observed; therefore, the resident's characteristics could not be linked with the role of nursing staff. It is not known if the nursing staff were more often involved and had different roles in the activities of residents with a lower functional capacity, that is, residents who needed more support by the nursing staff. Furthermore, the characteristics of the involved nursing staff (and others) were not assessed. Hence, it is not possible to examine whether the characteristics of the nursing staff, for example, educational level or years of experience, were associated with the extent to which activities were taken over. Lastly, when residents were observed without the involvement of nursing staff or others, it remains unclear if there had been involvement before the observation. The residents possibly had been encouraged to perform that activity themselves, and as a consequence, no involvement was observed. 


\section{Conclusions}

This study shows that, when involved, nursing staff took over almost half of residents' ADL and IADL. Supervision of these activities, in which the nurse observed a resident and could interfere when necessary, was rarely observed. Nurses who conducted the observations reported that many activities were unnecessarily taken over; residents could have performed these themselves. It becomes imperative that nurses have to demonstrate competencies in understanding the residents' needs and how to meet these care needs. This starts at nursing home admission from initial assessment through the evaluation of care that is planned. Encouraging residents' daily activities and their independence in these activities should be a key role of nursing staff in order to decrease residents' inactivity and functional decline. Future studies should provide tools to help nursing staff to encourage residents' activities, and their independence in daily care. 


\section{References}

1. Gronstedt H, Frandin K, Bergland A, et al. Effects of individually tailored physical and daily activities in nursing home residents on activities of daily living, physical performance and physical activity level: a randomized controlled trial. Gerontology. 2013;59:220-229.

2. Blair CE. Effect of self-care ADLs on self-esteem of intact nursing home residents. Issues Ment Health Nurs. 1999;20:559-570.

3. Edvardsson D, Petersson L, Sjogren K, Lindkvist M, Sandman PO. Everyday activities for people with dementia in residential aged care: associations with person-centredness and quality of life. Int J Older People Nurs. 2014;9:269-276.

4. Smit D, de Lange J, Willemse B, Twisk J, Pot AM. Activity involvement and quality of life of people at different stages of dementia in long term care facilities. Aging Ment Health. 2015:1-10.

5. Chan C, Slaughter S, Jones C, Wagg A. Greater independence in activities of daily living is associated with higher health-related quality of life scores in nursing home residents with dementia. Healthcare. 2015;3:503-518.

6. Andersen CK, Wittrup-Jensen KU, Lolk A, Andersen K, Kragh-Sorensen P. Ability to perform activities of daily living is the main factor affecting quality of life in patients with dementia. Health Qual Life Out. 2004;2:52.

7. den Ouden M, Bleijlevens MHC, Meijers JMM, et al. Daily (in)activities of nursing home residents in their wards: an observation study. J Am Med Dir Assoc. 2015;16:963-968.

8. MacRae PG, Schnelle JF, Simmons SF, Ouslander JG. Physical activity levels of ambulatory nursing home residents. J Aging Phys Activ. 1996;4:264-278.

9. Ice HG. Daily life in a nursing home: Has it changed in 25 years? J Aging Stud. 2002;16:345-359.

10. Sanford AM, Orrell M, Tolson D, et al. An international definition for "nursing home". J Am Med Dir Assoc. 2015;16:181-184.

11. Verkaik R, Francke AL, van Meijel B, Spreeuwenberg PMM, Ribbe MW, Bensing JM. The introduction of a nursing guideline on depression at psychogeriatric nursing home wards: effects on certified nurse assistants. Int J Nurs Stud. 2011;48:710-719.

12. Backhaus R, van Rossum E, Verbeek $H$, et al. Quantity of staff and quality of care in Dutch nursing homes: a cross-sectional study. J Nurs Home Res. 2016;2:90-93. 13.

13. Henderson V. Basic principles of nursing care. Geneva: International Council of Nurses. 1960.

14. Barton EM, Baltes MM, Orzech MJ. Etiology of dependence in older nursing home residents during morning care: the role of staff behavior. J Pers Soc Psychol. 1980;38:423-431.

15. Morris JN, Fiatarone M, Kiely DK, et al. Nursing rehabilitation and exercise strategies in the nursing home. J Gerontol A-Biol. 1999;54:494-500.

16. Johnson CSJ, Meyers AM, Jones GR, et al. Evaluation of the restorative care education and training program for nursing homes. Can J Aging. 2005;24:115-126.

17. Blair CE. Combining behavior management and mutual goal setting to reduce physical dependency in nursing home residents. Nurs Res. 1995;44:160-165.

18. Blair CE, Glaister J, Brown A, Phillips C. Fostering activities of daily living by intact nursing home residents. Educ Gerontol. 2007;33:679-699.

19. Galik EM, Resnick B, Gruber-Baldini A, et al. Pilot testing of the restorative care intervention for the cognitively impaired. J Am Med Dir Assoc. 2008;9:516-522.

20. Resnick B, Gruber-Baldini AL, Zimmerman S, et al. Nursing home resident outcomes from the Res-Care intervention. J Am Geriatr Soc. 2009;57:1156-1165.

21. Resnick B, Simpson M, Bercovitz A, et al. Pilot testing of the restorative care intervention: impact on residents. J Gerontol Nurs. 2006;32:39-47.

22. Resnick B, Simpson M, Bercovitz A, et al. Testing of the Res-Care pilot intervention: impact on nursing assistants. Geriatr Nurs. 2004;25:292-297.

23. Resnick B, Gruber-Baldini AL, Galik E, et al. Changing the philosophy of care in long-term care: testing of the restorative care intervention. Gerontologist. 2009;49:175-184. 
24. Galik E, Resnick B, Hammersla M, Brightwater J. Optimizing function and physical activity among nursing home residents with dementia: testing the impact of function-focused care. Gerontologist. 2014;54:930-943.

25. Resnick B, Rogers V, Galik E, Gruber-Baldini AL. Measuring restorative care provided by nursing assistants: Reliability and validity of the Restorative Care Behavior Checklist. Nurs Res. 2007;56:387-398.

26. Schols JM, Crebolder HF, van Weel C. Nursing home and nursing home physician: the Dutch experience. J Am Med Dir Assoc. 2004;5:207-212.

27. Verbeek H, Zwakhalen SMG, Schols JMGA, Hamers JPH. Keys to successfully embedding scientific research in nursing homes: a win-win perspective. J Am Med Dir Assoc. 2013;14:855-857.

28. de Haan R, Limburg M, Schuling J, Broeshart J, Jonkers L, van Zuylen P. Clinimetric evaluation of the Barthel index, a measure of limitations in dailly activities [in Dutch]. Ned Tijdschr Geneeskd. 1993;137:917-921.

29. Morris JN, Fries BE, Mehr DR, et al. MDS cognitive performance scale. J Gerontol. 1994;49:M174-M182.

30. Shrout PE, Fleiss JL. Intraclass correlations: uses in assessing rater reliability. Psychol bull. 1979;86:420-428.

31. Katz S, Ford A, Moskowitz R, Jackson B, Jaffe M. Studies of illness in the aged. The index of ADL: a standardized measure of biological and psychosocial function. JAMA. 1963;185:914-919.

32. Walk D, Fleishman R, Mandelson J. Functional improvement of elderly residents of institutions. Gerontologist. 1999;39:720-728.

33. Hingstman TL, Langelaan M, Wagner C. De dagelijkse bezetting en kwaliteit van zorg in instellingen voor langdurige zorg. Available from: http://www.nivel.nl/sites/default/files/bestanden/Rapport-dagelijksebezetting-zorg-in-instellingen.pdf; 2012:73-79. Accessed 21 June 16.

34. Munyisia EN, Yu P, Hailey D. How nursing staff spend their time on activities in a nursing home: an observational study. J Adv Nurs. 2011;67:1908-1917.

35. Paquay L, De Lepeleire J, Milisen K, Ylieff M, Fontaine O, Buntinx F. Tasks performance by registered nurses and care assistants in nursing homes: a quantitative comparison of survey data. Int J Nurs Stud. 2007;44:1459-1467.

36. Mallidou AA, Cummings GG, Schalm C, Estabrooks CA. Health care aides use of time in a residential longterm care unit: a time and motion study. Int J Nurs Stud. 2013;50:1229-1239.

37. Kieft RA, de Brouwer BB, Francke AL, Delnoij DM. How nurses and their work environment affect patient experiences of the quality of care: a qualitative study. BMC Health Serv Res. 2014;14:249.

38. Tuinman A, de Greef MH, Krijnen WP, Nieweg RM, Roodbol PF. Examining time use of Dutch nursing staff in long-term institutional care: a time-motion study. J Am Med Dir Assoc. 2016;17:148-154.

39. Elwyn G, Marrin K, Frosch D, White J. Sustainable change sequence: a framework for developing behavior change interventions for patients with long-term conditions. Eur J Pers Cent Healthc. 2014;2:212-216.

40. Cook C, Fay S, Rockwood K. Decreased initiation of usual activities in people with mild-to-moderate Alzheimer's disease: a descriptive analysis from the VISTA clinical trial. Int Psychogeriatr. 2008;20:952-963.

41. Schüssler S, Dassen T, Lohrmann C. Care dependency and nursing care problems in nursing home residents with and without dementia: a cross-sectional study. Aging Clin Exp Res. 2014;28(5):973-982.

42. Lahmann NA, Tannen A, Kuntz S, et al. Mobility is the key! Trends and associations of common care problems in German long-term care facilities from 2008 to 2012. Int J Nurs Stud. 2015;52:167-174.

43. Bourret EM, Bernick LG, Cott CA, Kontos PC. The meaning of mobility for residents and staff in long-term care facilities. J Adv Nurs. 2002;37:338-345.

44. Braun SM, Kleynen M, Bleijlevens MHC, et al. "Interactive surfaces" technology as a potential tool to stimulate physical activity in psychogeriatric nursing home residents. Disabil Rehabil Assist Technol. 2015;10:486-492.

45. van Alphen HJ, Hortobagyi T, van Heuvelen MJ. Barriers, motivators, and facilitators of physical activity in dementia patients: a systematic review. Arch Gerontol Geriat. 2016;66:109-118.

46. White-Chu EF, Graves WJ, Godfrey SM, Bonner A, Sloane P. Beyond the medical model: the culture change revolution in long-term care. J Am Med Dir Assoc. 2009;10:370-378.

47. Sloane PD, Zimmerman S, D'Souza MF. What will long-term care be like in 2040? NC Med J. 2014;75:326-330. 


\section{CHAPTER 4}

Do nursing staff encourage functional activity among nursing home residents?

A cross-sectional study of nursing staff perceived behaviors and associated factors

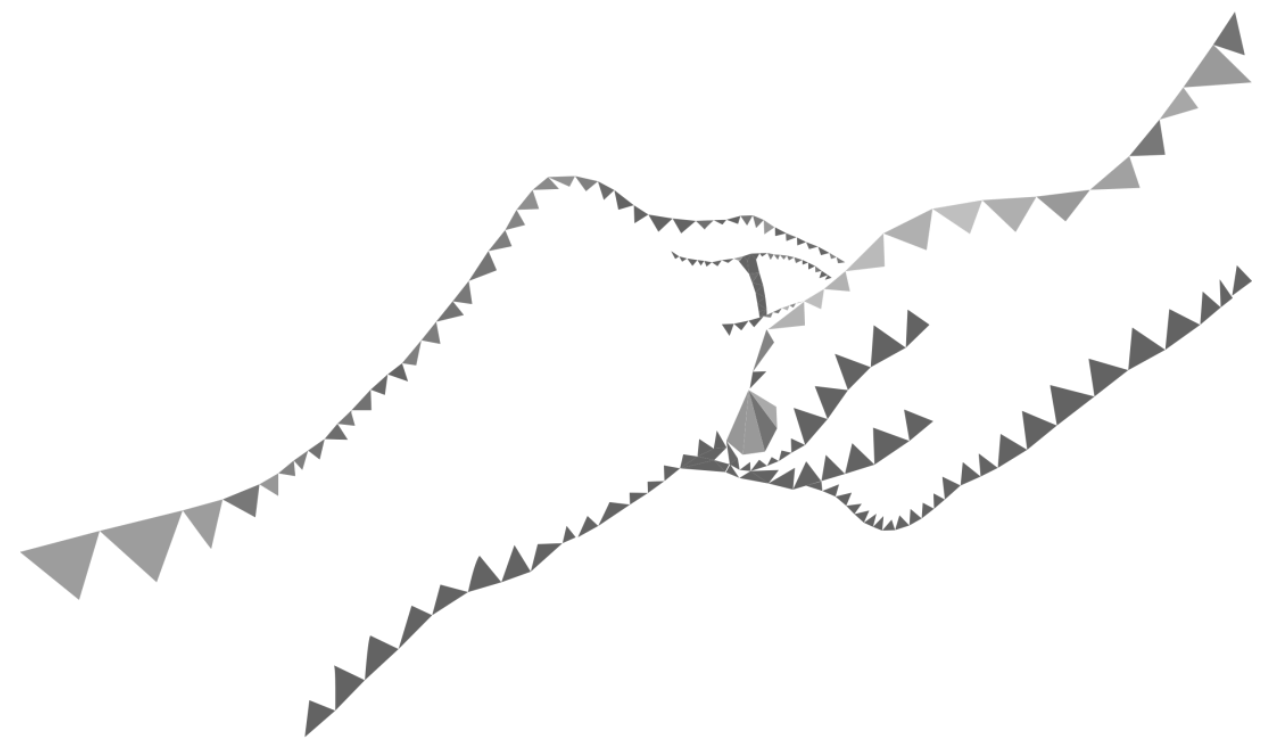

This chapter was published as:

Kuk NO, den Ouden M, Zijlstra GAR, Hamers JPH, Kempen GIJM, Bours GJJW. Do nursing staff encourage functional activity among nursing home residents? A cross-sectional study of nursing staff perceived behaviors and associated factors. BMC Geriatrics. 2017;17:18. 


\section{Abstract}

Background: Nursing home residents are mainly inactive. Nursing staff can encourage residents to perform functional activities during daily care activities. This study examines 1 ) the extent to which nursing staff perceive that they encourage functional activity in nursing home residents and 2) the associations between these nursing behaviors and professional characteristics, contextual factors, and information-seeking behaviors.

Methods: In this cross-sectional study, 368 registered nurses and certified nurse assistants, working in somatic and psychogeriatric wards of forty-one nursing homes throughout the Netherlands participated. Self-reported data were collected with a questionnaire, comprising the MAINtAIN-behaviors, which assesses the extent to which nursing staff encourage functional activities, including different activities of daily living $(A D L)$, household activities, and miscellaneous encouraging activities (e.g., discouraging informal caregivers from taking over activities residents can do themselves). Additional data collected included professional characteristics (e.g., age), contextual factors (e.g., ward type), and information-seeking behaviors (e.g., reading professional journals). Descriptive statistics were used to determine the extent to which functional activities were encouraged. Hierarchical linear regression analyses were performed to determine the associations between the encouragement of functional activities and other factors.

Results: Nursing staff perceived that household activities (mean 4.1 [scale range 1-9], SD 1.9) were less often encouraged than ADL (mean 6.9, SD 1.2) or miscellaneous activities (mean 6.7, SD 1.5). The percentage of nursing staff stating that different household activities, ADL, or miscellaneous activities were almost always encouraged ranged from $11 \%$ to $45 \%, 41 \%$ to $86 \%$, and $50 \%$ to $83 \%$ per activity, respectively. The extent to which these activities were encouraged differed for some of the professional characteristics, contextual factors, or information-seeking behaviors, but no consistent pattern in associations emerged.

Conclusions: According to nursing staff, household activities are not as often encouraged as ADL or miscellaneous activities. Professional characteristics, contextual factors, and information-seeking behaviors are not consistently associated with the encouragement of functional activity. Nursing staff should also focus on improving the encouragement of household activities. Future research could examine the role of other factors in encouraging functional activity, such as experienced barriers, and assess to what extent the perception of nursing staff corresponds with their actual behavior. 


\section{Background}

The importance of encouraging functional activity among nursing home residents is widely recognized. Research shows that being active and performing functional activities is associated with less anxiety, ${ }^{1}$ less disruptive behavior, ${ }^{1}$ higher self-esteem, ${ }^{2}$ and a higher quality of life $^{3}$ in nursing home residents. In the United States, federal regulations require the provision of care to maintain the highest level of function among nursing home residents. ${ }^{4}$ In the Netherlands, the Health Care Inspectorate emphasizes that nursing homes need to provide care that stimulates activity among residents, encouraging them to be active and perform functional activities on their own, instead of nursing staff taking over activities. ${ }^{5}$ Encouragement could take place during activities of daily living ( $A D L$ ) or during household activities, but also, for example, by discussing with the residents themselves which activities they previously conducted and motivating them to keep on performing them.

Promoting functional activity among residents is not only an opportunity nursing staff have, but also an important part of their job. In the past, nursing homes were mainly organized according to a medical model, ${ }^{6}$ in which nursing staff focused on taking care of the physical needs of residents. Currently, the autonomy of residents is crucial and more nursing homes strive to provide homelike environments, in which nursing staff encourage residents to continue their previous activities, including functional ones, as much as possible. ${ }^{7}$ In spite of this, research has shown that residents are largely inactive. ${ }^{8-10}$ Residents' participation in, for example, household activities is low. ${ }^{3,10}$ Nursing staff may be able to play a more substantial role in encouraging functional activities. $^{10}$

There is a lack of research regarding the extent to which nursing staff stimulate residents to be active. In addition, it is unknown how this encouraging behavior varies. Research regarding the use of evidence-based or best practices in nursing care indicates that different factors come into play, ${ }^{11-14}$ including professional characteristics of the nursing staff, such as age, ${ }^{11}$ educational level, ${ }^{12,13}$ or years of professional experience; ${ }^{11}$ and contextual circumstances, such as staff mix $^{15}$ or ward type. ${ }^{11,12}$ In addition, studies have shown that the information-seeking behavior (for example, reading professional journals) of nursing staff may be associated with the use of evidence-based practices. $^{12,14}$

It is not known how professional characteristics, contextual factors, or informationseeking behaviors are associated with the extent to which nursing staff encourage functional activity among nursing home residents. Therefore, we have conducted a cross-sectional study with a twofold purpose: first, to examine the extent to which nursing staff in the Netherlands perceive that they encourage functional activity in nursing home residents; and, second, to examine the association between these 
perceptions and various professional characteristics, contextual factors, and information-seeking behaviors of nursing staff.

\section{Methods}

Context: Nursing homes in the Netherlands

In nursing homes in the Netherlands, a distinction is made between residents with chronic physical problems, who live in somatic wards, and residents with psychogeriatric problems, such as dementia, who live in psychogeriatric wards. ${ }^{16}$ Dutch nursing homes provide more complex continuing care and monitoring compared with residential care homes. ${ }^{16}$ The meals are often taken in the wards and in many nursing homes small kitchen facilities are available in the ward, for example to prepare breakfast. The majority of the workforce in Dutch nursing homes are certified nurse assistants (CNAs) who receive three years of secondary-vocational training. In addition, care is provided by vocationally-trained or bachelor-educated registered nurses (RNs) who receive four years of training. Nursing homes are primarily non-profit organizations that are united in Actiz, the Dutch organization of healthcare providers. In contrast to some other countries, in the Netherlands there are no national databases comprising detailed information on all nursing homes (such as resident characteristics, or the number or type of staff).

\section{Design and sample}

A cross-sectional study was conducted among nursing staff of nursing homes in the Netherlands. From a list of nursing homes provided by Actiz, a random proportionate sample of 100 nursing homes was drawn by author NOK using the sampling procedure from IBM SPSS Statistics for Windows (Version 22.0. Armonk, NY: IBM Corp). Nursing homes were stratified according to five regions in the Netherlands (north, east, south, west, and central) and from each region a number of random nursing homes was drawn, proportionate to the total number of nursing homes in that region. Next, to warrant the exclusion of care homes with a single small nursing home ward, author NOK verified by telephone if the 100 selected nursing homes provided care to at least 25 somatic and/or 25 psychogeriatric nursing home residents. Twenty-five facilities were excluded because they did not meet this criterion and one nursing home no longer existed at the time of recruitment. Of the remaining 74 nursing homes, 46 agreed to participate (see Figure 4.1 for a flowchart). In this sample, nursing homes from all regions were represented, they were distributed largely according to the proportionate sample that was drawn; $11 \%$ of the nursing homes were situated in the north, $9 \%$ in the 
east, $39 \%$ in the south, $37 \%$ in the west, and $4 \%$ in the central region of the Netherlands.

Based on practical considerations, nursing homes with both somatic and psychogeriatric wards were asked to administer 16 questionnaires among the nursing staff (eight from each ward type); nursing homes with only one of these ward types were asked to administer ten questionnaires among the nursing staff. In total, 622 questionnaires were administered.

Nursing staff were eligible if they were RNs or CNAs. Nursing staff working exclusively on night shifts and nursing staff who did not have a contract for at least $12 \mathrm{~h}$ per week were excluded from this study because of their limited opportunities to encourage functional activities.

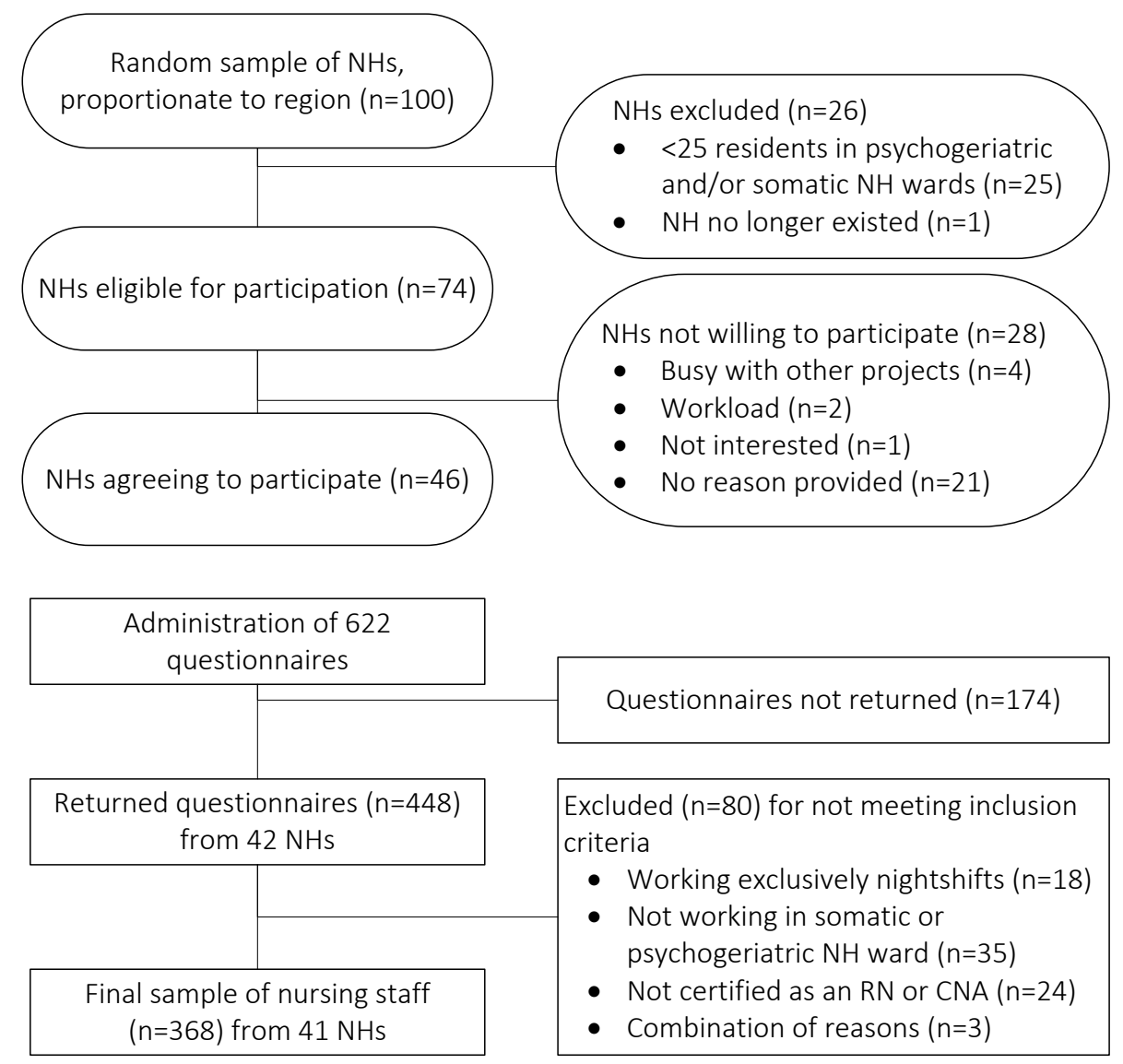

$\mathrm{CNA}=$ certified nurse assistant; $\mathrm{NH}=$ nursing home; $\mathrm{RN}=$ registered nurse.

Figure 4.1. Flowchart of the study sample. 


\section{Data collection}

In each participating nursing home a local contact person was asked to distribute the questionnaires among eligible nursing staff, these nursing staff did not have to work on the same ward. The contact persons would collect and return the anonymouslycompleted questionnaires to the research team within two weeks. If the research team had not received the questionnaires within three weeks, they would either telephone or send an email reminder to the contact person. All data were collected in January and February 2014.

\section{Measures}

Encouragement of functional activities (dependent variables)

The MAastrlcht Nurses Activities INventory-behaviors (MAINtAIN-behaviors) questionnaire ${ }^{17}$ was used to measure the extent to which nursing staff perceive that they encourage residents to perform functional activities. The MAINtAIN-behaviors was developed using a comprehensive method in which its usability and content validity were established in a study involving experts, nursing staff, residents and other nursing home professionals. ${ }^{17}$ The MAINtAIN-behaviors comprises three subscales assessing the degree to which nursing staff perceive they encourage residents to perform various types of activities: first, an 8-item subscale for encouraging ADL, for example, encouraging independent bathing or showering; second, a 6-item subscale for encouraging household activities, such as encouraging setting and clearing the table; third, a 5-item subscale for miscellaneous encouraging activities, such as promoting participation in organized activities, discussing and maintaining previous activities, encouraging informal caregivers not to take over activities, discussing the residents' preferred activities, and encouraging activity as part of the residents' care plan. For each item of the MAINtAIN-behaviors, respondents could rate to what extent a certain activity was encouraged in their ward ('in my ward, we encourage...'). Answer options ranged from ' $1=$ never' to ' 9 = always.' Internal consistency for the subscales, using Cronbach's alpha, in the present study was 0.83 for the ADL subscale, 0.79 for the household activities subscale, and 0.77 for the miscellaneous activities subscale.

\section{Professional characteristics, contextual factors, and information-seeking behaviors}

(independent variables)

Based on literature several professional characteristics, contextual factors, and information-seeking behaviors were selected. ${ }^{11-15}$ The professional characteristics comprised gender, age ( $\leq 35$ years, $>35$ years $\leq 50,>50$ years), profession (CNA or RN), years of professional experience in the care for older persons $(\leq 10$ years, $>10$ years $\leq$ $20,>20$ years), and number of work hours per week ( $\geq 12 \mathrm{~h}$ per week $\leq 26,>26 \mathrm{~h}$ per week $<32, \geq 32 \mathrm{~h}$ per week). The contextual factors consisted of ward type 
(psychogeriatric or somatic), and staff mix (proportion of RNs in the ward, i.e., the number of RNs divided by the total number of RNs and CNAs that worked in the ward, according to the respondent).

The information-seeking behaviors included how often respondents referred to specific information sources on care problems (websites, Dutch professional journals, Englishlanguage journals, guidelines, colleagues, and experts) or how often they attended specific activities to keep their professional skills and knowledge up-to-date (conferences, courses within their organization, courses outside of their organization, clinical courses in the ward, and reading groups). The behaviors were assessed using single-item questions that were developed for this study. First, it was assessed how often respondents used specific information sources in the past three months. Second, respondents indicated how often they attended professional development activities in the past 12 months. After recoding, the answer categories for each source of information or activity comprised 'never' or ' $\geq 1$ time' in the past three or 12 months.

\section{Statistical analyses}

Descriptive statistics were used to determine percentages for the categorical variables. Mean scores and standard deviations were determined for each subscale of the MAINtAIN-behaviors. For each subscale, missing values on the items were imputed with the respondent's average score for the other items, if at least $75 \%$ of the items of that subscale had been completed. Missing values for the ADL, household, and miscellaneous subscales were imputed for a total of $4.9 \%, 2.4 \%$, and $1.9 \%$ of the respondents, respectively.

Mean scores of the three subscales were compared by conducting paired-samples ttests, with a Bonferroni correction to account for multiple testing. Additional analyses were performed to provide an overview of the extent to which respondents encouraged activity among residents. For these analyses, the answer options of the MAINtAINbehaviors items were categorized into '(almost) never' (score 1-3), 'sometimes' (score 4-6), and '(almost) always' (score 7-9).

For each independent variable (professional characteristics, contextual factors, and information-seeking behaviors) mean scores and standard deviations of the three MAINtAIN-behaviors subscales were calculated. Hierarchical linear regression analyses (random intercept) were performed to determine the association between each independent variable and each subscale of the MAINtAIN-behaviors (possible range 1-9). In each model one independent variable was used, no additional variables were added to these models. In order to account for the hierarchical structure of the data, nursing staff (level one) were grouped by nursing home (level two). For all models, estimated marginal means, standard errors, $p$-values, and intraclass correlation 
coefficients (ICCS) were determined. For the independent variables with three categories (i.e., age, professional experience, and work hours per week), each category was used as a reference for the other two categories in the analyses (i.e., the first category was compared with the second category, the second category was compared with the last category and the last category was compared with the first category). Pvalues $<0.05$ were considered statistically significant. Sensitivity analyses were conducted by imputing missing values on the items of the ADL, household, and miscellaneous subscales with 1 and with 9 instead of the respondent's average score of the other items within that scale. All statistical analyses were performed using IBM SPSS Statistics for Windows (Version 22.0. Armonk, NY: IBM Corp).

\section{Results}

\section{Sample characteristics}

A total of 448 respondents from 42 nursing homes completed the MAINtAIN-behaviors (response rate $72 \%$; range per nursing home $50-100 \%$ ), but 80 questionnaires had to be excluded, because the respondents did not meet the inclusion criteria (see Figure 4.1). The 368 eligible respondents represented 41 nursing homes (sample characteristics are displayed in Table 4.1); 275 (75\%) of them were CNAs and 231 (63\%) worked in a psychogeriatric ward. Information-seeking behaviors varied, e.g., 5\% had searched for information in an English-language journal in the past three months, whereas $99 \%$ had consulted a colleague.

\section{Encouragement of functional activities}

Table 4.2 displays the perceived encouragement of functional activities. The mean scores for the ADL subscale, the household activities subscale, and the miscellaneous activities subscale were 6.9 (SD 1.2), 4.1 (SD 1.9), and 6.7 (SD 1.5), respectively, out of a theoretical range from 1 to 9 . These mean subscale scores differed significantly from each other ( $p<0.001$ for all comparisons after Bonferroni correction). More than half of the respondents (66-86\%) stated that ADL were (almost) always encouraged, but the need for assistive devices for independent dressing was not always discussed (41\%). Less than half of the respondents reported that household activities were (almost) always encouraged (ranging from 11\% for folding or putting away clothes to $45 \%$ for preparing sandwiches). Regarding miscellaneous encouraging activities, the majority of the respondents (50-83\%) indicated that all activities were (almost) always performed. For example, according to $83 \%$ of the respondents, residents were (almost) always encouraged to participate in organized activities, such as wheelchair dancing. 
Table 4.1. Sample characteristics $\left(N=368^{*}\right)$.

\begin{tabular}{|c|c|c|}
\hline & $N$ & $(\%)$ \\
\hline \multicolumn{3}{|l|}{ Professional characteristics } \\
\hline \multicolumn{3}{|l|}{ Gender } \\
\hline Female & 346 & $(94)$ \\
\hline \multicolumn{3}{|l|}{ Age } \\
\hline$\leq 35$ years & 116 & (33) \\
\hline$>35$ years $\leq 50$ & 141 & $(40)$ \\
\hline$>50$ years & 95 & $(27)$ \\
\hline \multicolumn{3}{|l|}{ Profession/educational level } \\
\hline CNA & 275 & $(75)$ \\
\hline RN & 93 & $(25)$ \\
\hline \multicolumn{3}{|l|}{ Professional experience } \\
\hline$\leq 10$ years & 127 & $(38)$ \\
\hline$>10$ years $\leq 20$ & 100 & $(30)$ \\
\hline$>20$ years & 108 & $(32)$ \\
\hline \multicolumn{3}{|l|}{ Work hours per week } \\
\hline$\geq 12$ hours per week $\leq 26$ & 109 & (30) \\
\hline$>26$ hours per week $<32$ & 83 & $(23)$ \\
\hline$\geq 32$ hours per week & 169 & $(47)$ \\
\hline \multicolumn{3}{|l|}{ Contextual factors } \\
\hline \multicolumn{3}{|l|}{ Ward type } \\
\hline Psychogeriatric ward & 231 & $(63)$ \\
\hline Somatic ward & 137 & $(37)$ \\
\hline \multicolumn{3}{|l|}{ Staff mix: proportion of RNs in the ward } \\
\hline$\leq 0.11$ & 153 & (49) \\
\hline$>0.11$ & 160 & $(51)$ \\
\hline \multicolumn{3}{|l|}{ Information-seeking behaviors } \\
\hline \multicolumn{3}{|l|}{$\geq 1 \times$ past three months } \\
\hline Reading on websites & 68 & $(19)$ \\
\hline Reading Dutch professional journals & 171 & (49) \\
\hline Reading English-language journals & 16 & $(5)$ \\
\hline Reading guidelines & 343 & (96) \\
\hline Consulting a colleague & 358 & (99) \\
\hline Consulting an expert & 276 & $(75)$ \\
\hline \multicolumn{3}{|l|}{$\geq 1 \times$ past year } \\
\hline Attending a conference & 112 & (31) \\
\hline Attending a course within the organization & 332 & (91) \\
\hline Attending a course outside the organization & 133 & (38) \\
\hline Participating in a clinical course in the ward & 254 & $(70)$ \\
\hline Participating in a reading group regarding care & 15 & $(4)$ \\
\hline
\end{tabular}

CNA = certified nurse assistant; RN = vocationally-trained or bachelor-educated registered nurse.

*N does not always add up to 368 due to missing data. 
Table 4.2. Perceived encouragement of ADL, household activities, and miscellaneous activities: means and item-scores per subscale $\left(\mathrm{N}=368^{*}\right)$.

\begin{tabular}{|c|c|c|c|}
\hline Subscales & & Mean \pm SD & \\
\hline$A D L$ & & $6.9 \pm 1.2$ & \\
\hline Household activities & & $4.1 \pm 1.9$ & \\
\hline \multirow[t]{4}{*}{ Miscellaneous activities } & & $6.7 \pm 1.5$ & \\
\hline & (Almost) & & (Almost) \\
\hline & never & Sometimes & always \\
\hline & $N(\%)$ & $N(\%)$ & $N(\%)$ \\
\hline \multicolumn{4}{|l|}{ Items $A D L$ subscale } \\
\hline Closely follow independent ADL performance & $14(4)$ & $109(30)$ & $243(66)$ \\
\hline Encourage independent performance of ADLs & $11(3)$ & $92(25)$ & $263(72)$ \\
\hline Discuss assistive devices for eating & $31(8)$ & $93(25)$ & $242(66)$ \\
\hline Compliment residents on dressing and undressing & $11(3)$ & $58(16)$ & $297(81)$ \\
\hline Discuss assistive devices for independent dressing & $89(24)$ & $126(34)$ & $151(41)$ \\
\hline Closely follow independent movement & $1(<1)$ & $61(17)$ & $304(83)$ \\
\hline Encourage independent movement & $6(2)$ & $46(13)$ & $314(86)$ \\
\hline Provide assistive devices for bathing & $25(7)$ & $89(24)$ & $252(70)$ \\
\hline \multicolumn{4}{|l|}{ Items household activities subscale } \\
\hline Prepare sandwiches & $51(14)$ & $149(41)$ & $166(45)$ \\
\hline Encourage setting and clearing the table & $89(24)$ & $120(33)$ & $157(43)$ \\
\hline Make the beds & $204(56)$ & $94(26)$ & $68(19)$ \\
\hline Encourage folding or putting away clothes & $222(61)$ & $104(28)$ & $39(11)$ \\
\hline Encourage light household activities & $175(48)$ & $108(30)$ & $82(22)$ \\
\hline $\begin{array}{l}\text { Discuss with residents household chores they can help with } \\
\text { Items miscellaneous activities subscale }\end{array}$ & \multicolumn{2}{|c|}{ Items miscellaneous activities subscale } & $84(23)$ \\
\hline Encourage participation in organized activities & $8(2)$ & $56(15)$ & $302(83)$ \\
\hline Discuss and maintain the residents' previous activities & $23(6)$ & $100(27)$ & $242(66)$ \\
\hline $\begin{array}{l}\text { Encourage family/informal caregivers to only help } \\
\text { residents when they cannot do something themselves }\end{array}$ & $47(13)$ & $135(37)$ & $183(50)$ \\
\hline Encouraging physical activity is part of care plan & $35(10)$ & $98(27)$ & $233(64)$ \\
\hline Discuss preferred activities & $60(16)$ & $105(29)$ & $201(55)$ \\
\hline
\end{tabular}

$A D L=$ activities of daily living.

*N does not always add up to 368 due to missing data. Answers scored on the 9-point scale were categorized into '(almost) never' (scores 1-2-3), 'sometimes' (4-5-6) and '(almost) always' (7-8-9).

Mean subscale scores are calculated based on the means of the original 9-point scale scores of all the items within that subscale; the scores can range from 1 (never encouraged) to 9 (always encouraged). 
Table 4.3. Mean encouragement of ADL, household activities and miscellaneous activities per professional characteristic and contextual factor.

\begin{tabular}{|c|c|c|c|c|c|c|}
\hline & \multicolumn{2}{|c|}{ ADL subscale } & \multicolumn{2}{|c|}{$\begin{array}{l}\text { Household } \\
\text { activities subscale }\end{array}$} & \multicolumn{2}{|c|}{$\begin{array}{l}\text { Miscellaneous } \\
\text { activities subscale }\end{array}$} \\
\hline & \multicolumn{2}{|c|}{ Mean $^{a} \pm S D$} & \multicolumn{2}{|c|}{$\operatorname{Mean}^{a} \pm S D$} & \multicolumn{2}{|c|}{$\operatorname{Mean}^{\mathrm{a}} \pm \mathrm{SD}$} \\
\hline \multicolumn{7}{|l|}{ Professional characteristics } \\
\hline \multicolumn{7}{|l|}{ Gender } \\
\hline Male & 6.9 & \pm 1.2 & 4.5 & \pm 1.8 & 6.6 & \pm 1.3 \\
\hline Female & 7.0 & \pm 1.2 & 4.4 & \pm 1.7 & 6.7 & \pm 1.5 \\
\hline \multicolumn{7}{|l|}{ Age $e^{b}$} \\
\hline$\leq 35$ years & 6.9 & \pm 1.2 & 4.2 & \pm 1.6 & $6.5^{\mathrm{c}}$ & \pm 1.5 \\
\hline$>35$ years $\leq 50$ & 7.1 & \pm 1.1 & 4.6 & \pm 1.7 & $6.9^{c}$ & \pm 1.3 \\
\hline$>50$ years & 7.1 & \pm 1.3 & 4.4 & \pm 1.8 & 6.7 & \pm 1.6 \\
\hline \multicolumn{7}{|l|}{ Profession/educational level } \\
\hline CNA & 7.1 & \pm 1.2 & 4.4 & \pm 1.7 & 6.8 & \pm 1.5 \\
\hline RN & 6.9 & \pm 1.2 & 4.4 & \pm 1.8 & 6.5 & \pm 1.4 \\
\hline \multicolumn{7}{|l|}{ Professional experience ${ }^{b}$} \\
\hline$\leq 10$ years & 7.0 & \pm 1.2 & 4.3 & \pm 1.7 & 6.7 & \pm 1.5 \\
\hline$>10$ years $\leq 20$ & 6.9 & \pm 1.2 & 4.3 & \pm 1.7 & 6.6 & \pm 1.6 \\
\hline$>20$ years & 7.1 & \pm 1.2 & 4.6 & \pm 1.8 & 6.8 & \pm 1.4 \\
\hline \multicolumn{7}{|l|}{ Work hours per week ${ }^{b}$} \\
\hline$\geq 12$ hours per week $\leq 26$ & 7.0 & \pm 1.2 & 4.3 & \pm 1.5 & 6.6 & \pm 1.4 \\
\hline$>26$ hours per week $<32$ & 7.0 & \pm 1.0 & 4.5 & \pm 1.7 & $6.5^{d}$ & \pm 1.5 \\
\hline$\geq 32$ hours per week & 7.0 & \pm 1.3 & 4.4 & \pm 1.9 & $6.9^{d}$ & \pm 1.4 \\
\hline \multicolumn{7}{|l|}{ Contextual factors } \\
\hline \multicolumn{7}{|l|}{ Ward type } \\
\hline Psychogeriatric ward & 7.1 & \pm 1.2 & $4.8^{\mathrm{e}}$ & \pm 1.6 & $6.9^{d}$ & \pm 1.4 \\
\hline Somatic ward & 6.9 & \pm 1.2 & $3.7^{\mathrm{e}}$ & \pm 1.6 & $6.4^{d}$ & \pm 1.4 \\
\hline \multicolumn{7}{|c|}{ Staff mix: proportion of nurses in the ward } \\
\hline$\leq 0.11$ & 7.0 & \pm 1.2 & 4.4 & \pm 1.7 & 6.8 & \pm 1.5 \\
\hline$>11$ & 7.0 & \pm 1.2 & 4.4 & \pm 1.8 & 6.6 & \pm 1.4 \\
\hline
\end{tabular}

$\mathrm{CNA}=$ certified nurse assistant; $\mathrm{RN}=$ vocationally-trained or bachelor-educated registered nurse.

${ }^{a}$ Unadjusted means are presented, these are similar to the estimated marginal means resulting from the hierarchical linear regression analyses (random intercept; level 1 - nursing staff, level 2 - nursing home) between each independent variable and each subscale of the MAINtAIN-behaviors (range 1-9). Indicated statistical significant differences $(p<0.05)$ are based on these analyses. No additional variables were added to the models. ICCs range from 0.06-0.10, 0.16-0.19 and 0.02-0.05 for the models with the outcome measure ADL, household activities and miscellaneous activities, respectively. ${ }^{b}$ For variables with three categories, each category was used as a reference for the other two. Because of these variables and to increase the comprehensibility of the table, no $p$-values are presented. ' Statistical significant differences between age ' $\leq 35$ years' and ' $>35$ years $\leq 50$.' d Statistical significant difference between working '> 26 hours per week $<32$ ' and ' $\geq 32$ hours per week.' ' Statistical significant difference between psychogeriatric ward and somatic ward. Due to missing data, sample size for each analysis varies from 311 to 366. 


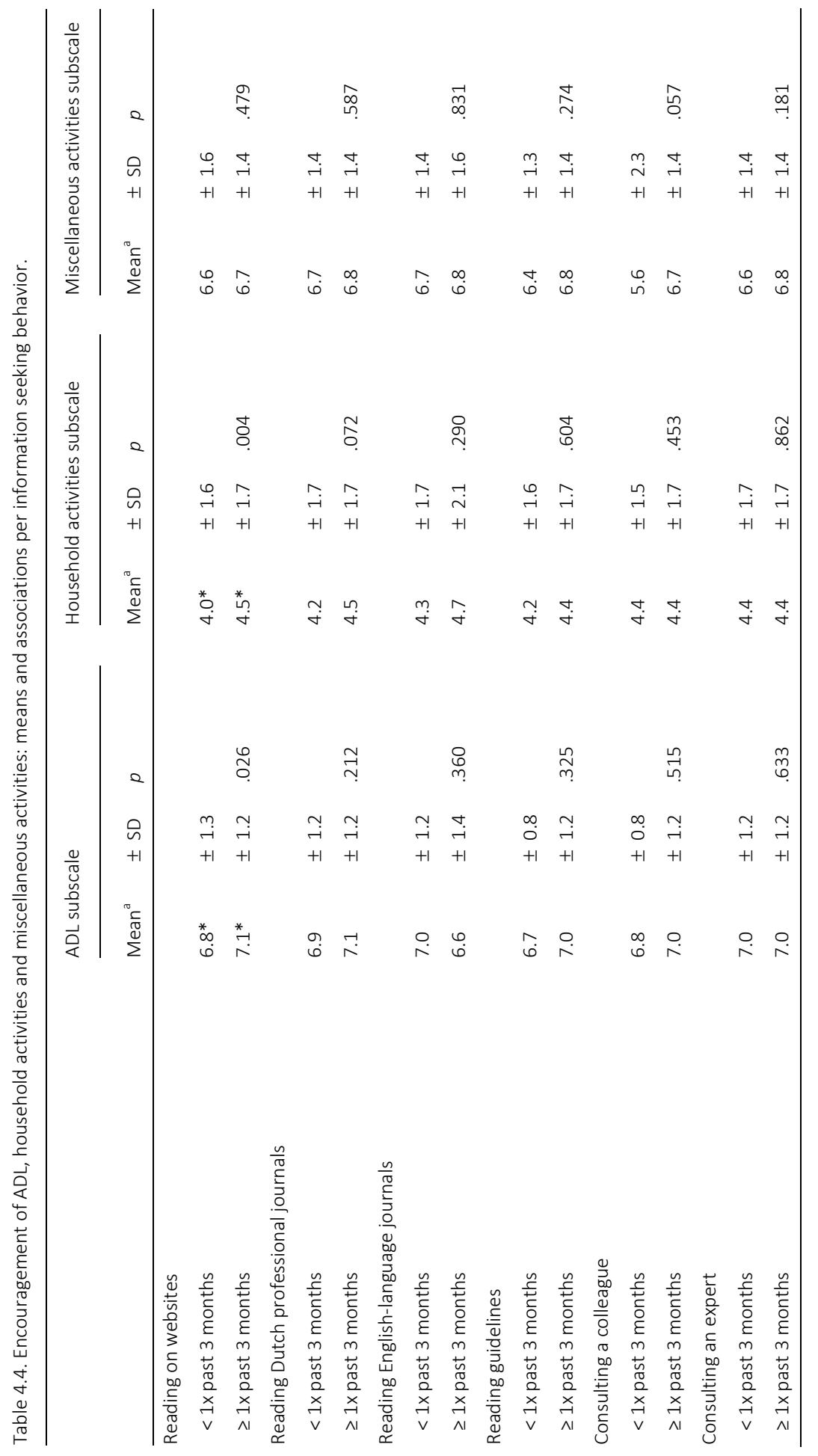


ENCOURAGEMENT OF FUNCTIONAL ACTIVITY AND ASSOCIATED FACTORS

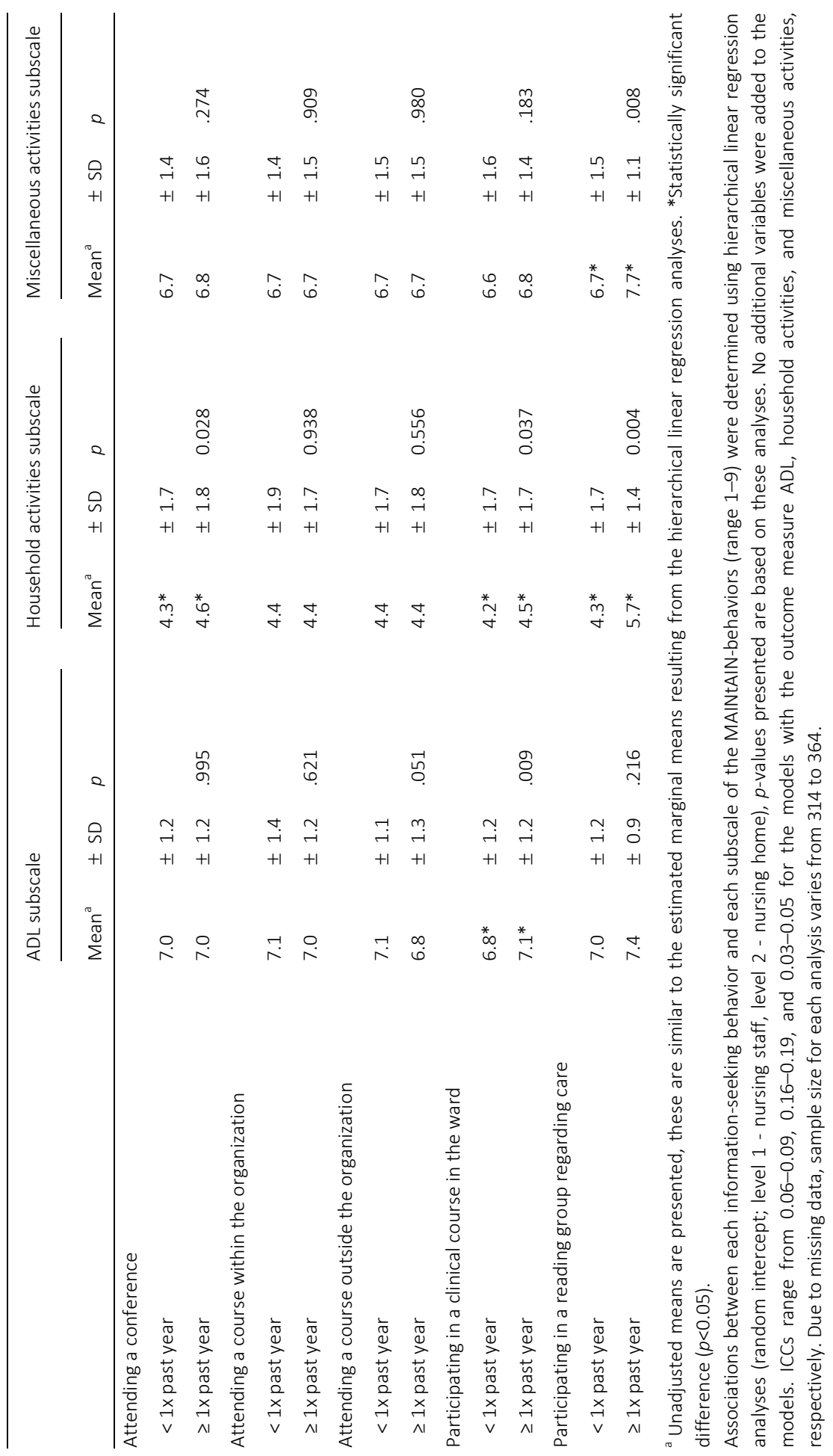


Factors associated with the perceived encouragement of functional activity

Table 4.3 shows the unadjusted mean scores for the ADL activities subscale, for the household activities subscale, and for the miscellaneous activities subscale per professional characteristic and contextual factor. These scores are similar to the estimated marginal means that resulted from the hierarchical linear regression analyses, therefore, only the unadjusted means are presented. The largest difference in the perceived encouragement of activities, in particular household activities, was between respondents working in different ward types. The hierarchical linear regression analyses showed that respondents working in psychogeriatric wards reported significantly more often that household activities were encouraged compared with respondents working in somatic wards ( $p<0.001$, mean score 4.8, SD 1.6 and 3.7, SD 1.6, respectively). The perceived encouragement of miscellaneous activities also differed significantly between respondents from psychogeriatric and from somatic wards, but the difference was smaller ( $p=0.001$, mean score 6.9, SD 1.4 and 6.4, SD 1.4, respectively). As Table 4.3 shows, the only other professional characteristics or contextual factors significantly associated with the encouragement of activities were age and work hours per week (associated with the subscale of miscellaneous activities).

Table 4.4 presents the unadjusted mean scores for the functional activity subscales for each information-seeking behavior. Again, these mean scores were similar to the estimated marginal means resulting from the hierarchical linear regression analyses. On the whole, few of the information-seeking behaviors were significantly associated with the encouragement of functional activities, most of the associations found were with the encouragement of household activities. The hierarchical linear regression analyses revealed that respondents who searched on websites, attended conferences, participated in clinical courses in the ward, or in reading groups regarding care reported significantly more encouragement of household activities in their wards.

Sensitivity analyses in which missing values on the functional activity subscales were imputed with either 'one' or 'nine' showed similar results for the analyses with the professional characteristics and contextual factors, as well as for the analyses with the information-seeking behaviors.

\section{Discussion}

This study showed that, according to nursing staff, household activities are not as often encouraged among residents as ADL or miscellaneous activities are. Some professional characteristics, contextual factors, and information-seeking behaviors were associated with the perceived encouragement of functional activity. However, no consistent pattern has emerged. 
Although no previous research has analyzed the extent to which functional activities are encouraged by nursing staff, there are studies looking into the behavior of residents. These show that residents are largely inactive and rarely participate in household activities. ${ }^{3,10}$ For example, in an observation study among residents of seven nursing homes in the south of the Netherlands, Den Ouden et al. ${ }^{10}$ showed that residents were engaged in household activities, but only in less than $3 \%$ of their observations. This percentage is lower than one would expect, given the results of the present study, in which $39 \%$ to $86 \%$ of the nursing staff stated that certain household activities were encouraged - at least sometimes. The differences between the two studies are quite large and may be explained by the different concepts measured, i.e., perceptions of nursing staff versus behavior by residents, and by the difference in the respective samples, i.e., randomly selected nursing homes throughout the Netherlands versus a convenience sample of nursing homes in the south of the Netherlands. Another explanation may be that encouragement by nursing staff does not always result in increased functional activity among residents.

The finding that household activities were not often encouraged, compared with ADL, or miscellaneous activities, contrasts with the culture change ${ }^{7}$ that is currently taking place in many nursing homes across the world. Nowadays, many nursing homes strive to maintain the meaningful activities residents previously conducted, including household activities. ${ }^{18-20}$ In some nursing homes, it is expected that nursing staff prepare dinner together with residents. ${ }^{18}$ In the Netherlands, this care philosophy particularly occurs in (small-scale) psychogeriatric wards. ${ }^{18}$ Indeed, in the present study, nursing staff from psychogeriatric wards stated significantly more often that household activities were encouraged, compared with nursing staff from somatic wards.

In this study, few associations were found between professional characteristics, contextual factors, and information-seeking behaviors, and the perception whether or not functional activities were encouraged. Associations that were found were inconsistent; factors that were associated with the perceived encouragement of household activities were not associated with the perceived encouragement of ADL. Furthermore, factors that were significantly associated with this perceived encouragement reflected relatively small differences. The different kinds of measures that were used in this study may explain the inconsistent findings. Encouraging functional activities refers to specific behaviors (i.e., specific daily activities), while the information-seeking behaviors were measured on a more general level. For example, respondents were asked if they attended courses in general, they were not asked if they attended courses focused on the encouragement of functional activities. Searching for information in a specific area does not necessarily imply knowledgeability about the encouragement of functional activities. In addition, although we carefully selected our independent variables drawing on previous studies, ${ }^{11-15}$ it might be that the professional characteristics, contextual factors, or information-seeking behaviors used are not the 
most important factors for encouraging functional activity. Perhaps more closelyrelated factors, specific barriers or facilitators, such as the perceived capabilities of residents, support of colleagues, ${ }^{17,21}$ or the availability of domestic facilities in the wards determine whether or not functional activities are encouraged.

The findings of this study indicate that nursing staff prefer sources that allow interaction, such as colleagues or clinical lessons, over traditional sources of knowledge, such as journals. This is in accordance with previous research investigating the knowledge sources of nursing staff. ${ }^{22}$ Given the relatively low educational level of nursing staff in nursing homes, it is not surprising that only few nurses in this study actively searched for written information. However, to warrant the quality of care in nursing homes, it is important that evidence-based or best practices reach the nursing staff. To ensure that nursing staff encourage functional activity, nursing homes need to use strategies that meet the preferences and competences of their nursing staff. Changing nursing behavior may be best done by using interactive strategies. To achieve this, it is essential that people with the appropriate knowledge and skills are available in the nursing home.

For this study, a proportionate random sample of nursing homes was drawn from different regions within the Netherlands, resulting in a, from a national perspective, large sample representing nursing home staff throughout the country. This is one of the few studies in the Netherlands that involved so many nursing homes. Most of the nursing homes that agreed to participate in this study were situated in the south of the Netherlands and least in the central region; their distribution was largely similar to the proportionate random sample that was drawn. The results of this study can be used as a reference for other researchers or nursing homes that want to use the MAINtAINbehaviors to measure the extent to which nursing staff perceive to encourage functional activities. However, the population in the present study might not be entirely representative for nursing home staff in other countries. The majority of the nursing staff participating in this study were CNAs, who are comparable to the licensed practical nurses in the United States. ${ }^{23}$ Dutch CNAs receive a three-year secondary-vocational training. In contrast, for example, in the United States the majority of the nursing home staff are nursing assistants who receive a minimal training of $75 \mathrm{~h}^{24,25}$

\section{Limitations}

The present study has a cross-sectional design; therefore, no causal relationships could be assessed. In addition, the aim of this study was to assess the extent to which nursing staff perceive that they encourage functional activity; therefore it assessed nursing staff perceptions, which may not necessarily be the same as the extent to which they actually encourage functional activity. Furthermore, respondents were asked to reflect upon their ward ('in my ward, we encourage...'), which might not always completely 
correspond to their own personal behavior. For a more objective perspective, observations could be conducted regarding the extent to which nursing staff encourage functional activities. Moreover, other contextual factors, such as the availability of specific domestic facilities, could also have been included in this study.

\section{Implications for research and practice}

The present study examined the association between professional characteristics, contextual factors, and information-seeking behaviors, and the perceived encouragement of functional activity. Future studies could consider factors that are possibly more closely-linked to the encouragement of functional activities, for example specific barriers or facilitators nursing staff perceive towards encouraging functional activity (e.g., capabilities of residents, self-efficacy of nursing staff, support of colleagues, or time constrains ${ }^{17,26,27}$ ). Furthermore, future studies could examine how the perception of nursing staff corresponds with their actual behavior, and if increased encouragement by nursing staff leads to improved functional activity among residents.

This study showed that household activities were less often encouraged than other activities, according to the nursing staff. Performing household activities is associated with a higher quality of life among nursing home residents. ${ }^{3}$ Here lies an opportunity for nursing homes; nursing homes could focus on improving the extent to which household activities are encouraged and nursing staff should be aware of the importance of these kinds of activities.

\section{Conclusion}

The findings of this study show that, according to the nursing staff, most household activities are not often encouraged by a large proportion of the nursing home staff. ADL and miscellaneous activities are more often perceived to be encouraged. Professional characteristics, contextual factors, and information-seeking behaviors are not consistently associated with the encouragement of functional activity. Future studies aimed at improving the encouragement of functional activity could focus on the encouragement of household activities, the association between perceptions and actual behavior of nursing staff, and potential barriers and facilitators for encouraging residents to participate in functional activities. Furthermore, studies providing insight into whether or not encouragement of functional activity by nursing staff leads to improved functional activity among nursing home residents are necessary. 


\section{References}

1. Resnick B, Galik E, Boltz M. Function focused care approaches: literature review of progress and future possibilities. J Am Med Dir Assoc. 2013;14(5):313-318.

2. Blair CE. Effect of self-care adls on self-esteem of intact nursing home residents. Issues Ment Health Nurs. 1997;20(6):559-570.

3. Edvardsson D, Petersson L, Sjogren K, Lindkvist M, Sandman PO. Everyday activities for people with dementia in residential aged care: associations with person-centredness and quality of life. Int J Older People Nurs. 2014;9(4):269-276.

4. Omnibus Budget Reconciliation Act OBRA, Subtitle C. Nursing Home Reform Act. Publ. No. PL 100-203. 1987, Washington DC, US Government Printing Office.

5. Inspectie voor de Gezondheidszorg (Dutch Health Care Inspectorate). In: State of health care 2012 Prevention in curative and long-term care: the need for vulnerable groups. [In Dutch: Staat van de gezondheidszorg 2012. Preventie in de curatieve en langdurige zorg: Noodzaak voor kwetsbare groepen]. 2012. https://www.rijksoverheid.nl/documenten/rapporten/2012/11/29/staat-van-de-gezondheidszorg2012 Accessed 25 April 2016.

6. White-Chu EF, Graves WJ, Godfrey SM, Bonner A, Sloane P. Beyond the medical model: the culture change revolution in long-term care. J Am Med Dir Assoc. 2009;10(6):370-378.

7. Rahman AN, Schnelle JF. The nursing home culture-change movement: recent past, present, and future directions for research. Gerontologist. 2008;48(2):142-148.

8. MacRae PG, Schnelle JF, Simmons SF, Ouslander JG. Physical activity levels of ambulatory nursing home residents. J Aging Phys Activ. 1996;4:264-278.

9. Ice, GH. Daily life in a nursing home: Has it changed in 25 years? J Aging Stud. 2002;16(4):345-359.

10. den Ouden M, Bleijlevens MH, Meijers JM, et al. Daily (in)activities of nursing home residents in their wards: an observation study. J Am Med Dir Assoc. 2015;16(11):963-968.

11. Estabrooks CA, Squires JE, Hayduk L, et al. The influence of organizational context on best practice use by care aides in residential long-term care settings. J Am Med Dir Assoc. 2015;16(6):537 e1-10.

12. Squires JE, Estabrooks CA, Gustavsson P, Wallin L. Individual determinants of research utilization by nurses: a systematic review update. Implement Sci. 2011;6:1.

13. Eizenberg MM. Implementation of evidence-based nursing practice: nurses' personal and professional factors? J Adv Nurs. 2011;67(1):33-42.

14. Milner M, Estabrooks CA, Myrick F. Research utilization and clinical nurse educators: a systematic review. J Eval Clin Pract. 2006;12(6):639-655.

15. Backhaus R, Verbeek H, van Rossum E, Capezuti E, Hamers JP. Nurse staffing impact on quality of care in nursing homes: a systematic review of longitudinal studies. J Am Med Dir Assoc. 2014;15(6):383-393.

16. Schols JMGA, Crebolder HFJM, van Weel C. Nursing home and nursing home physician: the Dutch experience. J Am Med Dir Assoc. 2004;5(3):207-212.

17. Kuk NO, Zijlstra GAR, Bours GJJW, Hamers JPH, Kempen GIJM. Development and usability of the MAINtAIN, an inventory assessing nursing staff behavior to optimize and maintain functional activity among nursing home residents: a mixed-methods approach. BMC Health Serv Res. 2016;16:38.

18. Verbeek H, van Rossum E, Zwakhalen SM, Kempen GI, Hamers JP. Small, homelike care environments for older people with dementia: a literature review. Int Psychogeriatr. 2009;21(2):252-264.

19. Rabig J. Home again: small houses for individuals with cognitive impairment. J Gerontol Nurs. 2009;35(8):10-15.

20. de Boer B, Hamers JPH, Beerens HC, Zwakhalen SMG, Tan FES, Verbeek H. Living at the farm, innovative nursing home care for people with dementia - study protocol of an observational longitudinal study. BMC Geriatr. 2015;15:144.

21. Resnick B, Petzer-Aboff I, Galik E, et al. Barriers and benefits to implementing a restorative care intervention in nursing homes. J Am Med Dir Assoc. 2008;9(2):102-108. 
22. Estabrooks CA, Rutakumwa W, O'Leary KA, et al. Sources of practice knowledge among nurses. Qual Health Res. 2005;15(4):460-476.

23. Verkaik R, Francke AL, van Meijel B, Ribbe MW, Bensing JM. Comorbid depression in dementia on psychogeriatric nursing home wards: Which symptoms are prominent? Am J Geriat Psychiat. 2009;17(7):565-573.

24. Harrington C, Choiniere J, Goldmann M, et al. Nursing home staffing standards and staffing levels in six countries. J Nurs Scholarsh. 2012;44(1):88-98.

25. Han K, Trinkoff AM, Storr CL, Lerner N, Johantgen M, Gartrell K. Associations between state regulations, training length, perceived quality and job satisfaction among certified nursing assistants: cross-sectional secondary data analysis. Int J Nurs Stud. 2014;51(8):1135-1141.

26. Resnick B. Restorative care nursing for older adults a guide for all care settings. New York: Springer; 2008.

27. Resnick B, Simpson M, Galik E, et al. Making a difference: nursing assistants' perspectives of restorative care nursing. Rehabil Nurs. 2006;31(2):78-86. 



\section{CHAPTER 5}

Feasibility of DAlly NURSE: a nursing intervention to change nursing staff behavior towards encouraging residents' daily activities and independence in the nursing home

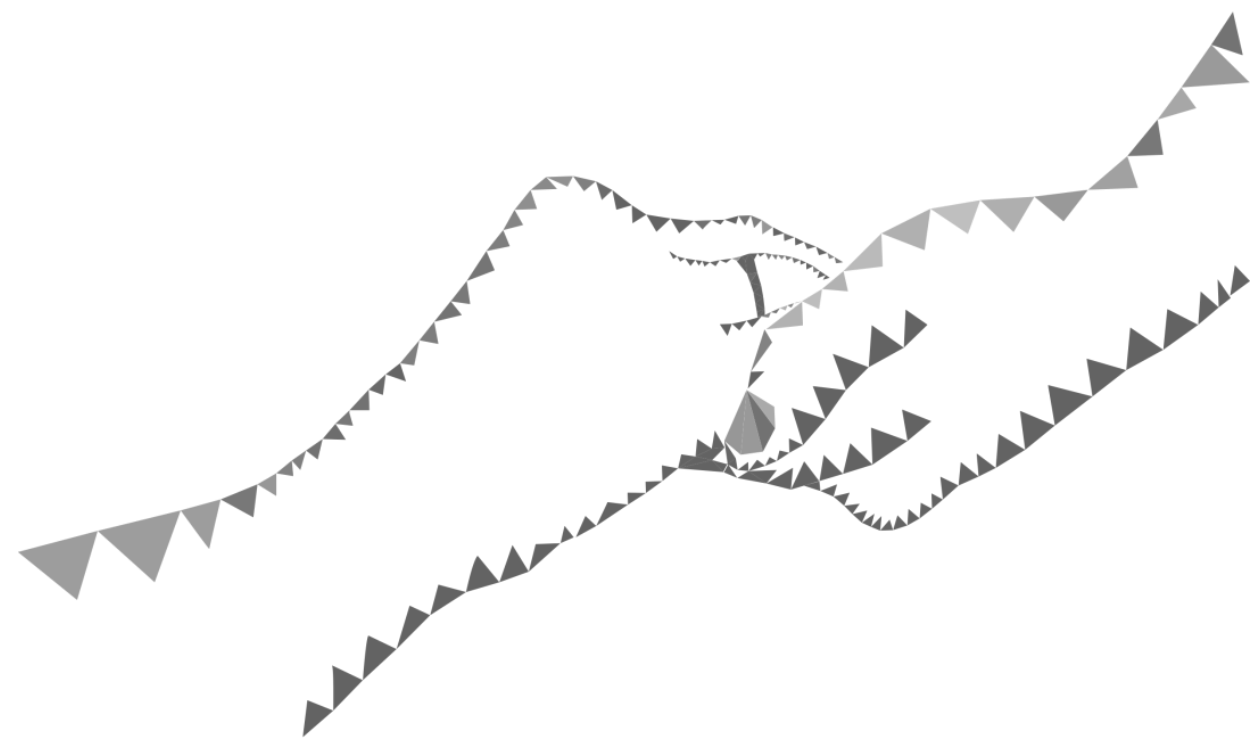

This chapter was submitted for publication as:

den Ouden M, Zwakhalen SMG, Meijers JMM, Bleijlevens MHC, Hamers JPH. Feasibility of DAlly NURSE: a nursing intervention to change nursing staff behavior towards encouraging residents' daily activities and independence in the nursing home. 


\section{Abstract}

Aims and objectives: This study examined the feasibility of DAlly NURSE, a nursing intervention to encourage nursing home residents' daily activities and independence.

Background: Nursing home residents are mainly inactive during the day. DAlly NURSE was developed to change nursing behavior towards encouraging nursing home residents' activities and independence by creating awareness. It consists of three components: education, coaching-on-the-job and policy.

Design: A mixed-method study

Methods: The feasibility of DAlly NURSE in practice was tested in six psychogeriatric nursing home wards, using attendance lists (reach), evaluation questionnaires (fidelity, dose received, barriers), notes made by the researcher (dose delivered, fidelity), and a focus group interview (dose received, barriers) with nursing home staff $(n=8)$ at the end of the study.

Results: The feasibility study showed that all three components (education, coachingon-the-job and policy) were implemented in practice. The attendance rate in the workshops was high (average: 82\%). Nursing home staff were satisfied with the workshops (mean score 9 out of 10 points) and agreed that DAlly NURSE was feasible in daily nursing care practice. Recommendations to optimize the feasibility of DAlly NURSE included: add video observations of a specific moment of the day to create awareness of nursing behavior; educate all nursing staff of the ward during the workshops; and organize information meetings for family members before the start of the intervention. Nursing staff were satisfied with the intervention and provided recommendations for adjustments to the content of the three components. The most important adjustment is the use of video observations to create awareness of nursing staff behavior.

Conclusions: DAlly NURSE, consisting of education, coaching-on-the-job and policy, is feasible in nursing home practice.

Relevance to clinical practice: DAlly NURSE might help to change nursing behavior towards encouraging residents' daily activities and independence. 


\section{Introduction}

Nursing home residents spend their day mainly inactive and sedentary. ${ }^{1,2}$ This has negative consequences on their quality of life and many other healthcare outcomes, such as cognitive functioning, incontinence, malnutrition, risk of falling and pressure ulcers. $^{3-5}$ So far, most activity programs have been aimed at the reduction of inactivity by focusing on physical exercise. A review by Weening-Dijksterhuis (2011) provides an overview of several physical exercise interventions to improve health outcomes in nursing home residents. These interventions include components of resistance, strength, balance, flexibility and/or aerobic exercises. Participation in these programs could improve residents' muscle strength, flexibility, endurance, balance, physical functioning and quality of life. ${ }^{6}$ The positive effects of exercise a few times a week for a limited amount of time might be small when the residents are still inactive and sedentary during the rest of the day. ${ }^{7}$ In a recent task force report by de Souto Barreto et al. (2016), it is therefore recommended to focus on reducing sedentary behavior and enhancing activity levels in daily life of all nursing home residents to maintain functioning. ${ }^{8}$

To enhance activity levels in daily life, nursing home residents should be more engaged in daily activities. Daily activities comprising activities of daily living (ADL), such as washing, eating and drinking, mobility, and instrumental activities of daily living (IADL), such as preparing a meal, setting the table and watering plants. ${ }^{1}$ These (I)ADL seem to be particularly important for nursing home residents, as they are often viewed as meaningful activities. ${ }^{9}$ By performing these activities, residents will maintain their functioning and are less care-dependent, ${ }^{10}$ which positively influences their sense of dignity. ${ }^{11}$

\section{Background}

Nursing staff play a key role in encouraging residents' daily activities and independence ${ }^{8,12}$ as they are available $24 / 7$ and spend $54 \%$ of their time with providing direct care. ${ }^{13}$ Nursing staff are also in charge of creating a homelike ward climate in which residents could perform their daily activities as they did before they entered the nursing home, ${ }^{14}$ such as engaging in preparing meals. A previous study by Kuk et al. (2017) in which nursing staff were asked about their perceived behavior towards encouraging activities, showed that nursing staff reported to encourage residents' daily activities often, especially ADL. ${ }^{15}$ However, observations in a study by den Ouden et al. (2016) showed that nursing staff took over almost half of residents' daily activities when they were involved in their activities (e.g. a nurse poured coffee with sugar and milk and even stirred the drink in front of the resident or a nurse pushed a resident in a 
wheelchair). ${ }^{12}$ This could indicate a difference between perceived and observed behavior. Therefore, it is essential that nursing staff are aware of their actual behavior and have the opportunity to encourage residents.

Encouraging nursing home residents can be challenging since nursing staff experience several barriers. Barriers such as care routines and communication and support within the team are strongly associated with the encouragement of activities and independency. ${ }^{16}$ In addition, nursing staff experience barriers such as time constraints, expectations of others and residents' capabilities. ${ }^{16,17}$ Nursing interventions should support nursing staff in creating awareness and changing their behavior towards encouraging nursing home residents' daily activities and independence.

Interventions focusing on changing nursing behavior towards encouraging nursing home residents in daily activities and their independence are scarce. The limited amount of interventions described in the literature lack effectiveness. ${ }^{18-24}$ Additionally, these interventions do not focus directly on creating awareness to change nursing behavior, as emphasized by de Souto Barreto et al. ${ }^{8}$ Important components of existing interventions as described above as well as existing intervention on other topics in nursing home care, like physical restraints, are: education, coaching and policy. ${ }^{22,25} \mathrm{~A}$ combination of different strategies is more useful than a single strategy such as education. ${ }^{25-28}$ An example of a multicomponent nursing intervention in this field is 'Daily Activities and Independence by NURsing Staff Encouragement' (DAlly NURSE), which aims to change nursing staff behavior in a way that nursing home residents are encouraged and supported to perform their daily activities as independently as possible during daily nursing practice. This change is supported by creating awareness of their own nursing behavior towards the encouragement of residents' daily activities and independence and the possible consequences of their behavior. The intervention consists of the following three components; education, coaching-on-the-job and policy. The steps of the development, including the main results of each step, and the content of the three components of DAlly NURSE are described in Box 5.1. DAlly NURSE has not been tested in daily nursing home practice. Therefore, the current study evaluates the feasibility of DAlly NURSE, aiming to optimize and finalize the intervention.

\section{Methods}

Study design

This study describes the feasibility testing of DAlly NURSE using a mixed-methods design, including qualitative and quantitative measures. 


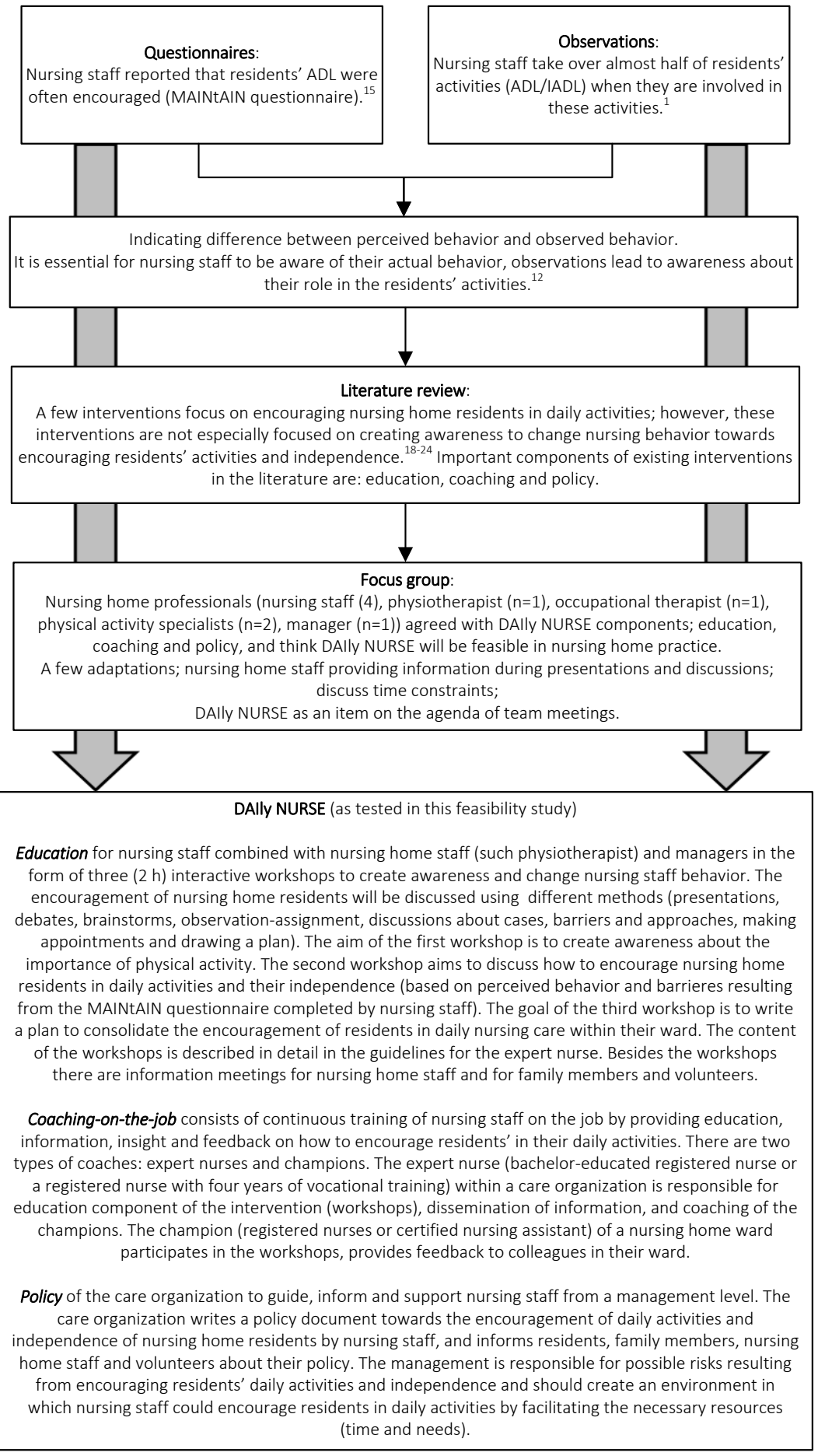

Box 5.1: Development including main results of each step and content of DAlly NURSE. 


\section{Sample}

DAlly NURSE was implemented in the psychogeriatric wards $(n=6)$ of two nursing homes (A and B). The two nursing homes were able to tailor the intervention to the organization by adapting minor aspects of DAlly NURSE. Therefore DAlly NURSE was tested in slightly different ways (see Figure 5.1). Nursing home A participated with five small-scale wards, housing six residents in each ward ( $n=30$ total). A total of 35 nursing staff were employed in the wards, of whom six champions $(n=6)$ were appointed to participate in the workshops. The expert nurse was 49 years old and had 11 years of working experience in elderly care and experience with providing education in the field of physical activity within the care organization. Nursing home B participated with one regular ward of 12 residents ( $n=12$ total); the whole team of nursing staff $(n=7)$ was involved in the workshops; in addition, other nursing home staff, such as the physiotherapist, were involved. The expert nurse in nursing home B was 36 years old and had 20 years of working experience in elderly care. All nursing staff participating in the workshops of this study were certified nurse assistants (CNAs), with three years of secondary-vocational training; the expert nurses in both nursing homes were registered nurses (RNs), with four years of secondary-vocational training or bachelor education. ${ }^{29}$ Both nursing homes used an observation-assignment between the workshops to create awareness of residents' capabilities in (I)ADL. This observation-assignment consisted of a list of daily activities divided into several steps. Nursing staff score whether a resident was able to perform this activity independently, with support or the resident was unable to perform this, furthermore they observe and score whether the resident actually does perform this (independently, with support or not). This observationassignment creates awareness of a possible difference between what a resident can do and what the resident actually does. In addition, video recordings of breakfast times were shown in the workshops of nursing home B to create awareness. Participants of the focus group interview were nursing home staff of both nursing homes (nursing home $A n=5$, nursing home $B n=3$ ). Most of the focus group participants were nursing staff $(n=7)$, while one had a background as an occupational therapist $(n=1)$. 


\begin{tabular}{|c|c|c|}
\hline \multicolumn{3}{|c|}{$\begin{array}{l}\text { Feasibility testing in nursing home practice } \\
\text { (questionnaires, attendance lists, notes, focus group interview) }\end{array}$} \\
\hline & Nursing home A & Nursing home B \\
\hline & 5 small-scale wards, 30 residents & 1 ward, 12 residents \\
\hline Provider(s) workshops & Expert nurse & $\begin{array}{l}\text { Expert nurse + physiotherapist/ } \\
\text { occupational therapist }\end{array}$ \\
\hline Participant workshops & Champions $(n=6)$ & Nursing (home) staff $(n=10)$ \\
\hline Awareness & Observations during assessment & $\begin{array}{l}\text { Assessment and video observations of } \\
\text { breakfast }\end{array}$ \\
\hline Information meeting & After workshops & Before workshops \\
\hline Time between workshops & $1.5-2$ weeks & 4 weeks \\
\hline
\end{tabular}

Figure 5.1: Overview of participating nursing homes; differences and similarities.

\section{Measurements}

The feasibility of DAlly NURSE in nursing home practice was defined according to the framework of Saunders Evans, and Joshi (2005): dose delivered, fidelity, dose receivedexposure, dose received-satisfaction, reach and barriers were assessed using selfadministered evaluation questionnaires, attendance lists, notes of the workshops, and a focus group interview (see Table 5.1). ${ }^{30}$ Self-administered evaluation questionnaires containing questions (10-point Likert scale and open-ended) about the clarity of the information received, sufficiency of time for discussions, satisfaction with the expert nurse, possibilities for improvement etc. were used to gather information about the fidelity, dose received-exposure, dose received-satisfaction, and barriers. Attendance lists were used to obtain insight into the reach of DAlly NURSE. Notes about the discussions during each workshop and information meeting were made by the researcher to measure dose delivered and fidelity. Participants of the feasibility study from both nursing homes $(n=8)$ discussed the feasibility (dose received-exposure, dose received-satisfaction, and barriers) of DAlly NURSE in nursing care practice during the focus group interview. During this meeting, the experiences with the three components of DAlly NURSE, and the similarities and differences in the implementation of DAlly NURSE in nursing practice between the different nursing homes were discussed. Topics considered were, for example, participants of the education, themes lacking in the workshops, focus on activities during a specific moment of the day, such as breakfast, information meetings for nursing staff and for residents' family, how to inform and involve family and volunteers, planning, creating awareness using video observations, and the implementation plan. 
Table 5.1: Measures of feasibility

\begin{tabular}{|c|c|c|c|c|c|}
\hline & \multirow[t]{2}{*}{ Operationalization } & \multicolumn{4}{|c|}{ Measurement instrument } \\
\hline & & Questionnaire & Attendance list & Notes & $\begin{array}{c}\text { Focus group } \\
\text { interview }\end{array}$ \\
\hline Dose delivered & $\begin{array}{l}\text { The extent to which all three } \\
\text { components were delivered }\end{array}$ & & & $x$ & \\
\hline Fidelity & $\begin{array}{l}\text { The extent to which DAlly NURSE } \\
\text { was implemented as planned }\end{array}$ & $x$ & & $x$ & \\
\hline $\begin{array}{l}\text { Dose received- } \\
\text { exposure }\end{array}$ & $\begin{array}{l}\text { The extent to which nursing staff } \\
\text { used the assignment }\end{array}$ & $x$ & & & $x$ \\
\hline $\begin{array}{l}\text { Dose received- } \\
\text { satisfaction }\end{array}$ & $\begin{array}{l}\text { Satisfaction of nursing home staff } \\
\text { regarding the components }\end{array}$ & $x$ & & & $x$ \\
\hline Reach & $\begin{array}{l}\text { Proportion of the target } \\
\text { population that attended the } \\
\text { workshops }\end{array}$ & & $x$ & & \\
\hline Barriers & $\begin{array}{l}\text { Barriers experienced by nursing } \\
\text { home staff during the } \\
\text { implementation }\end{array}$ & $x$ & & & $x$ \\
\hline
\end{tabular}

Additionally, to obtain insight into the nursing home environment, background information of the nursing home residents and nursing staff participating in the workshops was gathered. Data collected on nursing home residents included date of birth, date of admission to the nursing home, gender, mobility (mobile, wheelchairdependent or bedridden), physical functioning (Barthel Index), ${ }^{31}$ and cognitive functioning (Cognitive Performance Scale). ${ }^{32}$ Characteristics of nursing staff collected were: date of birth, gender, level of education, professional level, years of working experience, hours of working in the ward per week. Further, nursing staff completed the MAINtAIN questionnaire ${ }^{33}$ prior to the workshops to obtain insight into their perceived behavior towards and barriers to encouraging residents' activities. This questionnaire consists of 19 items about perceived behavior to encourage ADL, household and more general activities, and 33 items to measure barriers related to resident, professional, social or organizational level. The MAINtAIN questionnaire is validated on its content and positively tested on its usability. For each item nursing staff rate to what extent that activity was encouraged or that barrier was experienced on their ward ('on my ward ...'). Each item can be scored on a 9-point scale, ranging from 'never' to 'always' or 'completely disagree' to 'completely agree'. 33

\section{Procedure}

At the start of the implementation in nursing home practice, background characteristics of participating nursing home residents and nursing staff were gathered using questionnaires. Nursing staff completed the questionnaires about the residents based on the residents' files, as well as completing the questionnaires about themselves. The 
expert nurse receives the manual to lead the workshops. This manual contains a detailed description of the workshops, including hand-outs and background information for the expert nurse. Each workshop is divided in themes, which should be discussed or practiced for a certain amount of time. Before the start of the study, the principal researcher met with the expert nurse to deliver the manual and shortly discuss it, but did not provide a special training to the expert nurse. During each workshop and information meeting, the principal researcher made notes and at the end of each session the participants signed the attendance list and completed evaluation questionnaires. The results of the evaluation questionnaires provided input for the discussion of barriers and suggestions for improvement during the focus group interview. The interview took place after the implementation in nursing home practice. The principal researcher discussed the differences between the two nursing homes with the participants with the aim of reaching a consensus about adjustments to the intervention to be made in order to optimize the feasibility of DAlly NURSE and finalize its format.

\section{Statistical analyses}

The quantitative data from the evaluation questionnaires and background characteristics were analyzed using descriptive statistics in SPSS (version 24). Differences in background characteristics between the two nursing homes were determined using an independent t-test for the continuous variables and a chi-square test for the categorical variables. Qualitative data from open-ended questions were summarized and discussed in the focus group interview. The focus group interview was audio-taped and summarized by the principal author guided by the formulated questions from beforehand. Recommendations for improving the intervention were extracted from the summary.

\section{Ethical considerations}

The study protocol of the feasibility study was approved by the Medical Ethics Review Committee of Zuyderland Zuyd (16-N-131) in 2016. Nursing home directors provided permission to conduct the feasibility study. Legal representatives of each nursing home resident received an information letter and were asked to provide informed consent to gather background data about the resident. Further, the director of nursing home $\mathrm{B}$ asked the legal representatives of the nursing home residents to give permission for the video recordings during the information meeting for family members; if they were not present they were contacted by telephone. Nursing home staff participated voluntarily and consented to the recording of the focus group interviews. 


\section{Results}

\section{Nursing home environment}

Background characteristics of the residents and the nursing staff involved in the workshops can be found in Table 5.2. In nursing home A, 20 representatives replied to the informed consent letter, and 14 of them gave their informed consent. In nursing home B, 9 representatives replied and all gave informed consent. Nursing staff completed the questionnaires of 13 and 7 residents, respectively. Nursing staff involved in the workshops $(n=13)$ completed the questionnaires about their characteristics and the MAINtAIN questionnaire. No significant differences were found between the nursing homes in background characteristics of the group of nursing home residents and nursing staff participating in the workshops. Merely, results of the MAINtAINbehaviors questionnaire indicate that IADL were significantly more encouraged in the wards of nursing home A than in nursing home B. Important barriers for nursing staff to encouraging activities and independence of nursing home residents of both nursing homes, according to the MAINtAIN-barriers, were: nursing staff felt that it was not their responsibility to inform informal caregivers about the importance of residents' daily activities and independence; their manager did not communicate this importance; and nursing staff did not feel they were able to encourage residents to perform daily activities more independently. Further, in nursing home A, nursing staff experienced a lack of opportunities to attend courses as being the most important barrier, whereas in nursing home B nursing staff felt that it was not relevant for nursing home residents to perform daily activities independently.

\section{Dose delivered}

All three components of the intervention DAlly NURSE (education, coaching-on-the-job and policy) were delivered in both nursing homes. The three 2-hour workshops of the educational component were facilitated and scheduled by the nursing home management. Further, the management appointed coaches (expert nurse and champions). Nursing home staff and family members were informed by information letters of the management and during workshops or information meetings. The manager explained the institutional policy with regard to the encouragement of daily activities and independence of nursing home residents during one of the workshops and during information meetings. The expert nurse led the workshops following the manual. The coaching-on-the-job was provided by the expert nurse and champions. 
Table 5.2: Background characteristics of the nursing home residents and nursing staff participating in the workshops

\begin{tabular}{lll}
\hline & Nursing home A & Nursing home B \\
\hline Residents ( $\mathrm{n}$ ) & 13 & 7 \\
Average age in years (sd) & $84(9)$ & $84(9)$ \\
Female, \% & 85 & 86 \\
Average length of stay in months (sd) & $33(28)$ & $31(39)$ \\
Mobile, \% & 75 & 86 \\
Average physical functioning (sd) ${ }^{\dagger}$ & $9.3(7.1)$ & $11.4(4.9)$ \\
Cognitive functioning (sd) $)^{\ddagger}$ & $3.6(1.9)$ & $2.8(2.0)$ \\
& & 7 \\
Nursing staff in the workshops (n) & 6 & $33(10)$ \\
Age in years (sd) & $43(12)$ & $86 \%$ \\
Gender (\% female) & $100 \%$ & $100 \%$ CNA \\
Professional level & $100 \%$ CNA & \\
Working experience (years) & & 4 \\
in elderly care & 18 & 3 \\
in the ward & 7 & 25 \\
Working hours per week & 25 & $6.6(1.4)$ \\
MAINTAIN-behaviors & & $3.6(2.0)$ \\
ADL & $7.9(1.3)$ & $7.4(1.3)$ \\
IADL* & $8.0(0.8)$ & \\
Miscellaneous & $7.0(0.8)$ & \\
\hline
\end{tabular}

*Significant difference between nursing homes $(p<0.05)$. CNA=Certified Nurse Assistant

+Physical functioning: Barthel Index range 0-20 (a lower score indicates an increased disability). ${ }^{31}$

$\ddagger$ Cognitive functioning: Cognitive Performance Scale range 0-6 (a higher score indicates a more severe cognitive impairment). ${ }^{32}$

§MAINtAIN-behaviors: range 1-9 (a higher score indicates more encouragement). ${ }^{33}$

\section{Fidelity}

Figure 5.2 provides an overview of the provided components in the two nursing homes. In nursing home A the expert nurse led all three workshops and invited guest speakers the manager, occupational therapist, and psychologist; the champions participated. In nursing home $B$, the expert nurse provided all three workshops together with an occupational therapist and a physiotherapist. The whole team of nursing staff participated $(n=7)$. All sorts of different themes as described in the manual were addressed in the workshops in both nursing homes, including policy explained by a manager; nursing behavior and experienced barriers were discussed based on the results of the MAINtAIN questionnaire; and at the end of the three workshops, an implementation plan was made to continue encouraging residents in daily activities and 
independence. Nursing staff felt support of managers, by their attendance during the workshops and by their presentation of the policy regarding the encouragement of residents' daily activities and independence. In nursing home $A$, the workshops were spread over a total period of a month, with from 1.5 to 2 weeks between the workshops. The workshops in nursing home B were once a month, with 4 weeks between them. Nursing staff in nursing home A were informed about the study by an information letter before the start of the intervention. Furthermore, after the workshops, nursing staff who did not attend them were informed during a team meeting about the implementation plan that was made by the champions in the workshops. During this meeting, the expert nurse provided information about the implementation plan. The champions attended this meeting as well and complemented the expert nurse with their experiences. Family members of residents in this nursing home were informed about the study by a letter, in which they were invited to an information meeting provided by the expert nurse after the start of the intervention (after workshops). In nursing home B, nursing home staff and family members were informed by the nursing home director about the study during information meetings before the start of the intervention, and family members were invited to a meeting at the end of the study period to discuss the experiences with DAlly NURSE. The expert nurse attended all information meetings. Both care organizations have a policy document regarding their vision on the encouragement of daily activities and independence of nursing home residents' activities.

\section{Dose received-exposure}

In nursing home $A$, four of the six participating nursing staff completed the observationassignment before the second workshop, and in nursing home $B$, five of the seven nurses did so. According to the self-administered questionnaires, the nursing staff expressed different experiences with the assignment. One participant indicated that the assignment had no added value, whereas the others reported that the assignment led to more awareness of the capability of the residents. For example, the assignment showed that a resident was able to set the table independently, but this activity was always performed by nursing staff. The resident could be encouraged to participate in setting the table, and by making personal contact, providing compliments and confidence the resident was motivated to set the table. Another resident was putted in a wheelchair when she went outside whereas she was able to walk with her rollator. Additionally, a resident was washed by nursing staff whereas he was able to wash his own face, arms and breast, especially with some supervision or verbal instructions. The participants indicated that the assignment was difficult to carry out; therefore the assignment should be better explained and more attention to the assignment was needed during the workshop. Furthermore, the participants in nursing home A did not 
have much time to complete the assignment. Nevertheless, participants agreed that the assignment led to more awareness of the capability of residents.

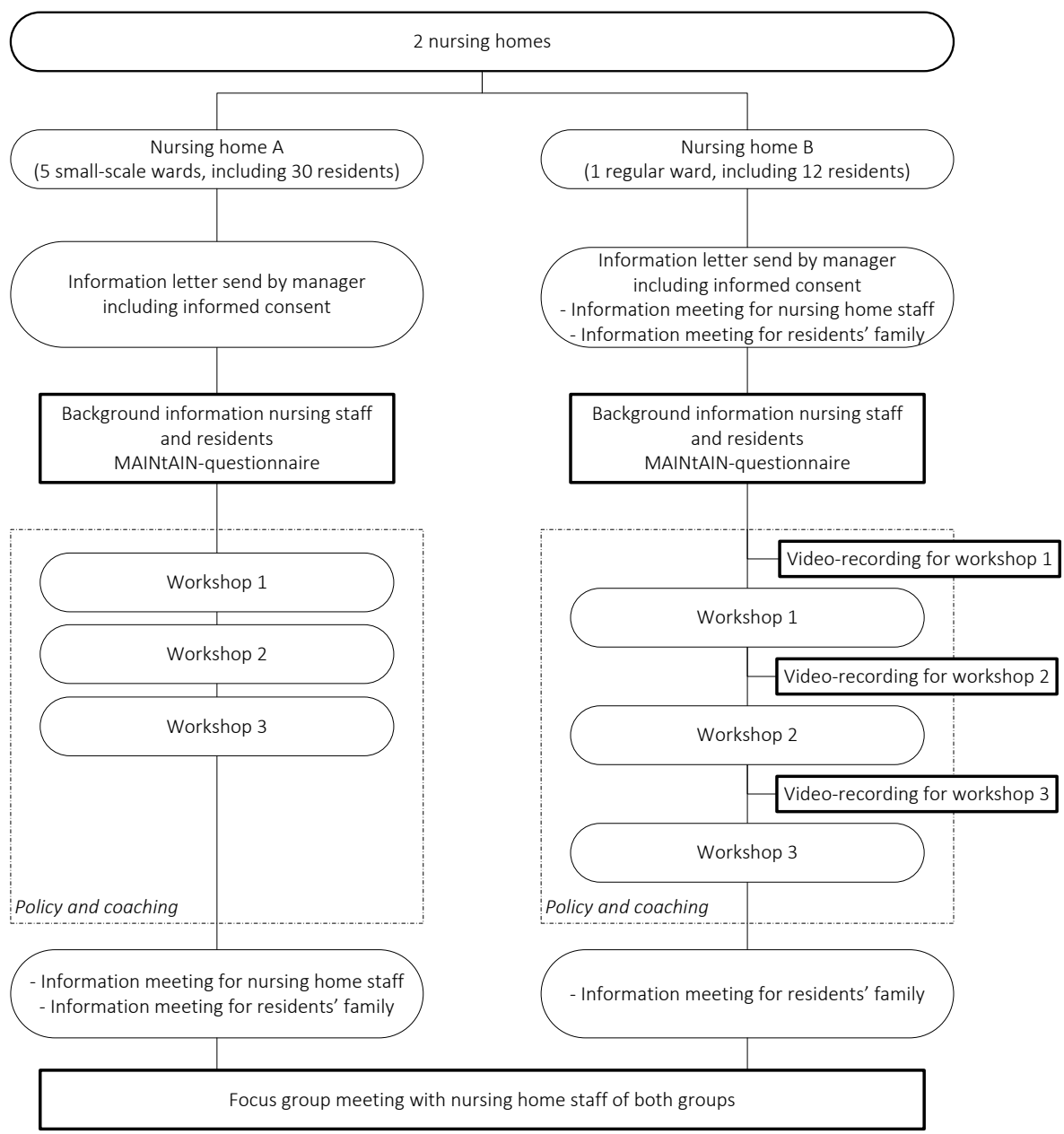

Figure 5.2: Overview of the provided components in the two nursing homes

\section{Dose received-satisfaction}

The participants of the workshops were satisfied with the educational component of DAlly NURSE; they gave, on average, a score of 9 out of 10 for their satisfaction with the workshops. Participants were satisfied with the duration of each workshop and reported that there was enough time for discussions and questions. Further, the participants mentioned that they liked the openness of the other participants, how they worked together during the workshops and appreciated the input of guest speakers. In 
nursing home $B$, the participants of the workshops mentioned that the video observations were very valuable in creating awareness: they indicated they had become more aware of the daily activities of nursing home residents and their role in these activities when observing a specific moment (breakfast) than after conducting the assignment in which they observed several ADL and IADL of a resident. For example, coffee and tea with sugar and milk were poured often in the kitchen, and even the drinks were stirred by the nursing staff. If a resident prepared their own sandwich, all requirements were placed in front of this person by nursing staff, whereas nursing staff could encourage the resident to collect the requirements in the kitchen and put them on the table himself. Video observations also provided insight into the context in which the residents perform daily activities, for example, when nursing staff run around the table with bread, spreads, medicine etc., as observed in the videos, residents were distracted from their meal. During the focus group interview, nursing staff of nursing home A stated that they would have liked to have seen themselves and their colleagues on video to observe their behavior and to create awareness. Furthermore, the participants of the focus group interview agreed that focusing on a specific moment during the day (for example, breakfast) could help nursing staff to start changing their behavior and extend their encouragement to other moments during the day. Mealtimes are important occasions in the day in the nursing home, and many daily activities could take place during that time. The participants of the information meetings for nursing staff were satisfied (8 out of 10 on average); they felt the information was clear and it made the participants aware of the importance of daily activities and independence for nursing home residents.

Coaching-on-the-job was difficult to evaluate since coaching should take place after the workshops in particular. Nursing staff of both nursing homes were satisfied with the expert nurse who provided the workshops (score range 8-10). Coaches indicated that it would be helpful to schedule reflection meetings to discuss experiences and evaluate the intervention once every (other) month. Nursing staff indicated that they felt supported by the policy and by the management who facilitated the workshops, attended a workshop and provided compliments.

Reach

The average attendance rate in the workshops was $82 \%$. In nursing home A, at least five of the six champions attended each workshop (83\%); in the second workshop all champions were present (100\%). In nursing home B, six of the team of seven nursing staff participated (86\%) in workshop 1 and 2, and the last workshop had the lowest attendance rate $(57 \%)$ due to illness $(n=2)$ and a conflicting appointment $(n=1)$. The information meetings for families had a low attendance rate. The meeting in nursing home A had only three visitors (10\%) and the meeting in nursing home B had five 
participants (42\%). During the focus group meeting, participants agreed that the best moment to inform family members, residents and volunteers is before the start of DAlly NURSE. They will become curious and it is essential to make them aware of the importance of daily activities and the positive influences.

\section{Barriers}

Barriers experienced by nursing home staff during the implementation differed in the nursing homes. In nursing home A, the champions participating in the workshops experienced resistance from colleagues who did not attend the workshops. Therefore, it is recommended to invite the whole team of nursing staff to attend the workshops to prevent this from happening. By educating the whole team in the workshops, coachingon-the-job will be easily integrated into daily nursing practice. During the workshops, volunteers could be asked to stay on the ward or nursing staff of other wards could cover. If all nursing staff participate in the workshops no information meeting is necessary, however nursing staff need to be informed by the management about DAlly NURSE before the start of the intervention. The time between workshops was too short in nursing home A; participants need more time between the workshops to do the observation-assignment and try to encourage residents in daily activities, so that their experiences can be discussed with other participants in the next workshop. Therefore, the time between two workshops should be 3-4 weeks; this will provide participants with enough time to conduct the assignment and change their behavior and discuss their experiences during the following workshop. In nursing home B, no barriers were mentioned in the evaluation questionnaires.

\section{Final version of DAlly NURSE}

The experiences with DAlly NURSE in nursing home practice and recommendations for the adjustments were used to make the intervention as feasible as possible in nursing home practice. DAlly NURSE consists of education, coaching-on-the-job and policy. Education in the form of three interactive workshops for the whole team of nursing staff, to create awareness and discuss the encouragement of (I)ADL in nursing home residents, and an information meeting for family members and volunteers before the start of DAlly NURSE. Coaching-on-the-job by expert nurse and champions to continue education, awareness and carry on encouraging nursing home residents for all nursing (home) staff. Policy supports all nursing (home) staff, and managers should inform them about DAlly NURSE before the start of the workshops. The final version of DAlly NURSE, including the adjustments, is described in Figure 5.3. 
DAlly NURSE (final version including adjustments)

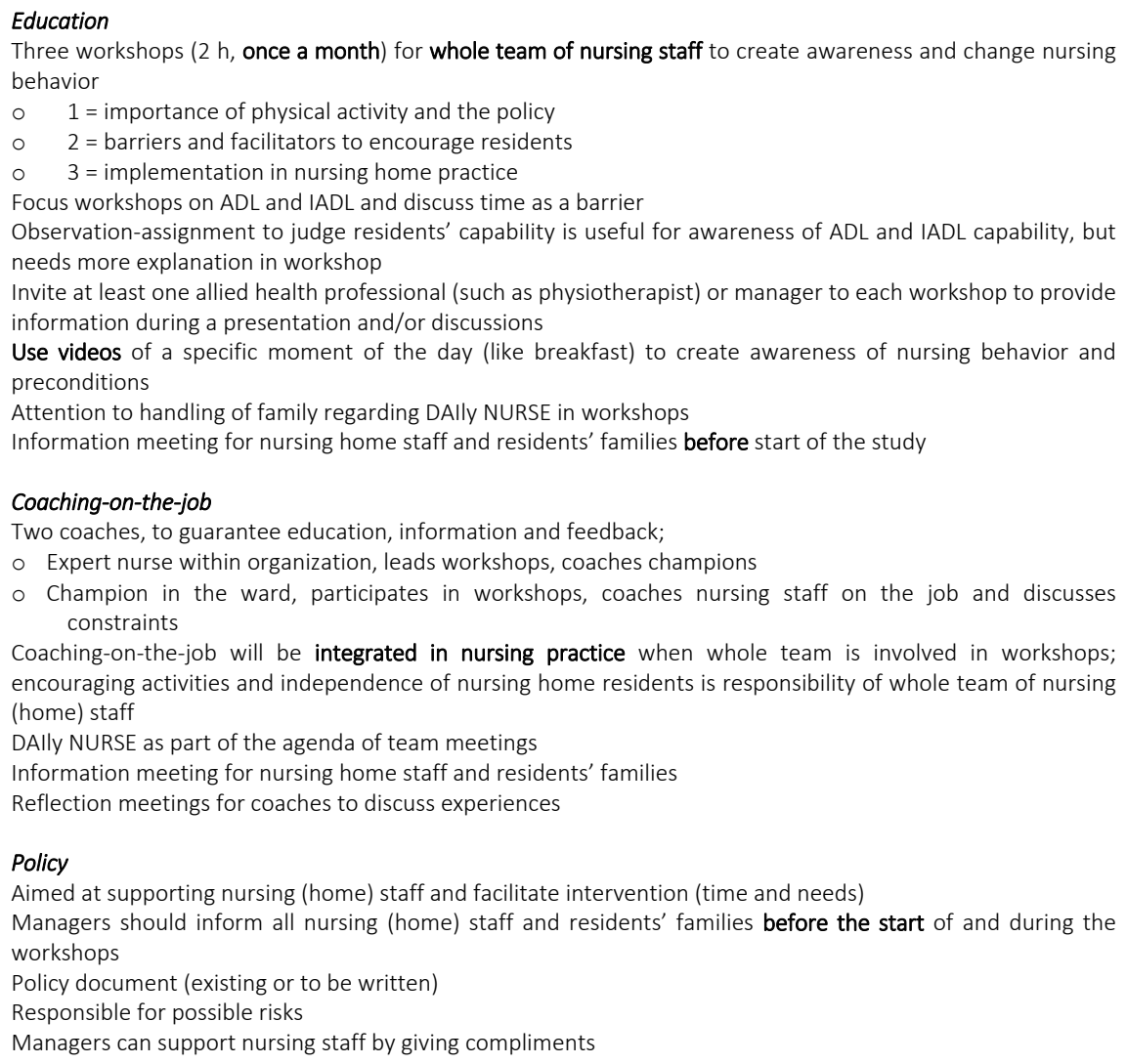

Figure 5.3: The content of DAlly NURSE including adjustments after the feasibility study.

\section{Discussion}

This study showed that the nursing intervention DAlly NURSE, including the three components education, coaching-on-the-job, and policy, is feasible in nursing home practice. DAlly NURSE brings policy into practice by facilitating education and coaching. The policy supports nursing staff in changing their behavior and managers spread information towards (in)formal caregivers. The coaches learn from each other and create awareness during the workshops. Nursing staff were satisfied with the workshops and the expert nursing who provided the workshops, and the attendance rate in the workshops was high. A few barriers were experienced, such as the reluctance of colleagues who did not attend the workshops. Recommendations for small adjustments about the content were provided by nursing staff to improve the feasibility of DAlly NURSE. 
DAlly NURSE is a complex nursing intervention according to the MRC Framework. ${ }^{34}$ It consists of interacting components and has different target groups including management, nursing (home) staff and nursing home residents. The MRC framework is a well-known framework that is most used to develop and evaluate complex interventions, provided by the Medical Research Council (MRC). The framework used consists of 4 phases; development, feasibility and piloting, evaluation, and implementation phase. ${ }^{34}$ Different steps were taken in the development phase of the MRC Framework, namely questionnaires, observations, literature review and focus group interview. The current study was part of the testing and piloting phase of the MRC framework. ${ }^{34}$ Feasibility studies do help to understand whether interventions can be implemented in practice and what should be adjusted to make the intervention (more) applicable. ${ }^{35}$ Attempting to tackle problems before the actual implementation is of major importance.

In the current study, the feasibility of DAlly NURSE was evaluated using the framework of Saunders et al. ${ }^{30}$ This framework provides insight into the process, and data on dose delivered and received, fidelity, reach and barriers were included. Several factors influence the process: each nursing home, staff member and resident is different; therefore, it is essential for nursing care practice to tailor the intervention to the context. Interventions will be most feasible if tailored to the context instead of being completely standardized, ${ }^{34}$ therefore, the content of the components of DAlly NURSE should be adaptable. For example, the discussions in the workshops are based on the most important barriers, as shown by the results of the MAINtAIN questionnaire, ${ }^{16}$ and provide input for the implementation plan, which should match the needs of nursing staff, and an awareness of residents' capabilities helps nursing staff to tailor their support. Furthermore, nursing home staff should work together, should use knowledge from different sources and disciples, and should take into account the context. ${ }^{36}$

Despite the differences in the testing of DAlly NURSE in the two nursing homes, the participants of both nursing homes agreed with the adjustments to make DAlly NURSE as feasible as possible in nursing care practice. The most important adjustment in the content of DAlly NURSE is the use of video observations of breakfast times during the workshops. Nursing staff in nursing home B experienced the videos as a positive feedback opportunity; reflection of own practice during a specific moment (breakfast) led to awareness and knowledge of their own behavior. ${ }^{37}$ Focusing on activities during mealtimes is essential in nursing homes, since mealtimes are the most important moments during the day for residents. ${ }^{38}$ Nursing staff can positively influence residents' quality of life by encouraging residents' autonomy and social interactions during mealtimes. ${ }^{38}$ Observations help nursing staff to create awareness of residents' daily activities and their own role in residents' dependency. ${ }^{12}$ In addition, the videos showed restlessness in the living room caused by the noise of the radio and machines, and by visits. Nursing staff of nursing home A, who did not use video observations, agreed in 
the focus group that videos would be of added value; therefore, the video observations of breakfast were added to the DAlly NURSE workshops, in addition to the capability list that is focused on ADL and IADL. In addition to the positive experiences of nursing staff with the video observations, these recordings could be used to evaluate the effectiveness of the intervention in future studies.

Although it is emphasized that remaining active is of major importance, interventions that actually focus on encouraging daily activity are scarce. ${ }^{39}$ Nevertheless, activity and mobility has been described as one of the fundamental care needs by nurse scientists, such as Henderson (1960) and Kitson et al. (2010). ${ }^{40,41}$ It is seen as one of the basic nursing care activities that is often undervalued by nursing staff and perceived as fulfilled. ${ }^{15}$ Fulfilling these basic care needs, such as encouraging and supporting mobility, enables a person's ability to interact with others and participate in their living environment. Therefore, optimizing opportunities for older residents to maintain independent mobility as long as possible and reducing inactivity is a key role of nursing staff. $^{40}$

This study has a few limitations. A small sample of psychogeriatric nursing home wards was included in this study. The two nursing homes implemented DAlly NURSE in two different ways. It would be preferable if both groups had the same experiences with and without video observations and both some of the team and the whole team were trained. However, here the differences could be discussed and consensus was reached during the focus group. The nursing home in which only the champions were part of the workshops, instead of the whole team of nursing staff, agreed to educate the whole team with workshops to prevent the resistance of colleagues. It remains unknown whether educating the whole team is most effective in supporting nursing staff to change their behavior towards encouraging residents' daily activities and independence. Another limitation is that coaching-on-the-job was hard to evaluate in this study, since the coaching should develop particularly in the period after the workshops, including reflection meetings for champions. Furthermore, not all elements of the framework were explicitly evaluated (recruitment and context). The management recruited the participants of the workshops and no contextual factors were identified during the study. Nevertheless, the data collected regarding the feasibility of the intervention provide enough useful information about the necessary adjustments to make DAlly NURSE feasible in nursing home practice.

DAlly NURSE was tested in nursing home practice, and finalized based on the recommendations of nursing home staff who have experiences with the intervention in nursing care practice. Both the development as well as the feasibility testing were conducted in close collaboration with nursing home staff to develop an intervention that is feasible in nursing home practice. ${ }^{42}$ This article described the feasibility and provided insight into the content of the components of DAlly NURSE. Most existing 
studies do not describe the details of the content of the intervention. This insight into the content as well as the feasibility of the intervention is needed to understand the possible effects of an intervention. ${ }^{43}$ Future studies will focus on the effectiveness of DAlly NURSE from the perspective of both the nursing staff and the residents.

\section{Conclusion}

DAlly NURSE is a feasible nursing intervention to encourage nursing home residents in their daily activities and independence. DAlly NURSE consists of three components: education; coaching-on-the-job, and; policy. Based on this feasibility study small adjustments were made to the content of these components to improve feasibility of DAlly NURSE.

\section{Relevance to clinical practice}

Nursing home residents are inactive, whereas it is well-known that remaining active is of major importance. Nursing staff providing care $24 / 7$ play an essential role in the activity levels of nursing home residents. Nursing interventions that actually focus on encouraging daily activity are scarce. DAlly NURSE is such a nursing intervention aiming to create awareness of the importance of residents' daily activities and the role of nursing staff in the dependency of nursing home residents. This intervention is feasible in nursing home practice, and might help nursing staff to change their behavior towards encouraging residents' daily activities and independence. 


\section{References}

1. den Ouden M, Bleijlevens, MHC Meijers, JMM et al. Daily (in)activities of nursing home residents in their wards: an observation study. J Am Med Dir Assoc. 2015;16:963-968.

2. van Alphen HJ, Volkers KM, Blankevoort CG, et al. Older adults with dementia are sedentary for most of the day. Plos One. 2016;11(3):e0152457.

3. Edvardsson D, Petersson L, Sjogren K, et al. Everyday activities for people with dementia in residential aged care: associations with person-centredness and quality of life. Int J Older People Nurs. 2014;9(4):269-276.

4. Lahmann NA, Tannen A, Kuntz S, et al. Mobility is the key! Trends and associations of common care problems in German long-term care facilities from 2008 to 2012. Int J Nurs Stud. 2015;52(1):167-174.

5. Volkers KM, Scherder EJ. Impoverished environment, cognition, aging and dementia. Rev Neurosciences. 2011;22(3):259-266

6. Weening-Dijksterhuis $\mathrm{E}$, de Greef $\mathrm{MH}$, Scherder EJ, et al. Frail institutionalized older persons: a comprehensive review on physical exercise, physical fitness, activities of daily living, and quality-of-life. Am J Phys Med Rehab. 2011;90(2):156-168.

7. Ikezoe $\mathrm{T}$, Asakawa $\mathrm{Y}$, Shima $\mathrm{H}$, et al. Daytime physical activity patterns and physical fitness in institutionalized elderly women: an exploratory study. Arch Gerontol Geriat. 2013;57(2):221-225

8. de Souto Barreto P, Morley JE, Chodzko-Zajko W, et al. Recommendations on physical activity and exercise for older adults living in long-term care facilities: a taskforce report. J Am Med Dir Assoc. 2016;17(5):381-392.

9. Kleynen M, Braun SM, van Vijven K, et al. The development of the MIBBO: a measure of resident preferences for physical activity in long term care settings. Geriatr Nurs. 2015;36(4):261-266.

10. Schüssler S, Dassen T, Lohrmann C. Care dependency and nursing care problems in nursing home residents with and without dementia: a cross-sectional study. Aging Clin Exp Res. 2014;28(5):973-982.

11. Franklin L-L, Ternestedt B-M, Nordenfelt L. Views on dignity of elderly nursing home residents. Nurs Ethics. 2006;13(2):130-146.

12. den Ouden M, Kuk NO, Zwakhalen SM, et al. The role of nursing staff in the activities of daily living of nursing home residents. Geriatr Nurs. 2016;38(3):225-230.

13. Tuinman A, de Greef MH, Krijnen WP, et al. Examining time use of Dutch nursing staff in long-term institutional care: a time-motion study. J Am Med Dir Assoc. 2016;17(2):148-154.

14. Edvardsson D, Sandman PO, Rasmussen B. Forecasting the ward climate: a study from a dementia care unit. J Clin Nurs. 2012;21(7-8):1136-1114.

15. Kuk NO, den Ouden M, Zijlstra GAR, et al. Do nursing staff encourage functional activity among nursing home residents? A cross-sectional study of nursing staff perceived behaviors and associated factors. BMC Geriatr. 2017;17(1):18.

16. Kuk NO, Zijlstra GAR, Bours GJJW, et al. Promoting functional activity among nursing home residents: a cross-sectional study on barriers experienced by nursing staff. J Aging Health. 2017:0898264316687407.

17. Resnick B, Petzer-Aboff I, Galik E, et al. Barriers and benefits to implementing a restorative care intervention in nursing homes. J Am Med Dir Assoc. 2008;9(2):102-108.

18. Blair CE. Effect of self-care ADLs on self-esteem of intact nursing home residents. Issues Ment Health Nurs. 1999;20:559-570.

19. Blair CE. Combining behavior management and mutual goal setting to reduce physical dependency in nursing home residents. Nurs Res. 1995;44:160-165.

20. Galik EM, Resnick B, Gruber-Baldini A, et al. Pilot testing of the restorative care intervention for the cognitively impaired. J Am Med Dir Assoc. 2008;9(7):516-522.

21. Morris JN, Fiatarone M, Kiely DK, et al. Nursing rehabilitation and exercise strategies in the nursing home. J Gerontol A-Biol. 1999;54:494-500.

22. Resnick B, Simpson M, Bercovitz $A$, et al. Pilot testing of the restorative care intervention: impact on residents. J Gerontol Nurs. 2006;32:39-47. 
23. Resnick B, Gruber-Baldini AL, Zimmerman S, et al. Nursing home resident outcomes from the Res-Care intervention. J Am Geriatr Soc. 2009;57(7):1156-1165.

24. Resnick B, Galik E, Gruber-Baldini A, et al. Testing the effect of function-focused care in assisted living. J Am Geriatr Soc. 2011;59(12):2233-2240.

25. Gulpers MJ, Bleijlevens $M H$, van Rossum E, et al. Belt restraint reduction in nursing homes: design of a quasi-experimental study. BMC Geriatr. 2010;10:11.

26. Gillespie LD, Gillespie WJ, Robertson MC, et al. Interventions for preventing falls in elderly people. Cochrane Db Syst Rev. 2003;(4):CD000340.

27. Huizing AR, Hamers JP, Gulpers MJ, et al. A cluster-randomized trial of an educational intervention to reduce the use of physical restraints with psychogeriatric nursing home residents. J Am Geriatr Soc. 2009;57(7):1139-1148.

28. Gulpers MJ, Bleijlevens MH, Ambergen $\mathrm{T}$, et al. Reduction of belt restraint use: long-term effects of the EXBELT intervention. J Am Geriatr Soc. 2013;61(1):107-112.

29. Verkaik R, Francke AL, van Meijel B, et al. The introduction of a nursing guideline on depression at psychogeriatric nursing home wards: effects on Certified Nurse Assistants. Int J Nurs Stud. 2011;48(6):710-719.

30. Saunders RP, Evans MH, Joshi P. Developing a process-evaluation plan for assessing health promotion program implementation: a how-to guide. Health Promot Pract. 2005;6(2):134-147.

31. de Haan R, Limburg M, Schuling J, et al. Clinimetric evaluation of the Barthel Index, a measure of limitations in daily activities [in Dutch]. Ned Tijdschr Geneeskd. 1993;137:917-921.

32. Morris JN, Fries BE, Mehr DR, et al. MDS Cognitive Performance Scale. J Gerontol. 1994;49:M174-M182.

33. Kuk NO, Zijlstra GAR, Bours GJJW, Hamers JPH, Kempen GIJM. Development and usability of the MAINtAIN, an inventory assessing nursing staff behavior to optimize and maintain functional activity among nursing home residents: a mixed-methods approach. BMC Health Serv Res. 2016;16:38.

34. Craig P, Dieppe P, Macintyre S, et al. Developing and evaluating complex interventions: the new Medical Research Council guidance. BMJ. 2008;337:a1655.

35. Bowen DJ, Kreuter M, Spring B, et al. How we design feasibility studies. Am J Prev Med. 2009;36(5):452-457.

36. Raad voor Volksgezondheid en Samenleving. Zonder context geen bewijs. Over de illusie van evidencebased practice in de zorg. 2017.

37. Hansebo G, Kihlgren M. Carers' reflections about their video-recorded interactions with patients suffering from severe dementia. J Clin Nurs. 2001;10(6):737-747.

38. Watkins R, Goodwin VA, Abbott RA, et al. Exploring residents' experiences of mealtimes in care homes: a qualitative interview study. BMC Geriatr. 2017;17(1):141.

39. Resnick B, Galik E, Boltz M. Function focused care approaches: literature review of progress and future possibilities. J Am Med Dir Assoc. 2013;14(5):313-318.

40. Henderson V. Basic principles of nursing care. Geneva: International Council of Nurses. 1960.

41. Kitson A, Conroy $T$, Wengstrom $Y$, et al. Defining the fundamentals of care. Int J Nurs Pract. 2010;16(4):423-434.

42. Power TJ, Blom-Hoffman J, Clarke AT, et al. Reconceptualizing intervention integrity: a partnership-based framework for linking research with practice. Psychol Schools. 2005;42(5):495-507.

43. Blankevoort CG, van Heuvelen MJ, Boersma F, et al. Review of effects of physical activity on strength, balance, mobility and ADL performance in elderly subjects with dementia. Dement Geriatr Cogn. 2010;30(5):392-402. 



\section{CHAPTER 6}

Encouraging the daily activities and independence of nursing home residents, the impact of nursing intervention DAlly NURSE: a quasi-experimental study

This chapter was submitted for publication as:

den Ouden M, Meijers JMM, Bleijlevens MHC, Zwakhalen SMG, de Vries E, Tan FES, Hamers JPH. Encouraging the daily activities and independence of nursing home residents, the impact of nursing intervention DAlly NURSE: a quasi-experimental study. 
CHAPTER 7

General discussion

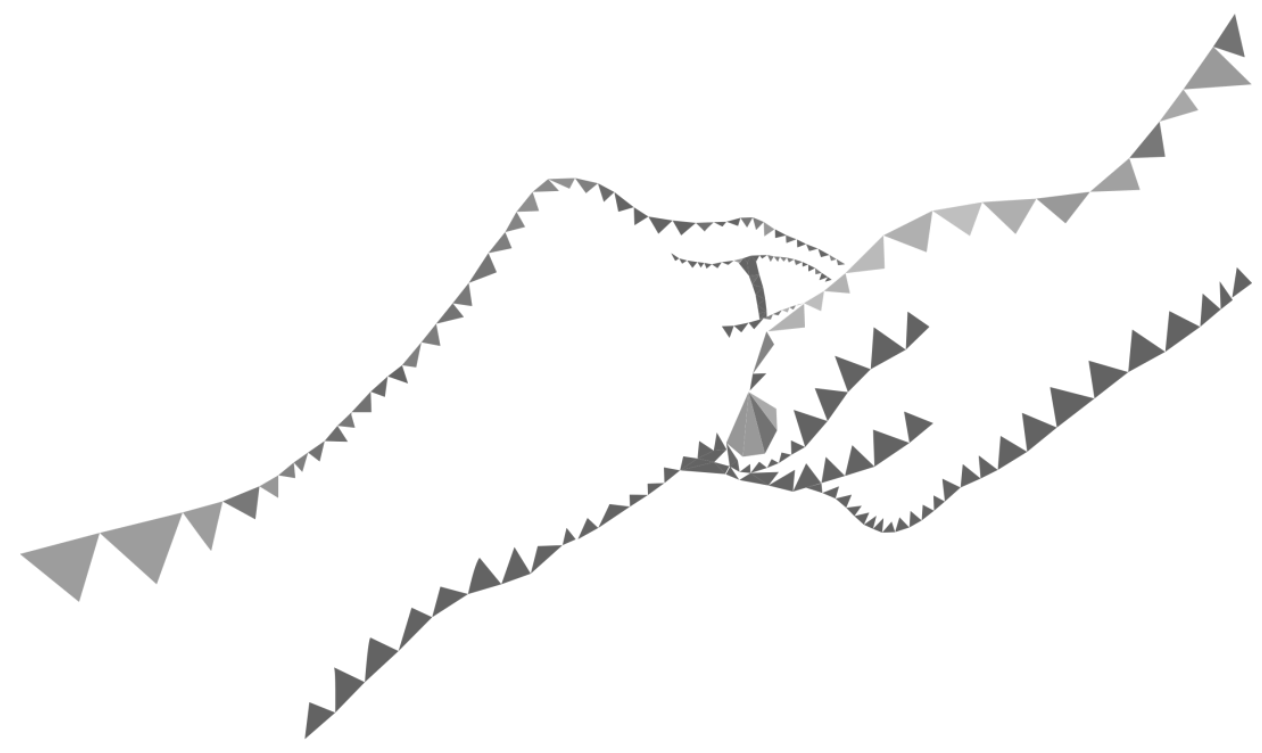



The overall objective of this dissertation was to develop a nursing intervention to change nursing behavior in encouraging the daily activities and independence of nursing home residents, and to evaluate the impact of this nursing intervention on both nursing staff and residents. In the view of this objective, this dissertation purposed:

1. to provide insight into the daily activities of nursing home residents;

2. to provide insight into the role of nursing staff in the daily activities of nursing home residents;

3. to provide insight into the extent to which nursing staff in the Netherlands perceive to encourage the activities of residents;

4. to develop and test a feasible nursing intervention to change nursing staff behavior towards encouraging nursing home residents in their daily activities and independence;

5. to evaluate the impact of this nursing intervention on both nursing staff behavior and the daily activities and independence of nursing home residents.

In this final chapter, the main findings of this dissertation will be summarized and discussed. There is critical reflection on some methodological and theoretical considerations. This chapter ends with the implications of the findings for research and practice.

\section{Main findings}

Nursing home residents were mainly inactive, spending the day on their ward in a sedentary position, watching TV, sleeping or doing nothing. Nursing home residents were rarely engaged in IADL activities. Insight into the role of nursing staff in residents' daily activities (ADL and IADL) showed that nursing staff took over almost half of these activities. According to the nurses who conducted the observations on their own ward many activities were taken over unnecessarily by nursing staff. In contrast with these findings, nursing staff perceived themselves as encouraging residents to perform ADL activities often, although, household activities were perceived as less often encouraged.

The nursing intervention DAlly NURSE was developed based on both these findings and a literature search, in close collaboration with nursing home professionals. DAlly NURSE is an acronym for Daily Activities and Independence by NURsing Staff Encouragement. It aims to change nursing behavior towards encouraging the activities and independence of nursing home residents, by creating awareness of nursing behavior. DAlly NURSE consists of the components education, coaching-on-the-job, and policy. The feasibility study showed that DAlly NURSE was feasible in nursing home practice according to the satisfied nursing home staff. Evaluation of the impact showed that although DAlly 
NURSE increased the engagement of nursing home residents in daily activities during breakfast and the context of the breakfast period, it did not affect the dependency levels of nursing home residents. Although no change was observed in the role of nursing staff, nursing staff perceived to encourage ADL and household activities more often after the intervention.

\section{Methodological considerations}

Methodological considerations regarding this dissertation will be discussed in this section. These considerations concern the complexity of research in the nursing home setting, the measurement of physical activity among nursing home residents, and the measurement of nursing behavior according to the encouragement of resident activities and independence.

\section{Complexity of research in the nursing home setting}

Developing, evaluating and implementing evidence-based interventions in the nursing home setting is challenging. The nursing home population is complex since residents are frail and suffer from heterogeneous health problems and multi-morbidities. ${ }^{1}$ Due to the ageing in place policy changes older adults live at home as long as possible and when admitted to a nursing home, nursing staff provide highly demanding complex care. ${ }^{2}$ Nursing staff are expected to focus on complex care cases, use technical innovations (such as electronic monitoring systems), work interdisciplinarily, should deliver personcentered care, and focus on the increasing expectations of the residents and their informal caregivers, but the educational levels of nursing staff are generally low in the nursing home setting. ${ }^{3}$ These factors of complex care demands, provided by lowereducated nursing staff with the involvement of informal caregivers, make nursing homes a complex setting to conduct research.

Interventions should be tailored to the daily care practice of this complex setting, and therefore interventions in these settings consist of different but related components (multifactorial), different target groups and several outcomes, which make the interventions complex according to the MRC framework. ${ }^{4}$ The context affects the implementation of interventions, and also affected the results of this study. Interventions are most effective if they can be tailored to the context of the setting rather than being completely standardized..$^{4-6}$ Tailoring to the context helps to address specific barriers and support the implementation of the intervention specified for that situation. ${ }^{7}$ When tailoring is in practice, interventions are more feasible and more likely to be implemented in the nursing home practice. Nevertheless, tailoring makes it harder to measure the effectiveness of interventions when compared to entirely 
standardized interventions. Evaluating an intervention should be undertaken with both quantitative outcomes, to measure changes over time, and qualitative outcomes to describe the context. To obtain insight into the implementation of the intervention, possible success factors of the intervention, and to understand the relationship between the elements of the intervention and the outcomes, a process evaluation could unravel the black box. ${ }^{8}$

DAlly NURSE was developed in the complex nursing home setting. Nursing home staff were involved in the development of the intervention to tailor DAlly NURSE into daily care practice and to make the intervention as feasible as possible. DAlly NURSE was tested as to its feasibility in daily care practice according to the process evaluation of Saunders et al. ${ }^{8}$ and adjustments were made to the content of the components of DAlly NURSE based on the recommendations of nursing staff. DAlly NURSE is a complex intervention $^{4}$ : it consists of three related components (education, coaching-on-the-job and policy), it targets different groups (care organization, nursing home staff, and residents) and has a number of outcomes (nursing behavior, resident activities and resident independence). DAlly NURSE considers the context (using the MAINtAINquestionnaire to obtain insight into perceived behavior and barriers), and uses different strategies based on the barriers nursing staff experience to tailor the implementation plan to the context. ${ }^{9,10}$ In order to tailor the intervention to the setting, DAlly NURSE should be implemented by the nursing home staff of the care organization, for example the expert nurse providing workshops should be employed in the organization. DAlly NURSE was tested in a quasi-experimental study using both quantitative and qualitative outcome measures to obtain insight into changes over time as well as contextual factors.

\section{Measuring physical activity of nursing home residents}

Physical activity includes all movements made, from chewing to running, and it is thus difficult to measure all aspects of physical activity. ${ }^{11}$ This dissertation focused on the daily activities of nursing home residents since these activities contribute to the maintenance of functioning and quality of life. ${ }^{12-17}$ Different instruments can be used to measure this; observations, questionnaires (diaries), or accelerometers. ${ }^{11,18}$ In this dissertation a variety of instruments were used to measure the physical activity levels of residents. (A combination of) measurement instrument(s) should be chosen, depending on the aim of the study, and taking into consideration the population, type of data, contextual factors, time and costs, and limitations of the instruments. ${ }^{19}$

Observations in the context of this dissertation obtain detailed insight into the physical activity of nursing home residents, since they provide information about the kind of daily activity in which residents were engaged. Observations can be conducted directly in real time by an independent observer in the same room as the study participant, or 
by using videos recordings of specific periods and conducting indirect observations afterwards using an independent observer. When measuring physical activity, you can follow a resident over time, or you can choose to take 'snapshots' during the day or during a specific period, depending on the aim of your study. In this dissertation, real time observations were used to obtain insight into the daily (in)activities of nursing home residents during the day (Chapter 2), and video recordings were used to observe the impact of DAlly NURSE on the daily activities and dependency levels of the residents during breakfast in the living room (Chapter 6). The advantages of video recording were the ability to observe more than one resident at the same time, and to observe interactions and the context. The observers could also be blinded, and the videos could be used for input in the workshops. The main disadvantage of real time and videorecorded observation is it that they are time consuming. The possible influence of the observer or the camera on the physical activity of the residents should be taken into account, $^{18}$ however, the effect of cameras might be smaller since the cameras were placed on cupboards and were often not seen or easily forgotten after a while.

Questionnaires can be used to subjectively measure different aspects of physical activity, such as type of activities, duration and intensity. Questionnaires (self-reported or filled in by proxies) are practical and well accepted instruments with low cost, however, within the study population of nursing home residents, self-reported questionnaires and diaries are difficult for both the residents to use themselves (e.g. due to cognitive impairment), and also for proxies such as nursing staff, who might forget to complete the diaries for residents due to the high workload that nursing staff experience and the various tasks they have. ${ }^{20,21}$ The problem with questionnaires, and with diaries in particular, is recall bias; it is difficult to remember low levels of physical activity with precision, and these are the most common in nursing home residents. Questionnaires are also often not sensitive enough for low levels of activity (such as walking or daily activities) and the validation of questionnaires is inconsistent, which makes it difficult to interpret the results. ${ }^{22}$ In this dissertation, the Barthel Index ${ }^{23}$ was used as a secondary outcome to measure the physical functioning of the nursing home residents. The questionnaire consists of 10 activities divided into 2-4 robust categories of independency. This questionnaire is commonly used and validated in different populations; however, it is not sensitive to small changes in dependency in specific daily activities. Small changes in daily activities are expected as a result of DAlly NURSE in this frail nursing home population whose functioning is deteriorating. For example, in the Barthel Index feeding is divided into: 'unable', 'needs help' or 'independent'. Observations by video recording were used so as to detect small changes. Nuances in breakfast activities could thus be detected, for example in the observations feeding was divided into: taking bread, taking spreads, preparing a sandwich, cutting bread, bringing food to the mouth, pouring drinks, pouring sugar/milk in drink, stirring drink, picking up 
cup/glass, bringing cup/glass to the mouth). Video observations were therefore used as a primary outcome.

Accelerometers are wearable devices that measure real-time accelerations in different axes, these accelerations are translated in activity intensities and sedentary time can be calculated, based on the cut-off points that are chosen. ${ }^{24,25}$ Accelerometers are mostly used to measure physical activity, ${ }^{18}$ although they do not measure the type of activity or the context. $^{25}$ Nowadays, a variety of validated accelerometers are available. ${ }^{25}$ Accelerometers were used preferentially in the studies for this dissertation, however, they are often validated with healthy young study populations, and these results may, therefore, not be translatable to study populations such as nursing home residents with extremely low activity levels. ${ }^{25}$ As long as accelerometers have a limited reliability and validity in frail populations, ${ }^{25}$ they are not recommended for future studies to measure physical activity.

The results of studies focusing on physical activity are often hindered by the limitations of the measurement instruments (such as reliance or the inability to measure type of activity), ${ }^{26}$ especially when focusing on low levels of physical activity in frail populations. Observations are recommended for the measurement of the daily activities of nursing home residents in future studies, as they exceed other instruments (accelerometers and questionnaires) in providing quantitative as well as contextual information (qualitative). ${ }^{18}$ Observations using video recordings can also not only be used to obtain insight into activity levels, but are also useful for interventions that create awareness of physical activity behavior.

\section{Measuring nursing behavior towards encouraging nursing home residents in daily activities and independence}

In this dissertation, nursing behavior was focused on the extent to which nursing staff encourage residents in their daily activities and independence. This behavior was measured with observations and/or questionnaires. It is important to choose the instrument(s) with which to measure nursing staff behavior based on the aim of the study and to consider the (dis)advantages of the instruments.

Observations provide insight into nursing behavior, in real time or using video recordings. In this dissertation, nursing behavior was observed in real time to obtain insights into the role of nursing staff in the daily activities of the residents (Chapter 3 ) and video recordings were used to observe the impact of DAlly NURSE on nursing behavior during the breakfast activities of residents (Chapter 6). This study focused on the role of nursing staff in relation to the breakfast activities of the residents and the interaction with residents in these activities; therefore, nursing staff were observed when they were involved in these daily activities of the residents, instead of following 
nursing staff during the day. A possible disadvantage of observations is social desirability, for example, nursing staff could encourage residents more often when they know they are observed (in real time or with cameras). It is also time consuming to observe a large group of nursing staff, and if you want to follow nursing staff over time you must take into account their working shifts. An advantage of observations and especially of observations using video recordings is that the videos could be used in the DAlly NURSE - workshops. During the workshops nursing staff watched their own behavior in encouraging nursing home residents, which led to an awareness of their actual behavior, according to the nursing staff. The first step to change nursing behavior is to create awareness. ${ }^{27}$ Another advantage of video-recorded observations is that these provide contextual information. For example, changes in the role of nursing staff were not detected with quantitative measures, however, contextual information about the ambiance in the living rooms and nursing staff providing feedback to each other about resident activities and independence could be observed in the videos. These changes in ambiance during mealtimes could influence the physical performance of residents $^{28}$ and their quality of life. ${ }^{28,29}$

Questionnaires can measure the perceived behavior of nursing staff on a large scale. In this dissertation the MAINtAIN-behaviors questionnaire ${ }^{9}$ was used in a nationwide study (Chapter 4). This questionnaire was developed especially to measure the perceived behavior of nursing staff towards maintaining and optimizing functional activity in nursing home residents. ${ }^{9}$ A possible disadvantage of questionnaires is social desirability; nursing staff might give a more positive answer about their perceived behavior which could affect the validity of the results. ${ }^{30,31}$ Since social desirability is more likely to occur when questions are about people's own competences, ${ }^{31}$ nursing staff were asked in the MAINtAIN-behaviors about the nursing behavior on their ward instead of their own behavior. A previous study showed the usability and content validity of the MAINtAIN, however, the psychometric properties (such as construct validity and sensitivity to change) of this questionnaire should be investigated in future studies. ${ }^{9}$ The results of the study on the impact of DAlly NURSE showed that this questionnaire is sensitive to changes, as the intervention group did demonstrate changes over time, and the control group did not change over time.

Comparing the different instruments, observations such as those as used in Chapter 3 and questionnaires such as those used in Chapter 4, we noticed a difference in what nursing staff perceive they do (in the questionnaires) and what they actually do (observed). This discrepancy was also seen in a study on hand hygiene, where people perceived that their hand hygiene was much better than observed. ${ }^{32}$ Observations provide a more realistic insight into nursing behavior and are therefore recommended in future studies. Nursing behavior also depends on the context, therefore, it is important to measure not only the behavior itself but also to take into account the context, which could be observed as well. In addition to the observations, MAINtAIN- 
behaviors can be used to measure the perceived behavior of nursing staff and to tailor interventions.

\section{Theoretical considerations}

DAlly NURSE focusses on changing nursing behavior towards encouraging the daily activities and independence of nursing home residents. It was expected that nursing staff behavior would change towards providing more support in resident activities and taking over fewer activities, however, the observed role of nursing staff did not change. It was also expected that nursing home residents would be more engaged in daily activities and perform more activities independently. DAlly NURSE improved the engagement of nursing home residents in daily activities during breakfast; however, no improvement was observed in residents' dependency. How can this be explained?

Nursing home residents require an increasing amount of support in their daily activities, due to their decline in physical functioning and cognition. ${ }^{33}$ The complex health problems of the residents require the nursing staff to have an awareness of the capabilities of the residents in performing activities and the consequences of their behavior on resident activities and dependency levels. ${ }^{10}$ Nursing home residents are still able to perform daily activities independently or with some support, especially when they enter the nursing home. ${ }^{34}$ Newly admitted residents performed many daily activities at home before admission during the day, such as making coffee, preparing breakfast and collecting the newspaper from their mailbox. When they enter the nursing home, these activities are mostly performed for them, which could easily lead to greater decline in functioning, to higher care dependency and to decline in quality of life. ${ }^{13}$ Newly admitted residents quickly become used to prepared sandwiches and dinner, a table that is set for them, transfers in wheelchairs, coffee and tea including sugar and milk stirred served, etc. When residents are used to care in which activities are performed for them, it will be hard to change that, and to encourage them to perform activities themselves. ${ }^{35}$ Nursing home residents should be encouraged in the continuation of activities and independence right from the point of admission. ${ }^{34}$ Even before admission, nursing staff can make home visits to obtain insights into a resident's daily activities and independence, and maintain these activities after admission for as long as possible. Daily activities are essential in order to increase physical activity levels and reduce sedentary time among nursing home residents, ${ }^{12}$ and these daily activities especially contribute to physical functioning and quality of life. ${ }^{13-17,36}$ Nursing home residents are able to learn despite cognitive problems ${ }^{37}$ and are able to increase their muscle strength despite functional decline. ${ }^{38}$ The 'use it or lose it' principle is also applicable to nursing home residents, including those with Alzheimer's disease. ${ }^{39}$ 
It is the role of nursing staff to maintain resident activities and independence for as long as possible, according to the definition of nursing by Henderson. ${ }^{40}$ It is expected that nursing staff encourage residents with pleasure and motivation, provide accurate support during their activities, and take into account the preferences of the residents. ${ }^{12}$ It remains difficult to encourage resident activities and independence since nursing staff are inclined to take over resident activities. ${ }^{41}$ They are trained to care for and do things for other people. Nursing staff are also task-oriented, have care routines, and experience different barriers, such as the lack of staff, time and resources, which stimulates them to take over resident activities. ${ }^{10,20,42}$ Despite these barriers, nursing staff became aware of the context in which nursing home residents had their breakfast, and made changes in this context that provided residents with the opportunity to engage in breakfast activities (such as improving mealtime ambiance by setting the table). Mealtimes are important periods during the day, since residents can perform daily activities, make their own choices during these periods, and socialize with other residents and nursing staff. ${ }^{28,29,43}$ It is therefore essential for nursing staff to encourage the residents during mealtimes. There is a lot of creativity and knowledge within the nursing staff teams, and therefore they should have the opportunity to search for their own tailored solutions to encourage nursing home residents. Looking at possibilities instead of the impossibilities offers nursing staff the opportunity to change things with the same resources and the same nursing staff.

Encouraging daily activities and independence by nursing staff also depends on the context and the care organization. The social context is important for nursing staff in the encouragement of residents. ${ }^{10}$ A setting can be encouraging (e.g. set tables and nursing staff eating together with residents) as well as distracting (e.g. nursing staff running around, ward visits and noise from devices). The video recordings facilitated the reflection and discussion context, such as the ambiance during breakfast and how tables are set (including changes over time). This reflection is not only important in interventions focusing on physical activity, but can also be used in interventions for, for example, communication. Further, the policy of the care organization can facilitate changes in nursing behavior. Nursing home management should therefore support change by supporting nursing staff as regards their time and needs so as to change their behavior, and with policy that underlines the importance of residents' daily activities and independence. Informal caregivers should be informed and involved in the encouragement of a resident's daily activities and independence. It is expected that care organizations will follow the ongoing shifts in the care culture from the medical model to the social model, focusing on residents' well-being, capabilities, autonomy and quality of life. ${ }^{44,45}$ Care organizations are also expected to implement the Dutch Quality Improvement Framework for Nursing Home Care, ${ }^{46}$ which aims, among other things, to contribute to residents' quality of life by encouraging them in meaningful daily activities 
and providing person-centered care. DAlly NURSE translates policy into practice through education and coaching, and therefore, fits into these changes and expectations.

\section{Implications}

The findings of this dissertation have implications for research and practice, as discussed in this section.

\section{Research}

In this dissertation DAlly NURSE was developed and tested aiming to change nursing behavior towards encouraging the daily activities and independence of nursing home residents. The period of breakfast was first chosen to create awareness and to evaluate the impact of DAlly NURSE. No video recordings were made of other mealtimes or other periods during the day, and so it is not known whether nursing behavior changed in encouraging nursing home residents at other points of the day. Future studies should investigate whether or not the role of nursing staff changes, and whether or not residents are more engaged during lunch and dinner or other periods of the day.

Another point of interest is to investigate the impact of DAlly NURSE on newly admitted residents. It is expected that nursing home residents perform daily activities at home before they enter the nursing home. A quasi-experimental study can investigate whether newly admitted residents are able to maintain these daily activities. In order to do this, the activity and dependency level of the residents should be studied in the home situation and monitored after nursing home admission. This will provide insight into any functional decline in residents after admission.

To evaluate interventions such as DAlly NURSE, not only should quantitative measures be used, but qualitative measures should be used to describe the possible changes in the context and the experiences of nursing home staff. A process evaluation would provide insight into the implementation of DAlly NURSE in nursing home practice. Aspects of the process evaluation should include: the extent to which the education, coaching-on-the-job and policy components are delivered (dose delivered) and implemented as planned (fidelity), satisfaction of nursing home staff (dose received), experienced barriers (barriers), and the proportion of the target population which receive the intervention (reach).

Based on previous studies, it was assumed that daily activities contribute to the maintenance of physical functioning and a higher quality of life, and that exercise would also be beneficial, but is too intensive for a frail nursing home population, and this was not investigated in this dissertation. A trail could be conducted with different groups 
(DAlly NURSE, exercise, DAlly NURSE combined exercise, control) to compare the differences between the types of physical activity and their benefits on the daily activities and functioning of residents.

\section{Practice}

The findings of this dissertation showed that nursing home residents are mainly inactive during the day, spending the day sedentarily, and that IADL activities in particular are rarely observed in nursing home wards. Nursing staff should enhance resident activity levels by encouraging daily activities such as setting the table, preparing sandwiches, pouring drinks and watering plants. To encourage nursing home residents during the day, it is essential to take into account the activity preferences of the residents.

When starting to change nursing behavior, an awareness of own behavior is the first step. Nursing homes should start with video recordings of one period during the day (for example breakfast) so as to create awareness. Guidelines for the intervention and detailed content of the workshops will be made available. Expert nurses should use these guidelines to implement DAlly NURSE within their care organization. In addition to nursing staff, other nursing home professionals should also be involved in the intervention; for example, an occupational therapist could provide information during a workshop, or physiotherapy could be given in the living room or in the corridors of the ward instead of bringing residents to exercise rooms. Nursing home management should support (new) nursing staff in changing their behavior towards encouraging the daily activities and independence of residents, for example by relaxing rules about having meals, or coffee and tea at a certain time, so that nursing staff have the opportunity to encourage residents at these times. There should be a policy of encouraging physical activity, and it is essential to spread this policy widely within the organization in order to support nursing home staff. In addition to the formal caregivers, informal caregivers should be involved so as to create an environment in which nursing home residents are encouraged to maintain their daily activities for as long and as independently as possible, right from the point of nursing home admission, or even before admission, through a home visit from nursing staff on the ward to obtain insight into a resident's daily activities and independence, and to discuss expectations about a resident's daily activities and independence. Informal caregivers should be informed and should also be aware of the effect of their behavior on the activities and independence of the residents. 
Research line: 'Nurses on the Move: towards high-quality care in nursing homes'

This dissertation was part of the research line 'Nurses on the move: towards high quality care in nursing homes', aiming to contribute to the improvement of quality of care in general, and, more specifically, to the improvement of functional status and the reduction of disability among nursing home residents. The results of the dissertations within this research line show that quality of care is not related to the number of nursing staff on the ward, and instead team climate is an important factor in quality of care. Nursing staff behavior seems to be important for quality of care. Baccalaureateregistered nurses are often not employed in nursing homes, and to increase the number of baccalaureate-registered nurses, a care organization needs a clear vision of nursing home managers and directors. These nurses can then be involved in implementing person-centered care and interventions such as DAlly NURSE. Nursing staff perceive themselves as encouraging residents' daily activities however it remains questionable whether or not they actually encourage the residents. To remove the barriers that nursing staff experience in encouraging nursing home residents, those most related to the encouragement of the residents should be taken into account instead of the most mentioned barriers. The TIP-toolbox is a feasible method for guiding nursing staff in six steps to a structured and tailored implementation plan. This toolbox is also used in the nursing intervention DAlly NURSE, so as to decrease the large amount of inactivity in nursing home wards by creating awareness among nursing staff and changing nursing behavior towards encouraging the daily activities and independence of nursing home residents. 


\section{References}

1. Schols JM, Crebolder HF, van Weel C. Nursing home and nursing home physician: the Dutch experience. J Am Med Dir Assoc. 2004;5:207-212.

2. Verbeek H, Zwakhalen SMG, Schols JMGA, Hamers JPH. Keys to successfully embedding scientific research in nursing homes: a win-win perspective. J Am Med Dir Assoc. 2013;14:855-857.

3. Backhaus $R$, Verbeek $H$, van Rossum $E$, et al. Future distinguishing competencies of baccalaureateeducated registered nurses in nursing homes. Geriatr Nurs. 2015;36(6):438-444.

4. Craig P, Dieppe $P$, Macintyre S, et al. Developing and evaluating complex interventions: the new Medical Research Council guidance. BMJ. 2008;337:a1655.

5. Campbell MJ, Donner A, Klar N. Developments in cluster randomized trials and statistics in medicine. Stat Med. 2007;26(1):2-19.

6. Raad voor Volksgezondheid en Samenleving. Zonder context geen bewijs. Over de illusie van evidencebased practice in de zorg. 2017.

7. Grol R, Wensing M. What drives change? Barriers to and incentives for achieving evidence-based practice. Med J Aust. 2004;180(6 Suppl):S57-60.

8. Saunders RP, Evans MH, Joshi P. Developing a process-evaluation plan for assessing health promotion program implementation: a how-to guide. Health Promot Pract. 2005;6(2):134-147.

9. Kuk NO, Zijlstra GAR, Bours GJJW, Hamers JPH, Kempen GIJM. Development and usability of the MAINtAIN, an inventory assessing nursing staff behavior to optimize and maintain functional activity among nursing home residents: a mixed-methods approach. BMC Health Serv Res. 2016;16:38.

10. Kuk NO, Zijlstra GAR, Bours GJJW, et al. Promoting functional activity among nursing home residents: a cross-sectional study on barriers experienced by nursing staff. J Aging Health. 2017:0898264316687407.

11. Plasqui G, Westerterp KR. Physical activity assessment with accelerometers: an evaluation against doubly labeled water. Obesity. 2007;15(10):2371-2379.

12. de Souto Barreto P, Morley JE, Chodzko-Zajko W, et al. Recommendations on physical activity and exercise for older adults living in long-term care facilities: a taskforce report. J Am Med Dir Assoc. 2016;17(5):381-392.

13. Edvardsson D, Petersson L, Sjogren K, et al. Everyday activities for people with dementia in residential aged care: associations with person-centredness and quality of life. Int J Older People Nurs. 2014;9:269-276.

14. Gronstedt H, Frandin K, Bergland A, et al. Effects of individually tailored physical and daily activities in nursing home residents on activities of daily living, physical performance and physical activity level: a randomized controlled trial. Gerontology. 2013;59:220-229.

15. Xue QL, Bandeen-Roche K, Mielenz TJ, et al. Patterns of 12-year change in physical activity levels in community-dwelling older women: can modest levels of physical activity help older women live longer? Am J Epidemiol. 2012;176:534-543.

16. Andersen CK, Wittrup-Jensen KU, Lolk A, Andersen K, Kragh-Sorensen P. Ability to perform activities of daily living is the main factor affecting quality of life in patients with dementia. Health Qual Life Out. 2004;2:52.

17. Chan C, Slaughter S, Jones C, Wagg A. Greater independence in activities of daily living is associated with higher health-related quality of life scores in nursing home residents with dementia. Healthcare. 2015;3:503-518.

18. Westerterp KR. Assessment of physical activity: a critical appraisal. Eur J Appl Physiol. 2009;105(6):823-828.

19. Tudor-Locke CE, Myers AM. Challenges and opportunities for measuring physical activity in sedentary adults. Sports Med. 2001;31:91-100.

20. Kieft RA, de Brouwer BB, Francke AL, Delnoij DM. How nurses and their work environment affect patient experiences of the quality of care: a qualitative study. BMC Health Serv Res. 2014;14:249.

21. Munyisia EN, Yu P, Hailey D. How nursing staff spend their time on activities in a nursing home: an observational study. J Adv Nurs. 2011;67:1908-1917.

22. Sylvia LG, Bernstein EE, Hubbard JL, et al. Practical guide to measuring physical activity. J Acad Nutr Diet. 2014;114(2):199-208.

23. de Haan R, Limburg M, Schuling J, et al. Clinimetric evaluation of the Barthel Index, a measure of limitations in daily activities [in Dutch]. Ned Tijdschr Geneeskd. 1993;137:917-921. 
24. Aguilar-Farias N, Brown WJ, Peeters GM. ActiGraph GT3X+ cut-points for identifying sedentary behaviour in older adults in free-living environments. J Sci Med Sport. $2014 ; 17(3): 293-299$.

25. Schrack JA, Cooper R, Koster A, et al. Assessing daily physical activity in older adults: unraveling the complexity of monitors, measures, and methods. J Gerontol A Biol Sci Med Sci. 2016;71(8):1039-1048.

26. Prince SA, Adamo KB, Hamel ME, et al. A comparison of direct versus self-report measures for assessing physical activity in adults: a systematic review. Int J Behav Nutr Phys Act. 2008;5:56.

27. Elwyn G, Marrin K, Frosch D, et al. Sustainable change sequence: a framework for developing behavior change interventions for patients with long-term conditions. Eur J Pers Cent Healthc. 2014;2:212-216.

28. Nijs KA, de Graaf C, Kok FJ, et al. Effect of family style mealtimes on quality of life, physical performance, and body weight of nursing home residents: cluster randomised controlled trial. BMJ. 2006;332(7551):1180-1184.

29. Nijs K, de Graaf C, van Staveren WA, et al. Malnutrition and mealtime ambiance in nursing homes. J Am Med Dir Assoc. 2009;10(4):226-229.

30. Abernethy M. Self-reports and observer reports as data generation methods: an assessment of issues of both methods. Univers J Psychol. 2015;3(1):22-27.

31. Van de Mortel TF. Faking it: social desirability response bias in self-report research. Aust J Adv Nurs. 2008;25(4):40.

32. Jenner EA, Fletcher B, Watson $P$, et al. Discrepancy between self-reported and observed hand hygiene behaviour in healthcare professionals. J Hosp Infect. 2006;63(4):418-422.

33. Giebel CM, Sutcliffe C, Challis D. Activities of daily living and quality of life across different stages of dementia: a UK study. Aging Ment Health. 2015;19(1):63-71.

34. Ang YH, Au SY, Yap LK, et al. Functional decline of the elderly in a nursing home. Singapore Med J. 2006;47(3):219-224.

35. Resnick B, Petzer-Aboff I, Galik E, et al. Barriers and benefits to implementing a restorative care intervention in nursing homes. J Am Med Dir Assoc. 2008;9(2):102-108.

36. Ikezoe T, Asakawa $\mathrm{Y}$, Shima $\mathrm{H}$, et al. Daytime physical activity patterns and physical fitness in institutionalized elderly women: an exploratory study. Arch Gerontol Geriat. 2013;57:221-225.

37. Hopper TL. "They're just going to get worse anyway": perspectives on rehabilitation for nursing home residents with dementia. J Commun Disord. 2003;36(5):345-359.

38. Fiatarone MA, O'Neill EF, Ryan ND, et al. Exercise training and nutritional supplementation for physical frailty in very elderly people. N Engl J Med. 1994;330(25):1769-1775.

39. Swaab DF, Dubelaar EJ, Hofman MA, et al. Brain aging and Alzheimer's disease; use it or lose it. Prog Brain Res. 2002;138:343-373.

40. Henderson V. Basic principles of nursing care. Geneva: International Council of Nurses. 1960.

41. Brown D, McWilliam C, Ward-Griffin C. Client-centred empowering partnering in nursing. J Adv Nurs. 2006;53:160-168.

42. Tuinman A, de Greef MH, Krijnen WP, et al. Examining time use of Dutch nursing staff in long-term institutional care: a time-motion study. J Am Med Dir Assoc. 2016;17(2):148-154.

43. Watkins R, Goodwin VA, Abbott RA, et al. Exploring residents' experiences of mealtimes in care homes: a qualitative interview study. BMC Geriatr. 2017;17(1):141.

44. Edvardsson D, Fetherstonhaugh D, Nay R. Promoting a continuation of self and normality: person-centred care as described by people with dementia, their family members and aged care staff. J Clin Nurs. 2010;19:2611-2618.

45. Eliopoulos C. Guest Editorial: cultural transformation in nursing homes. Int J Older People Nurs. 2010;5(1):1-2.

46. Zorginstituut Nederland. Kwaliteitskader $\quad 2017$.

https://www.zorginstituutnederland.nl/publicaties/publicatie/2017/01/13/kwaliteitskader-

verpleeghuiszorg. 

SUMMARY 
Nursing home residents are largely inactive during the day, even though it is known that physical activity and participation in daily activities have a positive influence on physical functioning and quality of life. Nursing staff who provide care 24/7 in the direct environment of nursing home residents play a key role in the daily life of those residents, and therefore, in their daily activities and independence. The aim of this dissertation is to develop and evaluate a nursing intervention to encourage nursing home residents in daily activities and independence.

Chapter 1, the general introduction of this dissertation, describes the importance of physical activity and especially the importance of daily activities for nursing home residents. It introduces the role of nursing staff in the daily activities of nursing home residents and their independence. This chapter specifies the main objectives and outline of this dissertation.

Chapter 2 reports on the daily activities in which nursing home residents participate and their body positions during these (in)activities. A cross-sectional observation study was conducted in seven nursing homes (19 psychogeriatric and 11 somatic wards), housing 723 nursing home residents in the Netherlands. Nursing home residents ( $n=723$ ) were observed in their wards, randomly five moments for one minute (5 observers, including 3 nurse observers). The observer recorded the activity of each resident. A total of 3282 observations were conducted. Both psychogeriatric and somatic residents were mainly observed in inactivities (range: $45-77 \%$ of the five observation moments), such as sleeping, doing nothing, and watching TV in their wards. When residents were engaged in Activities of Daily Living (IADL; range 15-38\%) they were mainly engaged in mobility and eating and drinking activities. Instrumental ADL (IADL), such as setting the table, preparing a sandwich or watering plants, were rarely observed (up to 4\%). Residents were mostly observed in a lying or sitting position (range: 89-92\%). No significant differences were found in activities or positions between the psychogeriatric and somatic wards. To decrease the large amount of inactivity nursing home residents should be encouraged to participate in daily activities in the wards, focusing on increasing ADL and especially IADL.

The role of nursing staff in the daily activities of the residents was also explored in the abovementioned cross-sectional observation study, and is described in Chapter 3 . The observer recorded the role of nursing staff or others in the activity of the resident, when they were involved. Roles were defined as 'taking over the activity', 'giving support', or 'supervision'. Nursing staff supported a resident's ADL and IADL physically and/or verbally in $51 \%$ of the observations. Nursing staff took over a resident's daily activities in $45 \%$ of the observations and supervision of these activities was rarely observed (4\%). In addition to the observations, the nurse observers $(n=3)$ were interviewed to obtain insight into their observation-experiences. Nurse observers, who knew the residents, indicated that the observations led to a greater awareness of the 
large amount of inactivity and that much activity was taken over unnecessarily since the residents could have performed it themselves. Based on these results, nursing staff are recommended to provide more supervision and support to optimize the daily activities and independence of residents.

The MAastr/cht Nurses Activities INventory (MAINtAIN)-behaviors questionnaire was used to obtain insight into the extent to which nursing staff perceive to encourage functional activity ( $A D L$, household and miscellaneous) among nursing home residents. This questionnaire consists of 19 items on ADL (e.g. encouraging residents to move about independently), household activities (e.g. encouraging residents to set the table) and miscellaneous activities (e.g. encouraging informal caregivers not to take over a resident's activities). Chapter 4 shows the results of a nationwide cross-sectional study among 368 nursing staff members working on the psychogeriatric and somatic wards of 41 Dutch nursing homes, who completed the MAINtAIN-behaviors questionnaire. Associations between their behavior and professional characteristics (e.g. age), contextual factors (e.g. ward type) and information-seeking behaviors (e.g. reading professional journals) were investigated in this chapter. The results showed that nursing staff perceive to encourage household activities less often than ADL or miscellaneous activities (e.g. discouraging informal caregivers from taking over a resident's activities) among nursing home residents. It is therefore recommended that nursing staff focus on improving their encouragement of household activities among the residents, are aware of the importance of these activities.

The development of the nursing intervention called DAlly NURSE, and its feasibility, are presented in Chapter 5. DAlly NURSE is an acronym for 'Daily Activities and Independence by NURsing Staff Encouragement'. This intervention was developed using observations (Chapter 2 and 3), questionnaires (Chapter 4), a literature review and (focus group) interviews. DAlly NURSE is a nursing intervention that aims to change nursing behavior by encouraging nursing the activities and independence of nursing home residents through creating awareness. It consists of three components: education, coaching-on-the-job, and policy. The feasibility tested dose delivered, fidelity, dose received (exposure and satisfaction), reach and barriers, using attendance lists, evaluation questionnaires, notes made by the researcher, and a focus group interview with nursing home staff $(n=8)$ at the end of the study. The study was conducted in six psychogeriatric nursing home wards of two nursing homes. All three components of DAlly NURSE (education, coaching-on-the-job and policy) were implemented in practice. The attendance rate for the workshops was high (average: $82 \%$ ). Nursing home staff were satisfied with the workshops (mean score 9 out of 10 points) and agreed that DAlly NURSE is feasible in daily nursing care practice and might help to change nursing behavior towards encouraging the daily activities and independence of residents. A few recommendations to further optimize the feasibility of DAlly NURSE included: add video observations of a specific period of the day to 
create awareness of nursing behavior; educate all nursing staff of the ward during the workshops; and organize information meetings for family members before the start of the intervention.

The impact of DAlly NURSE on both nursing staff and residents was evaluated in a quasiexperimental study (Chapter 6). A total of four psychogeriatric nursing homes participated, two were part of the experimental group ( $n=7$ wards) and two were part of the control group ( $n=5$ wards). The impact of DAlly NURSE was primarily evaluated on the role of nursing staff in resident daily activities and on the engagement of nursing home residents in daily activities and their independence, and the context was taken into account. This was evaluated using video recordings of breakfast during a pre- and posttest. Secondary outcomes were nursing staff behavior measured with the MAINtAIN-behaviors questionnaire and the physical functioning (Barthel Index) and nutritional status (Mini Nutritional Assessment) of residents. Data were analyzed using multilevel regression analyses. The results showed no statistically significant differences in the observed role of nursing staff in resident activities, however, nursing home residents in the experimental group were statistically significantly more often engaged in activities during breakfast after DAlly NURSE, and changes in the context were observed. Nursing staff in the experimental group perceived to encourage ADL and household activities more often after DAlly NURSE. In conclusion, DAlly NURSE had no impact on the observed role of nursing staff but impacted the engagement of nursing home residents positively in daily activities during breakfast.

In the final chapter (Chapter 7), the general discussion, the main findings of this dissertation are discussed. Methodological and theoretical considerations are described and the implications of the findings for research and practice are given. 
SAMENVATTING 
'Bewegen is goed, meer bewegen is beter', dit staat in de Nederlandse Beweegrichtlijnen die in 2017 zijn gepubliceerd. Bewegen heeft vele positieve effecten, niet alleen voor gezonde personen, maar ook voor kwetsbare doelgroepen zoals verpleeghuisbewoners. Deelname in dagelijkse activiteiten heeft een positieve invloed op het lichamelijk functioneren en de kwaliteit van leven van verpleeghuisbewoners. Desondanks zijn de meeste verpleeghuisbewoners inactief. Verpleegkundigen en verzorgenden spelen een sleutelrol in de dagelijkse activiteiten en zelfredzaamheid van verpleeghuisbewoners doordat zij 24 uur per dag in de directe omgeving van de verpleeghuisbewoners zorg leveren. Het doel van dit proefschrift is om een verpleegkundige interventie te ontwikkelen en te evalueren om verpleeghuisbewoners te stimuleren in dagelijkse activiteiten en zelfredzaamheid.

Hoofdstuk 1, de algemene introductie van dit proefschrift, beschrijft het belang van lichamelijke activiteiten en in het bijzonder het belang van dagelijkse activiteiten voor verpleeghuisbewoners. Daarnaast introduceert het de rol van verpleegkundigen en verzorgenden in de dagelijkse activiteiten en zelfredzaamheid van verpleeghuisbewoners. Dit hoofdstuk specificeert de hoofddoelen en de opzet van dit proefschrift.

Hoofdstuk 2 rapporteert over de dagelijkse (in)activiteiten waarin verpleeghuisbewoners betrokken zijn en hun lichaamshouding tijdens deze (in)activiteiten. Een cross-sectionele observatiestudie is uitgevoerd in 7 Nederlandse verpleeghuizen (19 psychogeriatrische en 11 somatische afdelingen) waar in totaal 723 bewoners verbleven. Psychogeriatrische en somatische verpleeghuisbewoners zijn op 5 willekeurige momenten gedurende de dag op hun afdeling gedurende 1 minuut geobserveerd door een observator (waaronder 3 verpleegkundigen). De observator noteerde vervolgens de activiteit en lichaamshouding van iedere bewoner aan de hand van een observatielijst op een tablet. In totaal zijn 3282 observaties uitgevoerd. Inactiviteiten zoals slapen, niets doen of TV kijken, werden het meest geobserveerd (range: $45-77 \%$ van de 5 observatiemomenten). Wanneer bewoners betrokken zijn bij ADL (activiteiten van het dagelijks leven) (range: 15-38\%), dan waren dat voornamelijk activiteiten gericht op mobiliteit of eten en drinken. HDL (huishoudelijke activiteiten van het dagelijks leven) zoals tafel dekken, brood smeren en planten water geven, zijn zelden geobserveerd (range: 0-4\%). Bewoners zijn meestal in een liggende of zittende positie (range: 89-92\%) geobserveerd. Er zijn geen verschillen gevonden tussen de psychogeriatrische en somatische afdelingen betreffende de activiteiten of lichaamshoudingen. Om de grote mate van inactiviteit te verkleinen zouden verpleeghuisbewoners gestimuleerd moeten worden in dagelijkse activiteiten (ADL en met name HDL) op hun afdeling. 
De rol van verpleegkundigen en verzorgenden in de dagelijkse activiteiten van verpleeghuisbewoners is ook onderzocht in de hierboven genoemde observatiestudie en wordt beschreven in Hoofdstuk 3. De observator noteerde de rol van verpleegkundigen en verzorgenden in de ADL en HDL van de bewoner, wanneer zij betrokken waren. De rol is gedefinieerd als 'overname', 'ondersteuning' of 'supervisie'. De resultaten laten zien dat verpleegkundigen en verzorgenden in $51 \%$ van de observaties de activiteit ondersteunen. Verpleegkundigen en verzorgenden namen de activiteit over in $45 \%$ van de observaties. Supervisie is zelden geobserveerd (4\%). Naast de observaties zijn de drie verpleegkundige-observatoren geïnterviewd om inzicht te krijgen in hun observatie-ervaringen. De verpleegkundige-observatoren, die de bewoners kenden, geven aan dat de observaties leiden tot bewustwording van de grote mate van inactiviteit en dat een groot deel van de activiteiten onnodig wordt overgenomen, omdat de bewoner die activiteit zelf had kunnen uitvoeren. Op basis van de resultaten wordt verpleegkundigen en verzorgenden aanbevolen om meer supervisie en ondersteuning te bieden om daarmee de activiteiten en zelfredzaamheid van verpleeghuisbewoners te optimaliseren.

Om inzicht te krijgen in het gedrag van verpleegkundigen en verzorgenden met betrekking tot de mate waarin zij functionele activiteiten stimuleren bij verpleeghuisbewoners is de 'MAastr/cht Nurses Activities INventory (MAINtAIN)behaviors' vragenlijst gebruikt. Deze vragenlijst bestaat uit 19 items over ADL (bijvoorbeeld bespreken we of bewoners hulpmiddelen nodig hebben bij het eten), huishoudelijke activiteiten (bijvoorbeeld stimuleren we bewoners om te helpen bij het tafeldekken) en algemene activiteiten (bijvoorbeeld het aanmoedigen van mantelzorgers om niet onnodig activiteiten van bewoners over te nemen). Hoofdstuk 4 laat de resultaten van een landelijke cross-sectionele studie zien gehouden onder 368 verpleegkundigen en verzorgenden, die de MAINtAIN-behaviors vragenlijst invulden en die werkzaam zijn op psychogeriatrische en somatische afdelingen van 41 Nederlandse verpleeghuizen. Daarnaast zijn de relaties onderzocht tussen het gedrag van de verpleegkundigen en verzorgenden en persoonlijke eigenschappen (bijvoorbeeld leeftijd), contextuele factoren (bijvoorbeeld type afdeling) en de mate waarin ze gebruik maken van verschillende informatiebronnen (bijvoorbeeld vakbladen). Verpleegkundigen en verzorgenden ervaren dat huishoudelijke activiteiten minder vaak gestimuleerd worden bij verpleeghuisbewoners dan ADL en algemene activiteiten. Er is geen consistent verband gevonden tussen het gedrag van de verpleegkundigen en verzorgenden en persoonlijke eigenschappen, contextuele factoren en het gebruik van informatiebronnen. Verpleegkundigen en verzorgenden wordt aanbevolen om met name de huishoudelijke activiteiten te stimuleren en zich bewust te zijn van het belang van deze activiteiten. 
De ontwikkeling en de uitvoerbaarheid van de verpleegkundige interventie, genaamd DAlly NURSE, wordt gepresenteerd in Hoofdstuk 5. DAlly NURSE is een acroniem voor 'Daily Activities and Independence by NURsing Staff Encouragement'. De interventie is ontwikkeld op basis van observaties (hoofdstuk 2 en 3), vragenlijsten (hoofdstuk 4), een literatuuronderzoek en (focusgroep)interviews. Het doel van DAlly NURSE is om het gedrag van verpleegkundigen en verzorgenden te veranderen in het stimuleren van dagelijkse activiteiten en zelfredzaamheid van bewoners, door bewustzijn te creëren. De interventie bestaat uit drie componenten, namelijk educatie (workshops), coaching en beleid. De uitvoerbaarheid is getest aan de hand van een procesevaluatie, waarbij getoetst is in hoeverre de interventie geïmplementeerd en uitgevoerd is zoals gepland, hoeveel medewerkers er zijn bereikt, hoe tevreden de medewerkers zijn met de interventie en welke barrières ze hebben ervaren. Vragenlijsten, presentielijsten, notities van de onderzoeker en een focusgroep interview met acht medewerkers aan het eind van de studie zijn gebruikt om de toepasbaarheid van DAlly NURSE te evalueren. De studie is uitgevoerd binnen zes psychogeriatrische verpleeghuisafdelingen van twee verpleeghuizen. Alle drie de componenten van DAlly NURSE (educatie, coaching en beleid) zijn geïmplementeerd. De aanwezigheid bij de workshops was hoog (gemiddeld 82\%). De deelnemers waren tevreden met de workshops (gemiddelde score 9 van 10 punten) en zijn het er over eens dat DAlly NURSE toepasbaar is in de dagelijkse zorgpraktijk en dat het verpleegkundigen en verzorgenden kan helpen om dagelijkse activiteiten en zelfredzaamheid van bewoners te stimuleren. Ook zijn er een aantal aanbevelingen gedaan om de toepasbaarheid van DAlly NURSE te optimaliseren: video-observaties van een specifiek moment gedurende de dag om bewustzijn te creëren van gedrag, alle verpleegkundigen en verzorgenden van de afdeling betrekken in de workshops en organiseren van informatiebijeenkomsten voor familieleden voor de start van de interventie.

De impact van DAlly NURSE op zowel de verpleegkundigen en verzorgenden en de verpleeghuisbewoners is geëvalueerd in een quasi-experimentele studie (Hoofdstuk 6). Vier psychogeriatrische verpleeghuizen namen deel, twee in de experimentele groep (7 afdelingen) en twee in de controle groep (5 afdelingen). De impact van DAlly NURSE is primair geëvalueerd op de rol van de medewerker en de betrokkenheid van bewoners bij de dagelijkse activiteiten en hun zelfredzaamheid, ook is de context meegenomen. Dit is gedaan aan de hand van video-opnames van het ontbijtmoment tijdens een vooren een nameting. Daarnaast zijn vragenlijsten afgenomen om de secundaire uitkomstmaten in kaart te brengen: MAINtAIN-behaviors om het gedrag van medewerkers in kaart te brengen en de Barthel Index en Mini Nutritional Assessment om het fysiek functioneren en de voedingsstatus van de bewoners in kaart te brengen. De data is geanalyseerd met multi-level analyses, om te kijken of er verschillen zijn 
tussen de groepen op de nameting, gecorrigeerd voor de verschillen op de voormeting. De resultaten laten geen verschillen zien in de rol van verpleegkundigen en verzorgenden (ondersteuning of overname) in de activiteiten van de bewoners tijdens het ontbijt. Wel zijn de bewoners meer betrokken bij de ontbijtactiviteiten na DAlly NURSE en zijn er veranderingen te zien in de context; stimulerende omgeving door gedekte tafels en medewerkers die elkaar feedback geven. Verpleegkundigen en verzorgenden ervaren dat zij ADL en huishoudelijke activiteiten meer stimuleren door DAlly NURSE. Er zijn geen verschillen gemeten in het fysiek functioneren en de voedingsstatus van verpleeghuisbewoners. DAlly NURSE heeft dus een positieve impact op de betrokkenheid van verpleeghuisbewoners bij de dagelijkse activiteiten en de context rondom het ontbijtmoment. Bovendien ervaren medewerkers de ADL en huishoudelijk activiteiten meer te stimuleren.

In het laatste hoofdstuk (Hoofdstuk 7), de algemene discussie, worden de hoofdresultaten van dit proefschrift samengevat. Methodologische en theoretische overwegingen worden beschreven en de implicaties van de resultaten voor onderzoek en praktijk worden gegeven. 



\section{VALORIZATION}


This chapter describes the relevance of the findings of this dissertation. It elaborates on how the daily activities of nursing home residents can be encouraged by the DAlly NURSE intervention, and on the dissemination of the findings.

\section{Relevance}

This dissertation provides insight into the daily activities of residents in nursing homes and the role of nursing staff. It resulted in a feasible intervention to change nursing staff practices towards encouraging residents' daily activities during daily care practice. This intervention, DAlly NURSE, fits into the ongoing changes in nursing home care, which extend from the medical model to the social model, focusing on residents' well-being, capabilities and quality of life. Furthermore, DAlly NURSE is in line with the Dutch Quality Improvement Framework of Nursing Home Care, published in 2017 by the National Health Care Institute. This framework intends to improve quality of care in the nursing homes by focusing on person-centered care with meaningful activities during the day to improve residents' quality of life. Performing meaningful daily activities helps residents to remain functioning and it enhances residents' self-esteem. In addition, it might delay residents' increasing care dependency. DAlly NURSE supports nursing home staff in providing person-centered daily nursing care. It encourages residents' independence in daily activities by focusing on what they can do rather than what they cannot.

In society, increasing attention is given to the positive effects of physical activity for young and older people. Physical activity is the central theme in this dissertation. The physical activity guidelines were updated last year by the Dutch Health Council and stated, 'physical activity is good, more is even better'. Nevertheless, physical activity does not need to be vigorous, since participation in daily activities is already beneficial for the frail nursing home population. Previous physical activity intervention studies in nursing homes focus on exercise rather than on activities in daily life. DAlly NURSE focuses on the encouragement by nursing staff of activities during the day designed to increase daily physical activity levels of nursing home residents. Since nursing staff provide care $24 / 7$ they play a key role in residents' daily life and, therefore, are the key persons to encourage the residents.

\section{How to create changes in nursing home practice}

The studies in this dissertation resulted in a change in nursing care practice, focusing on encouraging residents' daily activities. To change things and implement innovations in the nursing home it is necessary to obtain insight into the current situation, to have a 
clear starting point with insight into current behaviors and barriers. Observations in this dissertation provided insight into the activities of nursing home residents and the role of nursing staff; nevertheless, observations can also be used to obtain an insight into autonomy, communication, physical restraints, mood, etc. The advantage of the observations is that they do not only provide information about the activities, they also provide information about the environment in which these activities take place. For example, a resident might be encouraged to prepare a sandwich if provided with a set table, while a cleared table might discourage such activity. Distractive environments or ambiances can be similarly discouraging. Moreover, observations conducted by nursing staff create awareness of their own behavior and the environment in which they are working. Besides observations, insight into behavior and possible barriers for change can be obtained with questionnaires. The MAINtAIN questionnaire can be used to obtain this insight. ${ }^{a}$ However, as the results of this dissertation suggest perceived behavior might not be the same as actual behavior. Nevertheless, it is essential to obtain insight into possible barriers in order to tailor solutions; for example, if lack of knowledge within the organization is an important barrier, staff need education and information.

To implement innovations in nursing home practice, a safe and open environment should be created. Managers have an essential role in creating a safe environment and in supporting nursing staff in changing their behavior and implementing innovations. To support nursing staff, managers should have a clear vision about the innovation they wish to introduce. They should reflect on why things are done in a particular way, and they should invite nursing staff to critically reflect on their own behavior. Managers can be innovative by relaxing rules, such as, relaxing the rule that is common in nursing homes, 'all residents should have been washed and dressed before breakfast at 9 a.m.' In addition, managers should create a positive team climate and ensure nursing staff are enthusiastic in working together on common goals of: sharing good practices, reflecting on and learning from difficult situations, looking for possibilities instead of impossibilities, and providing positive feedback to each other.

A lot of knowledge and expertise is already present in nursing homes; however, to implement innovations nursing staff might need coaching and role models. Bacheloreducated nurses can be coaches and role models within their own care organization. As such, they are expected to work methodical and should be able to write an

\footnotetext{
${ }^{a}$ Kuk NO, Zijlstra GAR, Bours GJJW, Hamers JPH, Kempen GIJM. Development and usability of the MAINtAIN, an inventory assessing nursing staff behavior to optimize and maintain functional activity among nursing home residents: a mixed-methods approach. BMC Health Serv Res. 2016;16:38.
} 
implementation plan to implement innovations in nursing care practice; for example, by using the TIP-toolbox ${ }^{\mathrm{b}}$. This toolbox provides nursing staff with a stepwise method to write a structured and tailored implementation plan, and is used in the DAlly NURSE intervention, as well. Therefore, bachelor-educated nurses are the key persons to implement innovations in their own nursing home practice, providing coaching-on-thejob with structured feedback, and providing the education for an intervention, such as the interactive workshops of DAlly NURSE. Nevertheless, they can also ask other experts in the multidisciplinary work environment, for example, a physiotherapist can give a clinical lesson about the importance of daily activities, and a psychologist can provide tip and tricks about how to encourage residents to perform activities. Also, other formal and informal caregivers in the nursing home should be involved in changes in nursing home practice; for example, cleaning staff and residents' families should be involved in discussions on how innovations affect them or their work. Cleaning staff can invite residents to help them with light household chores and informal caregivers can take residents for a walk. Ideally, residents continue the daily activities they performed before coming to the nursing home. For example, if they went to the market with their spouse every Tuesday, they should continue to do so. The focus on encouraging residents' activities and independence can also be translated to home care, where nursing staff should support and encourage the older adults to continue their daily activities and maintain their functioning.

\section{Dissemination of the findings}

Dissemination of the findings of this dissertation started from the beginning of the project. Nursing staff were involved in the observation studies, and the intervention, DAlly NURSE, was developed with their close collaboration. The findings have or will be published in (inter)national scientific and peer-reviewed journals (for example, the Journal of the American Medical Directors Association). Furthermore, the results have or will be presented at (inter)national scientific conferences on geriatrics and nursing homes (like, the annual scientific meeting of the Gerontological Society of America, and the Nursing Home Research Conference). In addition, workshops have been offered at national conferences focusing on nursing home staff and other care professionals; for example, during a conference of 'Dignity and Pride' [in Dutch: Waardigheid en Trots], a program of the Dutch Secretary of Health, Welfare and Sport to improve quality of care

\footnotetext{
${ }^{b}$ Kuk NO, Bours GJJW, Hamers JPH, Kempen GIJM, Zijlstra GAR. Feasibility of the Translations Innovations into Practice-toolbox (TIP-toolbox): A mixed-methods study for implementing activity innovations in nursing homes. Geriatric Nursing. 2017;38:498-504.
} 
and life in the nursing homes. Presentations about the DAlly NURSE intervention are also given for other nursing staff, managers, and informal caregivers at different nursing homes of the care organizations who participate in the Living Lab on Ageing and LongTerm Care. The project has received attention from different professional organizations, who have published about this project in their journals, such as an educational journal for nursing staff, Bijzijn $X L$, and the national journal for physiotherapists, FysioPraxis. The daily newspaper, Trouw, reported the results of the observation study on residents' activities on their front page. As a result of this, it was also mentioned in a Belgium newspaper, Het Nieuwsblad, and on different news websites.

During the whole project of 'Nurses on the Move', the development of the intervention and the findings of the studies were discussed with representatives of national stakeholder organizations, including branch organization Actiz, client organization LOC, the Dutch Nurses Association V\&VN, the Health Care Inspectorate, and the Ministry of Health, Welfare and Sport. The results of the interrelated projects have been presented at international and national conferences. The dissertations, factsheets and products of the other projects can be found on the website of the Living Lab (www.academischewerkplaatsouderenzorg.n/). In addition, information about 'Nurses on the Move' and its results can be find at the website of the Netherlands Organization for Health Research and Development, who funded the project (www.zonmw.nl).

To disseminate the results further the following steps will be taken. As the research conducted in this dissertation is embedded in the Living Lab on Ageing and Long-Term Care, findings of the studies are shared and will be shared with the participating care organizations. For example, a factsheet will be published on the website of the Living Lab, describing the findings of this dissertation. The factsheet and the dissertation will be distributed among the care organizations who are member of the Living Lab on Ageing and Long-Term Care. In addition, a set of guidelines for nursing staff containing detailed description of the intervention, including each workshop, will be available on the website of the Living Lab from October 2018. An e-book of this dissertation will be available on the website of the Living Lab, as well as on the platform for scientific knowledge in the field of nursing (www.proefschriftenverpleegkunde.nl). 



\section{DANKWOORD}


Nu na ruim vier jaar mijn proefschrift (bijna) af is, is het tijd om het laatste en meest gelezen hoofdstuk van het proefschrift te schrijven: het dankwoord. In dit dankwoord wil ik een aantal mensen in het bijzonder bedanken, zonder hen was dit proefschrift er niet gekomen.

De deelnemers aan het onderzoek, de medewerkers van verpleeghuizen, zonder jullie lag dit proefschrift er zeker niet. Van het invullen van vragenlijsten tot deelname aan de interventiestudie, waarbij jullie je hebben blootgegeven tijdens de video-opnames, jullie inzet is onbeschrijfelijk! Ik heb veel bewondering voor jullie werk en ik hoop dat dit onderzoek en toekomstig onderzoek kan bijdragen aan jullie werkplezier.

In mijn promotietraject werd ik begeleid door een geheel Limburgs team, bestaande uit prof. dr. Hamers, prof. dr. Zwakhalen, dr. Meijers en dr. Bleijlevens. Ik wil dit team bedanken voor het vertrouwen, het delen van kennis en ervaringen, de discussies die we hebben gevoerd, de ondersteuning, de vele leermomenten en de (gezellige) congresbezoeken.

Prof. dr. Hamers, beste Jan, bedankt voor alle feedback die je mij de afgelopen jaren hebt gegeven. Mijn vragen werden regelmatig beantwoord met de vraag: 'Wat denk je zelf?'. Je hield het overstijgende geheel altijd in de gaten en de betekenis van de onderzoeksresultaten voor de verpleeghuis-praktijk.

Prof. dr. Zwakhalen, beste Sandra, jouw manier van feedback geven heb ik altijd erg prettig ervaren. De rust die jij uitstraalt en de manier waarop je de feedback verwoordt heeft mij erg geholpen. Jouw harde werken heeft nu geleid tot een promotie tot professor en ik ben al de tweede die jou als professor mag aanspreken in het dankwoord.

Dr. Meijers, beste Judith, je altijd vrolijke lach in combinatie met een kritische blik, leerde mij 'out-of-the-blue'-denken. Je bent een harde werker en je zit (letterlijk) nooit stil, jouw feedback en de korte lijntjes naar de praktijk hebben mij veel geleerd en snel verder geholpen.

Dr. Bleijlevens, beste Michel, je bent officieel geen copromotor, maar vanaf het begin van mijn promotietraject ben je betrokken geweest. Bedankt voor je feedback, belangstelling voor het onderzoek en persoonlijke interesse.

Graag wil ik de beoordelingscommissie, bestaande uit prof. dr. Marjolein de Vught, prof. dr. Bianca Buurman, prof. dr. Luc van Loon, prof. dr. Erik Scherder en prof. dr. Jos Schols, bedanken voor hun interesse in het proefschrift en de tijd die ze hebben genomen voor de beoordeling hiervan.

De leden van de klankbordgroep wil ik bedanken voor de waardevolle feedback tijdens de bijeenkomsten: Susanne Bruijns (Actiz), Sonja Kersten (V\&VN), Corry Ketelaars (IGZ), Kina Koster (Cicero Zorggroep), Marthijn Laterveer (LOC), Herm Leenders (Zuyderland), Jan Maarten Nuijens (Envida), Roger Ruijters (MeanderGroep), Trudie Severens (Sevagram) en Brigitte Verhage (VWS) en ook Dineke Abels (ZonMw) bedankt. 
Angelina, Bert, Deborah, Kirsten, Natascha, Pauline: heel erg bedankt voor jullie betrokkenheid en inzet bij de ontwikkeling en implementatie van DAlly NURSE. Daarnaast wil ik alle observatoren bedanken voor jullie hulp bij de dataverzameling en de analyse van de videobeelden.

Nienke en Ramona, 'the rockstars in my field', door en dankzij jullie kan ik dadelijk dit proefschrift verdedigen. Al voor de start van mijn promotietraject waren jullie erbij betrokken, ik kan mij dan ook geen promotietraject zonder jullie voorstellen. We leerden elkaar goed kennen in de afgelopen jaren doordat we de kamer deelden. En natuurlijk was het niet alleen de kamer die we deelden, maar vooral ook vele verhalen. Die verhalen gingen uiteraard niet alleen over werk of over onszelf. Lieve Nienke, bedankt voor de ontspanmomentjes, bijvoorbeeld 's avonds buiten in het zwembad in Orlando, op de kerstmarkt in Toulouse of gewoon in Maastricht. Lieve Ramona, ondanks dat Duitsers geen grappen maken kan ik jouw humor erg waarderen. Jouw kritische blik zet dingen weer in perspectief. Op DUB werden we wel eens gezien werden als drieeenheid en als één genoemd als 'de nurses', ik ben ook heel blij dat deze 'nurses' aan mijn zijde zullen staan tijdens mijn promotie als paranimfen. Bedankt!

Katya en Roy, mijn 'roomies' van het laatste jaar, ook met jullie heb ik weer geboft! Natuurlijk moest ik wennen nadat Nienke en Ramona weg waren, maar ik ben heel blij dat jullie al mijn gezeur over de worstelingen in het laatste jaar van het promotietraject aanhoorden, ook al waren jullie nog maar net begonnen. Dankzij jullie is het laatste jaar toch voorbij gevlogen en kwam ik met plezier naar kantoor. Ik wens jullie veel succes met jullie proefschriften! Erica, we werkten maar een jaar samen, maar het voelt alsof je al veel langer betrokken bent bij mijn onderzoek. Je hebt het afgelopen jaar enorm veel werk verzet voor mijn promotieonderzoek en dook er vanaf dag 1 meteen volop in. Wanneer jij er niet was geweest, dan was ik nu waarschijnlijk nog filmpjes van ontbijtmomenten aan het bekijken. Niet alleen tijdens het werk konden we het goed met elkaar vinden, maar ook buiten het werk hebben we gezellige avonden met elkaar doorgebracht, ik hoop dat we dit blijven doen! Martine, als bijna-buren in Maastricht vonden we elkaar om 's avonds samen te eten of een kop thee te drinken en tijdens vakanties hebben we op elkaars plantjes gepast, bedankt hiervoor! Rixt, bedankt voor de uitnodiging om mee te gaan korfballen, ik heb met veel plezier op het veld en in de zaal gestaan! Silke, bedankt voor de gezellige dagen die we samen in Chicago doorbrachten! Frans, bedankt voor alle statistische ondersteuning bij de verschillende studies in dit proefschrift. Brigitte, Joanna en Arnold bedankt voor jullie ondersteuning bij alles rondom het promoveren. Susy, bedankt voor jouw input bij mijn eerste artikel. Ook alle andere collega's die ik hier niet persoonlijk bij naam noem, bedankt voor de fijne tijd op DUB, tijdens lunch(wandelingen), refereerbijeenkomsten, dagjes uit, borrels of etentjes en tijdens congressen in binnen- en buitenland! 
Promoveren doe je niet alleen, maar ook ben je niet alleen bezig met promoveren. Gelukkig had ik de afgelopen jaren ook heel veel afleiding van lieve vrienden en familie.

De waardering van vaak jarenlange vriendschappen wordt niet zo vaak uitgesproken, daarom zou ik mijn vrienden en vriendinnen ook in dit hoofdstuk graag willen bedanken. Lotte en Sophie, wat is het heerlijk om met jullie af te spreken! Onze middagen, avondjes of weekenden samen zijn altijd een combinatie van sportiviteit, eten en gezelligheid. Goede gesprekken en samen lachen, ik kan voor alles bij jullie terecht. In Amsterdam, Den Haag, Maastricht, Doetinchem, Rome of ergens daartussenin, we weten elkaar altijd weer te vinden en dat is super! Jill en Margit, ik heb genoten van onze weekendjes weg! Hamburg, Milaan, Keulen en Berlijn waren topweekenden samen met jullie. Maar ook een middag samen de Tour kijken in Utrecht of Doesburg, het maakt eigenlijk niet uit waar wij elkaar treffen, het is altijd fijn om met jullie samen te zijn! Aleid, je bent een ontzettend lieve en belangstellende vriendin. Altijd op de hoogte van hoe het met mij gaat en altijd even belangstellend naar het onderzoek dat ik deed maar vooral ook wat ik daarbuiten doe. Even bellen lukt ons eigenlijk nooit, we hebben toch zeker een uur nodig om weer bij te praten. Ik heb genoten van onze vakantie in Luxemburg en wat fijn dat wij na ruim 15 jaar ein-de-lijk een keer samen zijn gaan zwemmen in Mosaqua. Ik heb veel bewondering voor jouw doorzettingsvermogen en positiviteit! Bente, Esmée en Irene, jullie zijn laiverds! Waar we in Groningen nog bijna alle vier in dezelfde wijk woonden, zo ver woonden we de afgelopen jaren uit elkaar. Toch hebben we altijd nog contact gehouden en dat vind ik heel fijn. Onze afspraakjes 'in the middle' kunnen dadelijk worden voortgezet in Veenendaal! Joost, we kennen elkaar al bijna 30 jaar! Ik vind het bijzonder dat onze vriendschap al zoveel jaren duurt, en niet alleen die van ons, maar ook van onze ouders. Het weekend voordat ik startte in Maastricht zocht ik jou op in Wallingford. Daarna volgden nog veel gezellige weekendjes en dagjes in Enschede, Rotterdam, Amersfoort, Eindhoven en Maastricht. Het is ook altijd leuk om met $z$ 'n vieren af te spreken, hopelijk kunnen we weer samen op wintersportvakantie gaan! Marvin, bedankt voor de afleiding van werk met jouw humor. Altijd tijd voor het sturen van een filmpje of een grap. We plannen regelmatig een etentje of een drankje in Doesburg, Doetinchem of Maastricht, ik hoop dat we dit nog heel lang voort blijven zetten! Thea, als 'lotgenoten' leerden we elkaar kennen tijdens ons gezamenlijke bachelor afstudeerproject, samen gingen we op pad door de ommelanden van Groningen. Het fijne contact bleef tijdens onze master, en ook nu zijn we 'lotgenoten' tijdens onze promotieprojecten, jij in Groningen, ik in Maastricht. Wat is het fijn om samen te praten over de projecten, maar vooral ook over alles eromheen. Ik kijk uit naar jouw promotie! Esmee, wat is het leuk om een 'Groninger' tegen te komen in het zuiden! De etentjes waren altijd heerlijk en gezellig, maar ook ons uitje naar de schaatsbaan was tof! Jantine, we leerden elkaar vroeger kennen op de camping en nog steeds hebben we contact. We zien elkaar niet zo heel vaak, maar onze jaarlijkse weekendjes zijn altijd enorm gezellig en daar heb ik ook heel 
veel warme herinneringen aan! Donja, eigenlijk was het gek dat wij elkaar nog niet kenden. Onze ouders kennen elkaar, onze mannen waren huisgenoten en we hebben zelfs vriendinnen die bevriend zijn. Ik ben blij dat we elkaar de afgelopen jaren hebben leren kennen op DUB en daarbuiten. Een weekendje naar Vlissingen, een spelletjesavond, een drankje in Maastricht of een etentje in Duiven, er is altijd genoeg om over te kletsen!

Het spreekwoord luidt: 'Beter een goede buur dan een verre vriend', maar als je naast zoveel goede maar verre vrienden ook nog eens een goede buurvrouw hebt, dan heb je het wel heel erg getroffen. Tiny, hartelijk bedankt voor je belangstelling, de gezellige praatjes, een extra doosje aardbeien die je voor ons meenam als je langs de boer ging en de zelfgemaakte wafeltjes, vlaai en jam. Dat alles maakte het wonen in Maastricht wel extra fijn!

Linet en Nadia, jullie zijn dan misschien letterlijk groter, ik ben en blijf jullie grote zus! Lieve Linet, je weet wat je wilt en daar ga je dan ook voor: geneeskunde studeren, in opleiding tot jeugdarts, een huis kopen in Doetinchem, en het lukt je ook nog eens! Ook al ben je het bijna vergeten, we hebben een aantal jaren samen in Maastricht gewoond, waar we samen hebben gewandeld, geklust en gebarbecued in de tuin. Lieve Nadia, wat ben jij een harde werker, ik vind het knap hoe jij je studies, je werk en je sociale leven combineert! Onze vakanties in Italië en Engeland waren heerlijk: samen rondreizen, samen lachen (om niets), spelletjes spelen, haren vlechten, bergen beklimmen, ijsjes eten en ga zo maar door. Ik heb genoten van onze zussendagen; een wandeling over de Koekedaal, een knutselmiddag, een dagje Utrecht en concertbezoek. Ik hoop dat er nog veel zussendagen komen en dat we nog veel mooie momenten met elkaar mogen delen!

Papa en mama: oost west, thuis best. In het oosten zijn wij altijd welkom bij jullie en jullie steunen ons alle drie in de verschillende wegen die we bewandelen. Jullie geven ons de ruimte om te doen wat bij ons past. Waar we tijdens de studies erg verspreid zaten over het land (Groningen, Amsterdam, Maastricht) komen we nu wat meer in de buurt. Helaas worden de weekendjes Maastricht nu minder, maar daarentegen zijn jullie niet meer zo lang onderweg. Lieve papa, met jou reed ik naar Groningen om naar de open dag van Bewegingswetenschappen te gaan, om samen kamers te kijken, en ook nu hebben weer samen naar woningen gekeken voor de volgende stap. Je hebt altijd doorgestudeerd en je haalde net een jaar eerder dan ik je mastertitel. Ga je nu ook nog voor de doctorstitel?! Nu we bijna allemaal zijn 'afgestudeerd', kijk ik uit naar ons uitstapje naar Madrid! Lieve mama, de interesse in de (ouderen)zorg heb ik waarschijnlijk van jou: de vele verhalen die je vertelde wanneer je thuiskwam van het werk, maar ook jouw betrokkenheid bij de mantelzorg van opa's en oma's. Ik vind het leuk om te zien dat je na een aantal jaren nu toch weer in de zorg bent gaan werken, en je weer met nieuwe enthousiaste verhalen terugkomt over hoe jij de bewoners hebt 
kunnen stimuleren tijdens de dagelijkse activiteiten of een activiteit hebt georganiseerd voor de bewoners. Lieve papa en mama, ik vind het fijn om te zien dat jullie genieten van de tijd die jullie samen doorbrengen thuis, van de wandelingen met Cato en de weekendjes weg en ik hoop dat jullie dat ook nog heel lang blijven doen!

Liefste Kevin, wie had dat gedacht, dat wij zouden gaan samenwonen in Maastricht!? Door jouw komst naar Maastricht werd mijn huis een thuis. Een thuis waar we onszelf zijn, tot rust komen, gek doen, plannen maken, niets doen, eropuit gaan, vrienden en familie uitnodigen, en waar wij samen zijn. Je weet mij tot rust te brengen met je relativeringsvermogen wanneer ik overloop van dingen die ik wil of moet doen, en aan de andere kant weet je mij te motiveren om toch nog even door te gaan wanneer dat nodig is. Ik vind het bijzonder dat jij een belangrijke bijdrage hebt kunnen leveren aan mijn proefschrift door de cover te ontwerpen. Je steunt mij in de keuzes die ik maak, je staat altijd achter mij en samen gaan we ervoor. Ik kijk uit naar alles wat we samen gaan beleven!!! 
ABOUT THE AUTHOR 
Mirre den Ouden was born in Doetinchem, the Netherlands, on the $13^{\text {th }}$ of March 1988. She completed her secondary school (VWO) at 'Rietveld lyceum' in Doetinchem (20002006) and moved to Groningen to study Human Movement Sciences at Rijksuniversiteit Groningen. In 2010, she obtained her Bachelor's degree, and continued with the twoyear Master's program 'Healthy Aging'. During her Master's, she did an internship at Semmelweis University in Budapest, Hungary, focusing on cognitive movement strategies for Parkinson patients. During and after her studies, Mirre worked as a research assistant in various research projects, at both the Rijksuniversiteit Groningen and the VU Medical Center in Amsterdam.

At the end of 2013, Mirre started as a PhD candidate within the 'Living Lab in Ageing and Long-Term Care' at the department of Health Services Research at Maastricht University. Her PhD study focused on how nursing staff can encourage daily activities in nursing home residents. This study was part of the project Nurses on the Move funded by ZonMW. Mirre presented her work at different national and international conferences. In addition to her research, she was involved in the organization of the European Doctoral Conference in Nursing Science (EDCNS) in Maastricht in 2014. Further, she was involved in educational activities, including the supervision of Bachelor's and Master's students and tutoring in different courses of the Bachelor's program 'Health Sciences'.

Since May 2018, Mirre is employed at the 'Netherlands Association of Sports Medicine' (in Dutch: Vereniging voor Sportgeneeskunde) as a coordinator of the research network. 


\section{LIST OF PUBLICATIONS}




\section{Articles}

den Ouden M, Meijers JMM, Zwakhalen SMG, Bleijlevens MHC, de Vries E, Tan FES, Hamers JPH. Encouraging the daily activities and independence of nursing home residents, the impact of nursing intervention DAlly NURSE: a quasi-experimental study. Submitted for publication

den Ouden M, Zwakhalen SMG, Meijers JMM, Bleijlevens MHC, Hamers JPH. Feasibility of DAlly NURSE: a nursing intervention to change nursing staff behavior towards encouraging residents' daily activities and independence in the nursing home. submitted for publication

Kuk NO, den Ouden M, Zijlstra GAR, Hamers JPH, Kempen GIJM, Bours GJJW. Do nursing staff encourage functional activity among nursing home residents? A cross-sectional study of nursing staff perceived behaviors and associated factors. BMC Geriatrics. 2017; 17:18.

den Ouden M, Kuk NO, Zwakhalen SMG, Bleijlevens MHC, Meijers JMM, Hamers JPH. The role of nursing staff in the activities of daily living of nursing home residents. Geriatric Nursing. 2016; 38(3): 225-230.

den Ouden M, Bleijlevens MHC, Meijers JMM, Zwakhalen SMG, Braun SM, Tan FES, Hamers JPH. Daily (in)activities of nursing home residents in their wards: an observation study. Journal of the American Medical Directors Association. 2015; 16(11): 963-8.

\section{Published abstracts and presentations}

den Ouden M, Meijers JMM, Zwakhalen SMG, Tan FES, Hamers JPH, Bleijlevens MHC. The impact of DAlly NURSE on nursing staff behavior in nursing homes. $70^{\text {th }}$ Annual scientific meeting of Gerontological Society of America, 14-18 November 2018, Boston, MA, USA. Accepted for presentation.

den Ouden M, Zwakhalen SMG, Meijers JMM, Bleijlevens MHC, Hamers JPH. A feasibility study of a nursing intervention to encourage nursing home residents' daily activities and independence. Nursing Home Research conference, 13-15 October 2017, St. Louis, MO, USA. Journal of Nursing Home Research. 2017; 3: 10.

den Ouden M, Zwakhalen SMG, Bleijlevens MHC, Meijers JMM, Hamers JPH. The development of a nursing intervention to encourage nursing home residents in daily 
activities. $69^{\text {th }}$ Annual scientific meeting of Gerontological Society of America, 16-20 November 2016, New Orleans, LA, USA. Gerontologist. 2016; 56 (suppl. 3): 196.

den Ouden M, Kuk NO, Zwakhalen SMG, Bleijlevens MHC, Hamers JPH, Meijers JMM. The Involvement of nursing staff in residents' activities of daily living: an observation study. $5^{\text {th }}$ European Nursing Congress, 4-7 October 2016, Rotterdam, the Netherlands. Journal of Advanced Nursing. 2016; 72 (suppl. 1): 87.

den Ouden M, Bleijlevens MHC, Meijers JMM, Zwakhalen SMG, Braun SM, Tan FES, Hamers JPH. Daily activities of nursing home residents in their wards: results of an observation study. Nursing Home Research conference, 2-3 December 2015, Toulouse, France. Journal of Nursing Home Research. 2015; 1: 11.

den Ouden M, Meijers JMM, Zwakhalen SMG, Bleijlevens MHC, Hamers JPH. Involvement of Nursing Staff in Daily Activities of Nursing Home Residents. $68^{\text {th }}$ Annual Scientific Meeting Gerontological Society of America, 18-22 November 2015, Orlando, FL, USA. Gerontologist. 2015; 55(suppl. 2): 142.

den Ouden M, Bleijlevens MHC, Meijers JMM, Zwakhalen SMG, Hamers JPH. Daily Activities of Nursing Home Residents: An Observational Study. $68^{\text {th }}$ Annual Scientific Meeting Gerontological Society of America, 18-22 November 2015, Orlando, FL, USA. Gerontologist. 2015; 55(suppl. 2): 559.

den Ouden M, Bleijlevens MHC, Meijers JMM, Zwakhalen SMG, Braun SM, Hamers JPH. Dagelijkse activiteiten van verpleeghuisbewoners: resultaten van een observatiestudie. $13^{\mathrm{e}}$ Nationaal Gerontologie congres, 2 October 2015, Ede, the Netherlands. Tijdschrift voor Gerontologie en Geriatrie. 2015; 46(4): 225.

den Ouden M, Bleijlevens MHC, Zwakhalen SMG, Meijers JMM, Hamers JPH. Measuring physical activity of nursing home residents in their daily life: a feasibility pilot study. $14^{\text {th }}$ European Doctoral Conference in Nursing Science, 12-13 September 2014, Maastricht, the Netherlands. Abstract book of the 14th European Doctoral Conference in Nursing Science. 2014;90-91. 



\section{LIVING LAB IN AGING AND LONG-TERM CARE}




\section{Living Lab in Ageing and Long-Term Care}

This thesis is part of the Living Lab in Ageing and Long-Term Care, a formal and structural multidisciplinary network consisting of Maastricht University, seven long-term care organizations (Cicero Zorggroep, Envida, Mosae Zorggroep, MeanderGroep ZuidLimburg, Sevagram, Vivantes and Zuyderland) and Zuyd University of Applied Sciences, all located in the southern part of the Netherlands. In the Living Lab we aim to improve the quality of care and quality of life for older people via a structural multidisciplinary collaboration between research, policy, education and practice. Practitioners (such as nurses, physicians, psychologists, physio- and occupational therapists), work together with managers, researchers, students, teachers and older people themselves to develop and test innovations in long-term care.

\section{Academische Werkplaats Ouderenzorg Zuid-Limburg}

Dit proefschrift is onderdeel van de Academische Werkplaats Ouderenzorg ZuidLimburg, een structureel, multidisciplinair samenwerkingsverband tussen de Universiteit Maastricht, zeven zorgorganisaties (Cicero Zorggroep, Envida, Mosae Zorggroep, MeanderGroep Zuid-Limburg, Sevagram, Vivantes en Zuyderland) en Zuyd Hogeschool. In de werkplaats draait het om het verbeteren van de kwaliteit van leven en zorg voor ouderen. Zorgverleners (zoals verpleegkundigen, verzorgenden, artsen, psychologen, fysio- en ergotherapeuten), beleidsmakers, onderzoekers, studenten en ouderen zelf wisselen kennis en ervaring uit. Daarnaast toetsen en evalueren we vernieuwingen in de dagelijkse zorg. Praktijk, beleid, onderzoek en onderwijs gaan hierbij hand in hand.

\section{PhD-theses Living Lab in Ageing and Long-Term Care / Proefschriften Academische Werkplaats Ouderenzorg Zuid-Limburg}

Mirre den Ouden. Every step counts. Daily activities of nursing home residents and the role of nursing staff. 2018

Theresa Thoma-Lürken. Innovating long-term care for older people. Development and evaluation of a decision support app for formal caregivers in community-based dementia care. 2018

Eveline van Velthuijsen. Delirium in older hospitalised patients: diagnosis and management in daily practice. 2018

Bram de Boer. Living at a green care farm. An innovative alternative for regular care in nursing homes for people with dementia. 2017 
Nienke Kuk. Moving forward in nursing home practice. Supporting nursing staff in implementing innovations. 2017

Irma Everink. Geriatric rehabilitation. Development, implementation and evaluation of an integrated care pathway for older patients with complex health problems. 2017

Ramona Backhaus. Thinking beyond numbers. Nursing staff and quality of care in nursing homes. 2017

Martin Van Leen. Prevention of pressure ulcers in nursing homes, a big challenge. 2017

Mariëlle Daamen-Van der Velden. Heart failure in nursing home residents. Prevalence, diagniosis and treatment. 2016

Armand Rondas. Prevalence and assessment of (infected) chronic wounds. 2016

Hanneke Beerens. Adding life to years. Quality of life of people with dementia receiving long-term care. 2016 (Cum Laude)

Donja Mijnarends. Sarcopenia: a rising geriatric giant. Health and economic outcomes of community-dwelling older adults with sarcopenia. 2016

Tanja Dorresteijn. A home-based program to manage concerns about falls. Feasibility, effects and costs of a cognitive behavioral approach in community-dwelling, frail older people. 2016

Basema Afram. From home towards the nursing home in dementia. Informal caregivers' perspectives on why admission happens and what they need. 2015

Noemi Van Nie-Visser. Malnutrition in nursing home residents in the Netherlands, Germany and Austria. Exploring and comparing influencing factors. 2014

Esther Meesterberends. Pressure ulcer care in the Netherlands versus Germany 0-1. What makes the difference? 2013

Math Gulpers. EXBELT: expelling belt restraints from psychogeriatric nursing homes. 2013

Hilde Verbeek. Redesigning dementia care. An evaluation of small-scale homelike care environments. 2011

Judith Meijers. Awareness of malnutrition in health care, the Dutch perspective. 2009

Ans Bouman. A home visiting program for older people with poor health. 2009

Monique Du Moulin. Urinary incontinence in primary care, diagnosis and interventions. 2008

Anna Huizing. Towards restraint free care for psychogeriatric nursing home residents. 2008

Pascalle Van Bilsen. Care for the elderly, an exploration of perceived needs, demands and service use. 2008

Rixt Zijlstra. Managing concerns about falls. Fear of falling and avoidance of activity in older people. 2007

Sandra Zwakhalen. Pain assessment in nursing home residents with dementia. 2007 
